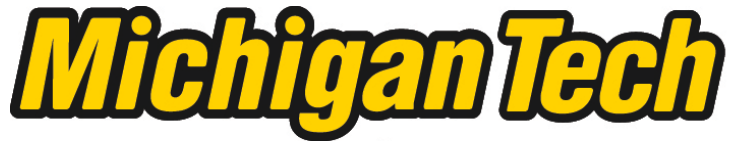 \\ Michigan Technological University Create the Future Digital Commons @ Michigan Tech
}

\section{Treatment of osteoporosis in a mouse model of Duchenne muscular dystrophy using black bear parathyroid hormone}

Sarah K. Gray

Michigan Technological University

Follow this and additional works at: https://digitalcommons.mtu.edu/etds

Part of the Mechanical Engineering Commons

Copyright 2012 Sarah K. Gray

\section{Recommended Citation}

Gray, Sarah K., "Treatment of osteoporosis in a mouse model of Duchenne muscular dystrophy using black bear parathyroid hormone", Master's Thesis, Michigan Technological University, 2012.

https://doi.org/10.37099/mtu.dc.etds/368

Follow this and additional works at: https://digitalcommons.mtu.edu/etds

Part of the Mechanical Engineering Commons 


\title{
TREATMENT OF OSTEOPOROSIS IN A MOUSE MODEL OF DUCHENNE MUSCULAR DYSTROPHY USING BLACK BEAR PARATHYROID HORMONE
}

\author{
By \\ Sarah K. Gray \\ A THESIS \\ Submitted in partial fulfillment of the requirements for the degree of \\ MASTER OF SCIENCE \\ (Mechanical Engineering)
}

MICHIGAN TECHNOLOGICAL UNIVERSITY 2012

(C) 2012 Sarah K. Gray 
This thesis, "Treatment of Osteoporosis in a Mouse Model Duchenne Muscular Dystrophy Using Black Bear Parathyroid Hormone,” is hereby approved in partial fulfillment of the requirements for the Degree of MASTER OF SCIENCE IN MECHANICAL ENGINEERING.

Department of Mechanical Engineering-Engineering Mechanics

Signatures:

Thesis Advisor

Seth Donahue $\mathrm{PhD}$

Committee Member

Rupak Rajachar PhD

Committee Member

Gopal Jayaraman PhD

Department Chair

William Predebon PhD

Date 


\section{Contents}

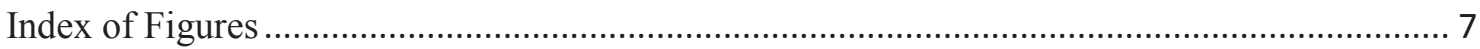

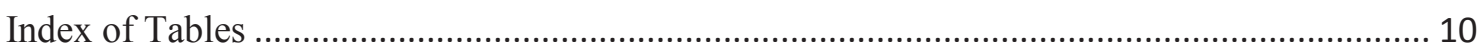

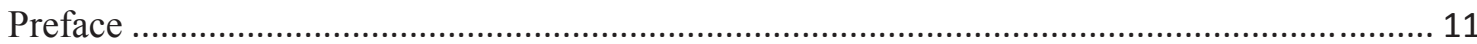

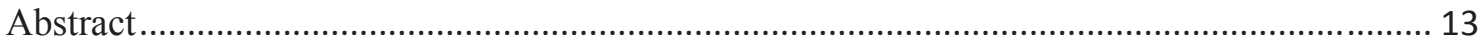

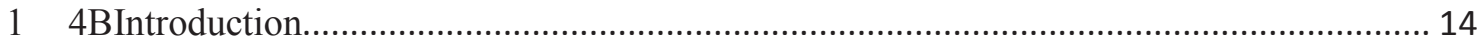

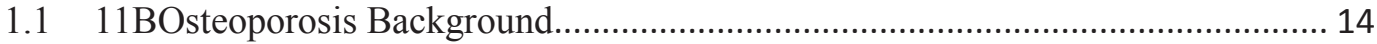

1.2 12BMenopause- and Age-related Osteoporosis.............................................. 15

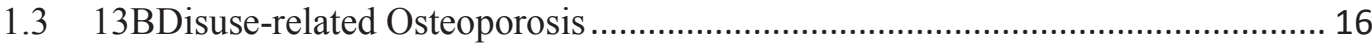

1.4 14BDuchenne Muscular Dystrophy ………....................................................... 17

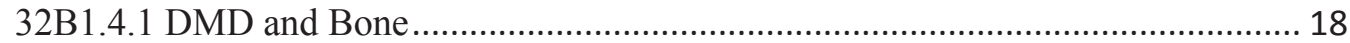

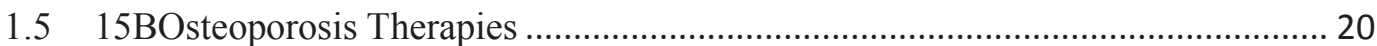

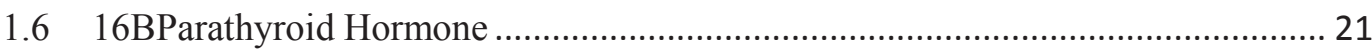

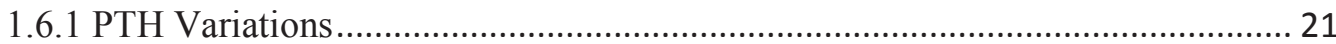

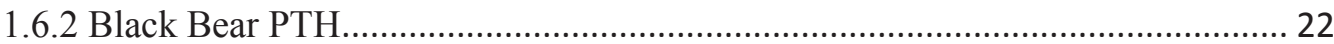

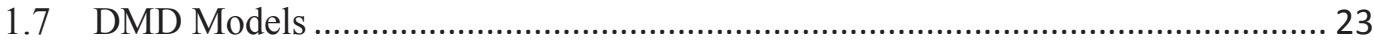

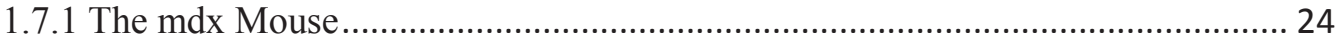

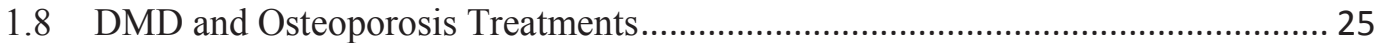


2 Chapter 2: Black Bear Parathyroid Hormone has Greater Anabolic Effects on Trabecular Bone in Dystrophin-deficient Mice than in Wild Type Mice0F

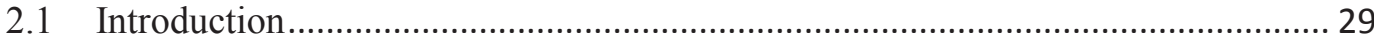

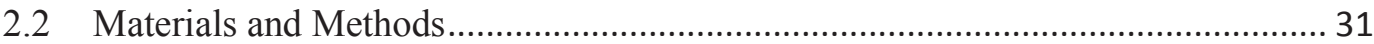

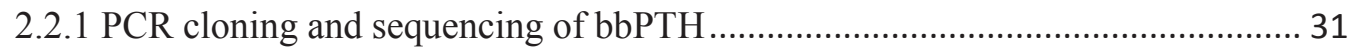

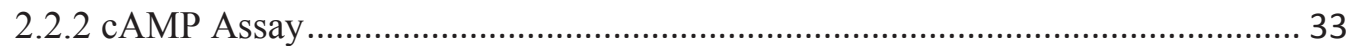

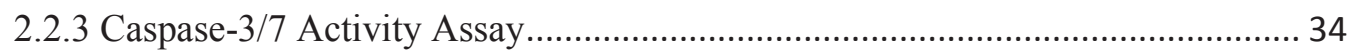

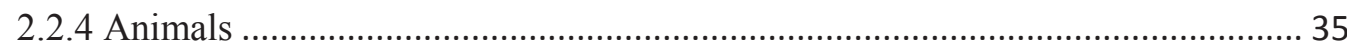

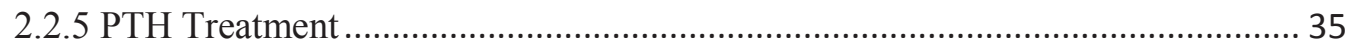

2.2.6 Isolation, Culture, and Mineralization of Bone Marrow Stromal Cells (BMSCs)

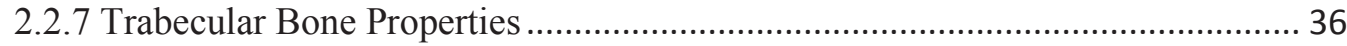

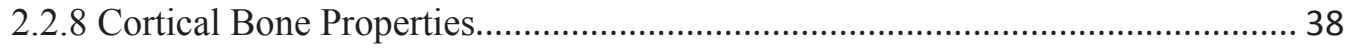

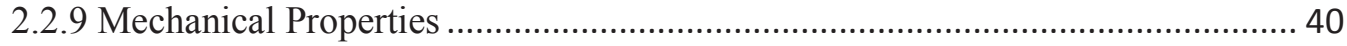

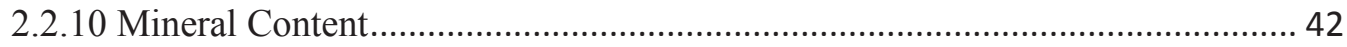

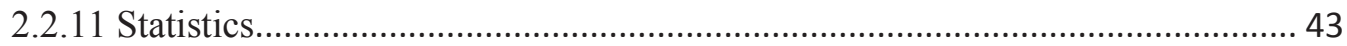

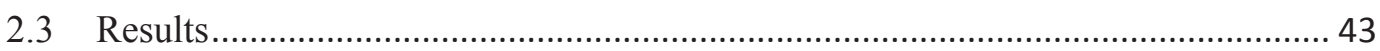

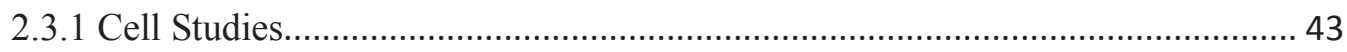

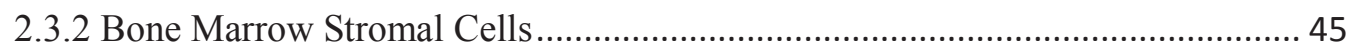


2.3.4 Cortical Bone. 49

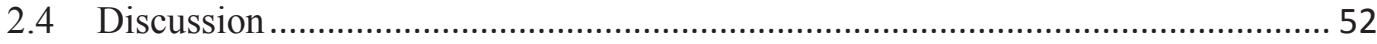

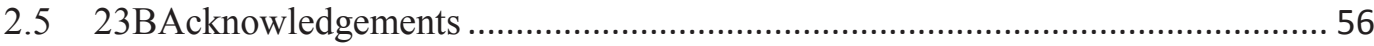

3 Chapter 3: Black Bear PTH is more Potent than Human PTH in a Dose-Responsive Manner in Trabecular Bone in Dystrophin-Deficient Mice 1F....................................................... 57

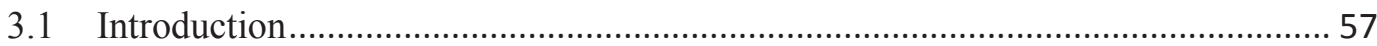

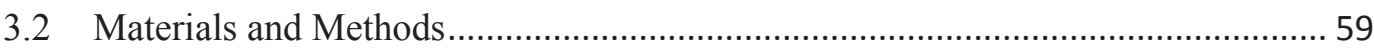

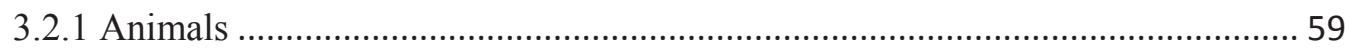

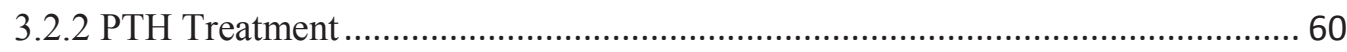

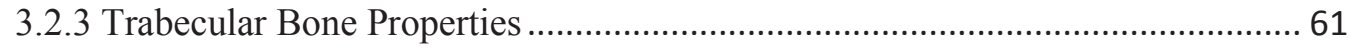

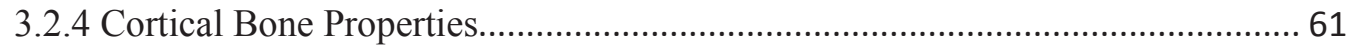

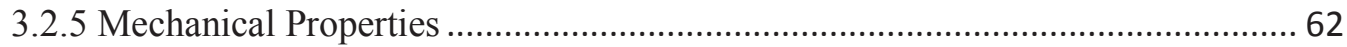

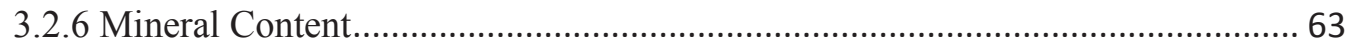

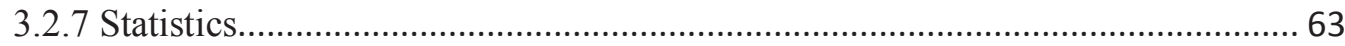

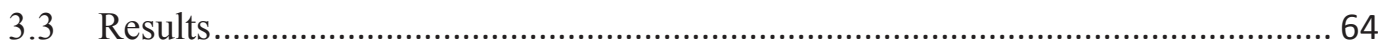

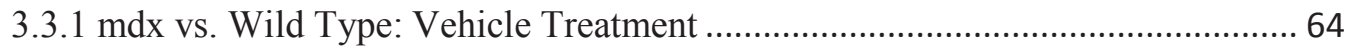

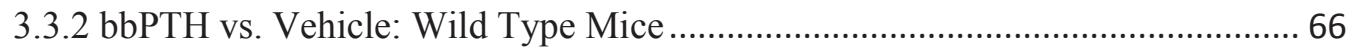

3.3.3 bbPTH vs. hPTH in mdx Mice: Relative Potency Analysis............................... 68

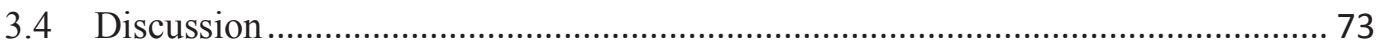


3.4.1 mdx vs. Wild Type: Vehicle Treatment

3.4.2 bbPTH vs. Vehicle: Wild Type Mice

3.4.3 bbPTH vs. hPTH in mdx Mice: Relative Potency Analysis ................................. 75

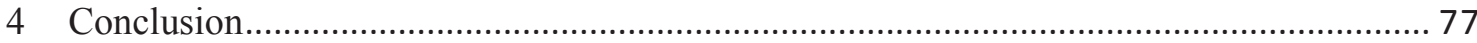

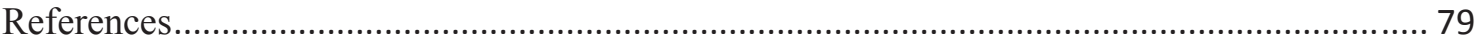

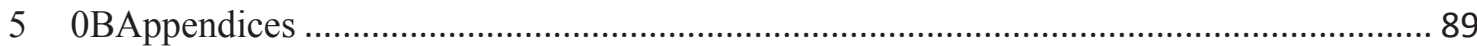

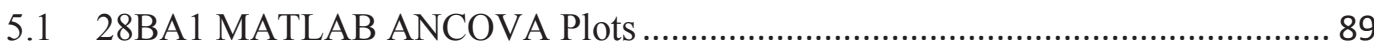

5.2 1BA.2 Dose Response Calculations Using the Delta Method .............................. 104

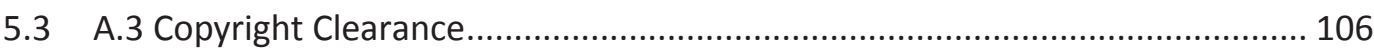




\section{Index of Figures}

Figure 1.1 Amino acid sequence of human PTH 1-84. Amino acid substitutions in bear PTH 184 are highlighted next to the corresponding amino acid in the human sequence. 23

Figure 2.1: Micro-CT image of the distal femur trabeculae 37

Figure 2.2: Von Kossa MacNeal staining of trabecular bone was used to determine osteoid surface and thickness. Osteoid appears as a light blue seam surrounding black trabecular struts.

Figure 2.3: Tartrate-resistant acid phosphatase (TRAP) stained trabecular bone was used to measure osteoclast and osteoblast surface. Osteoclasts appear as pink streaks along the white trabecular struts, and osteoblasts appear as blue cuboidal cells along the trabeculae. 38

Figure 2.4: Calcein-labeled trabecular bone was used to determine mineralizing surface/bone surface (MS/BS) and mineral apposition rate (MAR) based on label distance.

Figure 2.5: A custom macro and Scion Image were used to determine cortical geometrical properties including Iml, Iap, and Imax, and cortical area. Anatomical axes are indicated.

Bioquant was used to calculate cortical thickness

Figure 2.6: Calcein-labeled cortical cross sections were evaluated to measure single- and double-labeled surfaces to determine mineralizing surface and mineral apposition rate on the periosteal and endosteal surfaces.

Figure 2.7: Three-point bending setup with anterior surface in tension 41

Figure 2.8: Load-displacement plot for 3-pt bending of a mouse femur 42

Figure 2.9: bbPTH increased cAMP production in a dose-responsive manner $(\mathrm{p}<0.0001) \ldots . .44$

Figure 2.10: bbPTH was antiapoptotic in serum starved MC3T3 cells $(\mathrm{p}<0.0001)$. Groups with different letters are significantly different from one another. 44 
Figure 2.11: Alizarin red stained mineralized matrix in 21 day BMSC cultures from the humeri of A) $m d x$ and B) wild type mice. The percentage of well area stained for mineralized matrix was quantified.

Figure 2.12: A) Bone volume fraction was lower in vehicle-treated $m d x$ femurs compared to wild type femurs. Mdx femurs showed greater response to PTH treatment than wild type femurs. B) Vehicle-treated $m d x$ mice had lower trabecular number in the femur compared to wild type mice $(\mathrm{p}=0.0028)$. Trabecular number increased with PTH treatment in $m d x$ mice $(\mathrm{p}<0.0001)$, but not wild type $(\mathrm{p}=0.2047)$. Mean values with standard error bars. Groups with different letters are significantly different $(\mathrm{p}<0.05)$ from each other. 48

Figure 2.13: Micro-CT images of distal femoral metaphyses show compromised trabecular architecture in $m d x$ mice compared to wild type mice and improved trabecular architecture with PTH treatment, particularly in $m d x$ mice. 48

Figure 2.14: $m d x$ femoral cross-sections (left) had a more prominent linea aspera than wild type mice (right). Images are femoral cross-sections of vehicle-treated animals, but are representative of all samples treated or untreated. 51

Figure 3.1: Bone volume fraction was not greater in wild type mice compared to $m d x$ mice.... 66

Figure 3.2: bbPTH increased BV/TV in a dose-responsive manner in wild type mice 68

Figure 3.3: Dose-response of PTH treatments in $m d x$ mice showed greater BV/TV in bbPTHtreated animals 72

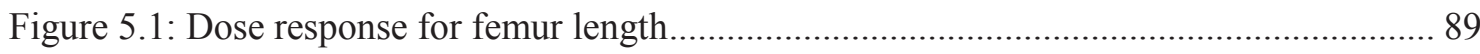

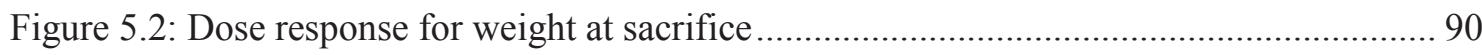

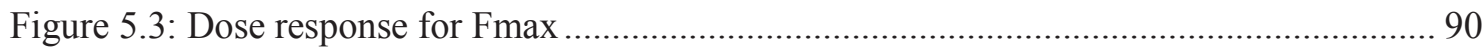

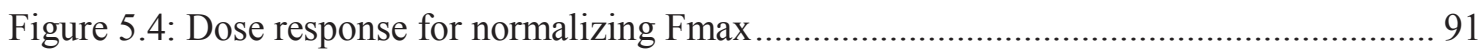

Figure 5.5: Dose response for energy to failure ................................................................ 91

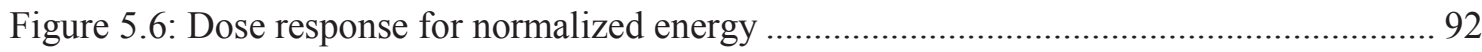


Figure 5.7: Dose response for LV bone volume fraction. 92

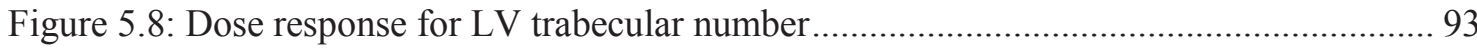

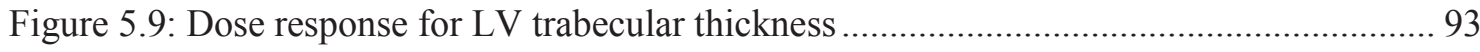

Figure 5.10: Dose response for LV trabecular spacing ............................................................. 94

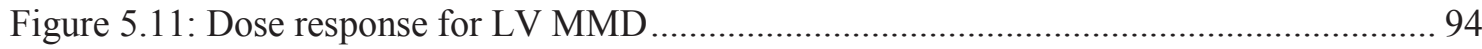

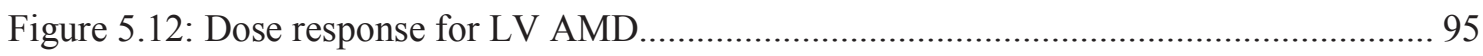

Figure 5.13: Dose response for femur bone volume fraction.................................................. 95

Figure 5.14: Dose response for femur trabecular number..................................................... 96

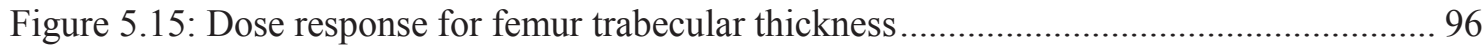

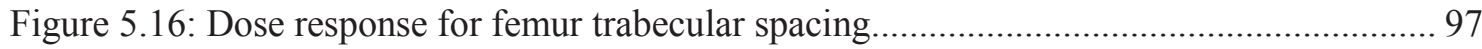

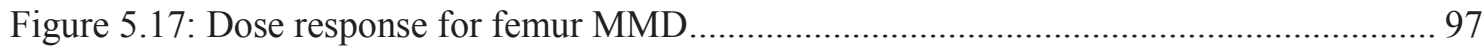

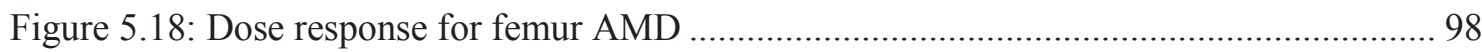

Figure 5.19: Dose response for LV cortical bone volume …................................................. 98

Figure 5.20: Dose response for LV cortical structural modulus ............................................ 99

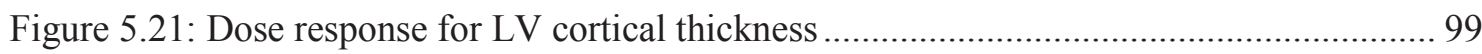

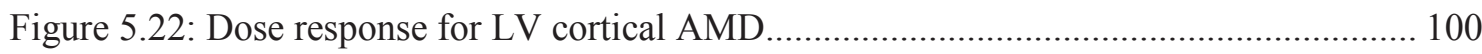

Figure 5.23: Dose response for LV cortical MMD ............................................................. 100

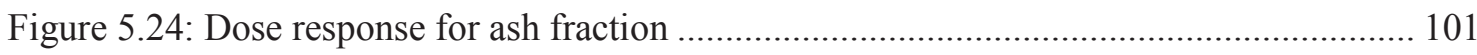

Figure 5.25: Dose response for endosteal mineralizing surface ......................................... 101

Figure 5.26: Dose response for periosteal mineralizing surface .......................................... 102

Figure 5.27: Dose response for endosteal mineral apposition rate ..................................... 102

Figure 5.28: Dose response for periosteal mineral apposition rate ........................................ 103

Figure 5.29: Sketch indicating determination of relative potency occurs at wild type vehicle

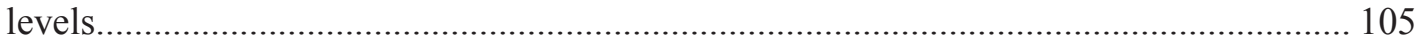




\section{Index of Tables}

Table 2.1 The distal femur and proximal tibia trabecular regions show 1) compromised trabecular architectural parameters in $m d x$ mice vs. wild type; 2) an anabolic effect of bbPTH in $m d x$ and wild type mice, with a stronger effect in $m d x ; 3)$ bbPTH treatment increased $m d x$ trabecular microarchitecture beyond vehicle-treated wild type values.

Average \pm SE

Table 2.2: bbPTH did not change mechanical properties of cortical bone in $m d x$ or wild type, or strongly affect geometric values. The only change in geometry was $\mathrm{I}_{\mathrm{ml}}$, the moment of inertia about the bending axis in PTH-treated $m d x$ animals. Average \pm SE....................... 52

Table 3.1: Bone parameters for vehicle treated $m d x$ and wild type mice ............................... 65

Table 3.2: Bone parameters in bbPTH-treated and vehicle-treated wild type mice .................. 67

Table 3.3: Dose response curves for PTH treated $m d x$ mice. Slopes and intercepts correspond to

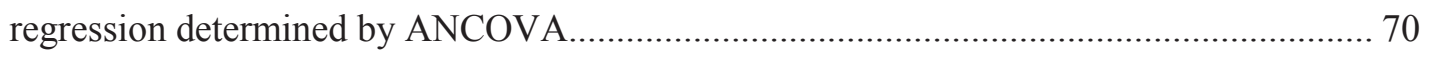

Table 3.4: Relative potencies of bbPTH and hPTH in $m d x$ mice. Relative potency determined as dose bbPTH/dose hPTH to achieve wild type vehicle-treated values. 


\section{Preface}

Chapters 2 and 3 are constructed of submissions to academic journals based on work as part of this thesis. Animal studies, histological analyses, and statistics were conducted by S. Gray. In vitro work concurrent with the in vivo studies was conducted by J. Sanders. PTH cloning was performed in Dr. Chung-Jui Tsai's lab. TRAP and VKM slides were prepared by Dr. Keith Condon at IUPUI with additional sample processing help from D. Weyland and R. Gridley. 


\section{Acknowledgements}

I would like to thank all the people that helped me make this project a success.

My adviser: Dr. Seth Donahue

My committee members: Dr. Rupak Rajachar and Dr. Gopal Jayaraman

For statistical help: Dr. Tom Drummer

My labmates: Sam Wojda, David Weyland, Richie Gridley, and Jen Sanders

The Bonelab Superstar: Dr. Meghan McGee-Lawrence

The MATLAB pro: Alex Hardy

And my Parents: Dan and Patty Gray 


\section{Abstract}

Duchenne muscular dystrophy (DMD) is a progressive disease affecting skeletal and cardiac muscle, as well as bone. Long term disuse and glucocorticoid treatments cause progressive osteoporosis in DMD patients, leading to an increase in fracture incidence. Treatments for osteoporosis in these patients have not been widely explored. Parathyroid hormone (PTH), an anabolic treatment for post-menopausal osteoporosis, could benefit DMD patients by improving skeletal properties and reducing fracture risk. Other PTH analogues are not currently FDA approved to treat osteoporosis, but may have improved osteogenic effects compared to the human analogue. Black bear PTH is especially promising as an osteoporosis treatment for the DMD population. Black bears are unique models of bone maintenance during disuse, since during six months of inactivity (hibernation), they maintain skeletal properties, unlike other hibernators. Additionally, black bear PTH has been correlated to bone formation markers during hibernation, indicating it may be, at least in part, the mechanism by which bears maintain bone during disuse. Employing black bear PTH as a treatment for osteoporosis in DMD patients could greatly improve quality of life for these individuals, and reduce the pain and expense associated with frequent fractures. 


\section{Introduction}

\subsection{Osteoporosis Background}

Osteoporosis is a widespread disease, currently affecting over 10 million Americans. With an aging population and declining global bone health, by the year 2020, the National Osteoporosis Foundation estimates that over one half of the American population will be at risk for the disease. Current health expenditures total \$20 billion annually for treatment of the disease and osteoporosis-related fractures. That number is projected to exceed $\$ 45$ billion annually by the year 2020 ("National Osteoporosis Foundation," 2011). Between the years of 2000 and 2007, hospitalizations for major osteoporotic fractures increased by nearly $40 \%$ in Switzerland, and the trend is similar for most developed Western nations (Lippuner, et al., 2004).

Characterized by a weakening of load-bearing bones due to a decreased bone mineral density of 2.5 standard deviations below the young adult mean of the population, osteoporosis increases porosity and overall fracture risk (Kanis, et al., 1994). Commonly associated with menopause and aging, $5.6 \%$ of men and $12.7 \%$ of women over the age of 50 have experienced at least one osteoporosis-related fracture (Langsetmo, et al., 2007). In addition to commonly occurring age- and menopause-related osteoporosis, an increase in bone porosity and resulting decreases in bone mineral density and strength can be caused by chronic oxidative stresses occurring naturally with aging or from glucocorticoid use for inflammatory conditions (Lane and Yao, 2010), or from chronic disuse scenarios such as during spaceflight (Cavanagh, et al., 2005), after spinal cord injury (Phaner, et al., 2004), or due to mobility-limiting diseases like Duchenne muscular dystrophy (DMD) (Bianchi, et al., 2003). Regardless of the cause, 
osteoporosis results from an uncoupling of the bone resorption/formation response, leading to a coincident increase in porosity, decreased bone volume and bone mineral density, and cortical thinning. These changes lead to decreased bone strength and an increase in fracture incidence, particularly in the lumbar vertebrae, femoral neck, and the long bones of the arm. Hip (femoral neck) fractures make up approximately $50 \%$ of all major osteoporotic fractures, many occurring from only a low-trauma impact such as a fall from a standing height or from a seated position (Langsetmo, et al., 2007).

\subsection{Menopause- and Age-related Osteoporosis}

The most prevalent form of osteoporosis results from aging and menopause. As systemic estrogen levels decrease during menopause and in those with pathogenic estrogen deficiency, permanent bone loss and net bone calcium wasting has been observed (Frost, 1999, Riggs, et al., 1998). Estrogen and estrogen-related receptor (ERR) proteins protect bone by reducing oxidative stresses, reducing osteocyte apoptosis, and by regulating mesenchymal stem cell differentiation into osteoprogenitors and adipocytes (Almeida, et al., 2004, Almeida, et al., 2007, Mann, et al., 2007, Brennan, et al., 2010, Gallet and Vanacker, 2001). This decline in systemic estrogen affects both males and females, but to a lesser degree in males (Clarke and Khosla, 2010). In addition to losses due to estrogen deficiency, osteoporosis also increases with age in both sexes. Trabecular bone losses have been attributed to aging in those as young as 20 years of age, with cortical losses being observed as early as age 30 with no underlying bone pathophysiology (Specker, et al., 2010). These losses progresses continually with age, with increased oxidative stresses leaching calcium from bone (Syed, et al., 2010, Kanis, et al., 1994, 
Manolagas, 2010, Jilka, et al., 2010). In addition, as mesenchymal stem cells - the progenitors of osteoanabolic cells - age, they show a greater tendency to differentiate into fat-forming adipocytes rather than osteoprogenitors, leading to the greater fat store accumulation observed in the geriatric population (Syed, et al., 2010). Compounding the deleterious effects of age on bone, the elderly often experience impaired mobility due to osteoarthritis and decreased muscle strength. As a result, they tend to adopt more sedentary lifestyles, leading to decreased bone strain, which causes disuse osteoporosis.

\subsection{Disuse-related Osteoporosis}

Bone formation in healthy, young bone is heavily regulated by mechanical signaling. Added stresses from such things as long distance running or military cadet marching have an additive effect on bone through promotion of osteoblast proliferation and differentiation. Conversely, disuse scenarios, including a sedentary lifestyle, spaceflight, spinal cord injury, and mobilitylimiting diseases such as DMD, lead to a decrease in overall bone volume and strength. According to the mechanostat theory, load-bearing bone remodeling activity occurs to maintain a constant physiologic strain, and adjusts its geometry accordingly. This form-follows-function relationship is known as Wolff's Law (Bartel, et al., 2006), and is the reason why a tennis player's racket arm has substantially larger bones than the contralateral and why a sedentary person is more prone to fractures than an active one (Bikle and Halloran, 1999, Skerry and Suva, 2003). Disuse-related losses in load-bearing bones have been observed in astronauts spending lengths of time in microgravity, with changes in overall bone formation and mass as well as decreased cell differentiation and altered osteoblast morphology observed in vitro (Bikle 
and Halloran, 1999, Bikle, et al., 2003, Carmeliet, et al., 2001). Spinal cord injury, resulting in paraplegia or quadriplegia, leads to substantial bone losses due to similar decreases in mechanical loading (Elias and Gwinup, 1992, Jiang, et al., 2006).

Mechanical signaling plays a large role in regulating the formation and resorption responses in bone. Stretch-activated ion channels in the cellular membrane and cytoskeletal deformations control cell-to-cell signaling and proliferation responses in osteocytes, which in turn signal osteoblast and osteoclast activity (Srinivasan, et al., 2010). This mechanical signaling pathway is triggered by fluid flow across the bone cross-section. Since load bearing bones are loaded primarily in bending, fluid flow across a section is cyclic (Burger and Klein-Nulen, 1999). Mirroring fluid flow, piezoelectric forces generated in the bone mineral may also contribute to bone formation and maintenance (Elias and Gwinup, 1992).

\subsection{Duchenne Muscular Dystrophy}

Duchenne muscular dystrophy is a fatal X-chromosome linked disease occurring in approximately 1 in 3500 live male births, with 8000 boys currently affected in the United States (Emery, 1991, Novotny, et al., 2011). The gene at locus Xp21 on the X chromosome encodes the dystrophin protein. Dystrophin plays a role in skeletal and cardiac muscle maintenance and repair. Dystrophin deficiency leads to muscular fibrosis and necrosis, weakened force generating capacity, and, by the ages of $20-25$, death due to failure of cardiac or respiratory muscle (Bianchi, et al., 2003). Boys with DMD experience progressive limitations in mobility, 
and by the time they reach 12-15 years of age, are typically confined to a wheelchair (Nair, et al., 2001). To treat the fibroses observed in DMD muscle, patients are frequently prescribed anti-inflammatory glucocorticoids such as prednisone or deflazacort (Bianchi, et al., 2010, Straathof, et al., 2009). Despite the positive outcomes observed in muscle after glucocorticoid treatment, glucocorticoids have deleterious effects on bone by causing an environment of increased oxidative stresses. These drugs increase the function of osteoclasts, decrease the function of osteoblasts, and lead to a net decrease in calcium phosphate absorption (Cohran, et al., 2008). The result is glucocorticoid-induced osteoporosis. In addition, the limited mobility in DMD patients leads to bone loss due to disuse. The result is progressive osteoporosis and an increase in risk of fractures in the DMD population.

\subsubsection{DMD and Bone}

Duchenne muscular dystrophy patients treated with glucocorticoids show decreases in bone mineral content and bone mineral density in load bearing bones (lumbar spine, hip, tibia, and femur). Compared to healthy age-matched controls, DMD patients show a $30-50 \%$ decrease in bone mineral density, with greater losses observed in trabecular bone due to its elevated surface area, and therefore, elevated metabolic potential (Soderpalm, et al., 2007, Bianchi, et al., 2010, Larson and Henderson, 2000, Aparicio, et al., 2002, Crabtree, et al., 2009, McDonald, et al., 2002). These substantial changes in bone mineral lead to an increase in fracture incidence,

despite the fact that DMD patients are typically less active and less likely to engage in risky behaviors than the average school-aged boy. In DMD patients treated with glucocorticoids, $44 \%$ of 71 boys evaluated sustained one or more long bone fractures (Larson and Henderson, 2000). 
As DMD patients age and as the amount of time they undergo glucocorticoid treatments increases, fracture risk increases as well. By the age of $16,67 \%$ of DMD patients had sustained at least one long bone fracture, with a large proportion of these fractures occurring after the loss of ambulation (Larson and Henderson, 2000). Regardless of corticosteroid treatment, one study found that over $20 \%$ of DMD patients had sustained a fracture. Of these fractures, $47 \%$ were in the lower limb long bones in mobile patients, and 30.4\% were in the lower limb long bones in wheelchair-bound boys (McDonald, et al., 2002). Long bone fractures were more common in the femur than the tibia in both mobile and wheelchair-bound patients, with the majority of fractures occurring in the highly trabecularized proximal and distal regions of the femur (McDonald, et al., 2002, Siegel, 1977, Gray, et al., 1992, Hsu, 1982, Hsu, 1979, Hsu and Garcia-Ariz, 1981). Vertebral fractures are even more common than long bone fractures in DMD patients, but often go unnoticed, as these patients typically experience painful kyphoscoliosis due to weakening of the muscles supporting the spine, making the pain of vertebral fracture go unnoticed, or they may experience an asymptomatic vertebral fracture (Balaban, et al., 2005, Lord, et al., 1990, Smith, et al., 1989, Yasuma and Sakai, 1999). With glucocorticoid treatment, it was determined through regression analyses that beginning at 40 months of treatment, $25 \%$ of glucocorticoid-treated DMD patients will sustain a vertebral fracture, and by 100 months of treatment, $75 \%$ of boys with DMD will have experienced at least one vertebral fracture, regardless of whether or not they are ambulant (Bothwell, et al., 2003). These fracture rates are drastically high, especially when compared to the approximately $1-4 \%$ fracture incidence in healthy boys of similar age (McDonald, et al., 2002). In addition, fractures in DMD patients most frequently occur from low trauma incidents, such as falls from a standing height or falls from a wheelchair onto outstretched hands or knees. These traumatic fractures are often the tipping point, transitioning patients who were mobile with assistance devices to being permanently wheelchair-bound, further accelerating muscle and bone loss due to disuse. 


\subsection{Osteoporosis Therapies}

Osteoporosis therapies have not been widely explored in DMD patients, despite the wide occurrence of fractures in this population. The major focus in pediatric osteoporosis is strictly dietary, including calcium and vitamin D supplementation. Current pharmaceutical osteoporosis therapies include antiresorptives and anabolic agents, but are not approved for use in a pediatric population. Antiresorptives work to inhibit the deleterious action of osteoclasts on bone, with no effect on osteoblastic action. Most currently approved treatments fall into this anti-catabolic category. Bisphosphonates including ibandronate, alendronate, zoledronate, and risedronate, known by brand names such as Boniva ${ }^{\circledR}$ (Roche), Reclast ${ }^{\circledR}$ (Novartis), and Fosamax ${ }^{\circledR}$ (Merck), make up the majority of the osteoporosis drug market. Other anti-catabolic drugs include selective estrogen receptor modulators (SERMs), which signal estrogen receptors in a manner similar to endogenous estrogen (Lyritis, et al., 2010). Prior to SERMs, estrogen replacement therapy (ERT) had been explored to treat not only menopause-related osteoporosis, but other negative symptoms associated with menopause as well. However negative results from a single clinical trial where ERT administration was attributed to an increase in cancer risk effectively stifled the public's confidence in such a treatment (Pinkerton and Stovall, 2010, Khosla, 2010). Currently, there is only one FDA approved anabolic treatment for osteoporosis. Teriparatide, branded as Forteo ${ }^{\circledR}$ (Lilly), utilizes recombinant human parathyroid hormone 134 and is administered via daily subcutaneous injection for a period of up to two years. Teriparatide increases bone anabolism by promoting osteoblast survival. The result is an improvement in the bone formation: resorption ratio without hindering bone's remodeling capabilities which require resorption of old bone tissue to produce new bone in a targeted manner. 


\subsection{Parathyroid Hormone}

In humans, parathyroid hormone (hPTH) is an 84 reside amino acid chain produced on the short arm of chromosome 11 in the parathyroid glands (Mallya, et al., 2010, Antonarakis, et al., 1983). PTH is released in response to low serum calcium. The result is an increase in osteoclastic resorption and release of calcium ions into the blood (Marieb and Hoehn, 2007). But PTH is a dual-action hormone. In chronic hyperparathyroidism or from continual PTH injection (such as through a PTH pump) (Jilka, et al., 2006), bone properties, including cortical thickness and trabecular bone volume decrease as would be expected through the classic action of the hormone (Parfitt, 2002). However, when administered intermittently, PTH actually promotes osteoblast differentiation and survival through the prevention of osteoblast apoptosis, and leads to a net accrual of both trabecular and cortical bone (Parfitt, 2002, Aslan, et al., 2001, Bellido, et al., 2003, Jilka, et al., 1999, Jilka, 2007, Jilka, et al., 2009). As such, intermittently injected recombinant human parathyroid hormone has been shown to be an effective anabolic treatment for osteoporosis.

\subsubsection{PTH Variations}

Across species, there are several variations in parathyroid hormone structure, though its function in calcium homeostasis remains essentially the same. In a comparison dose-response study of rat and bovine PTH 1-34 administered to ovariectomized rats (a rodent model of post- 
menopausal bone loss), it was found that bovine (Bos taurus) PTH was 2-5 times more potent than rat (Rattus norvegicus) PTH when looking at outcome variables such as trabecular bone volume fraction, bone mineral content, bone mineral density, and mineral apposition rate ( $\mathrm{Li}$, et al., 2001). The varied bone properties resulted from a peptide treatment varying in only 6 amino acid residues across the 34 residue truncated sequence (Altschul, et al., 1997). A difference in only a few amino acid residues across the PTH peptide may drastically alter cyclic adenosine monophosphate (cAMP) signaling in target cells (Hilliker, et al., 1996, Reidhaar-Olson, et al., 2000). These results suggest further exploration of various parathyroid hormone sequences may lead to the discovery of a more anabolic treatment for osteoporosis than the currently approved hPTH.

\subsubsection{Black Bear PTH}

Black bear parathyroid hormone (bbPTH), over the 84 amino acid residues of the full length protein (Figure 1.1), is an excellent choice to study as an osteoporosis treatment because of the unique bone maintenance observed in these animals during extended periods of disuse. Black bears spend up to six months in hibernation annually, during which they do not wake to eat or excrete waste (Schooley, 1994, Oli, et al., 1997), yet do not experience bone losses attributed to disuse (Donahue, et al., 2006, Donahue, et al., 2006). Other hibernators, such as bats and ground squirrels do not display this level of bone maintenance during disuse (McGee-Lawrence, et al., 2010, Doty and Nunez, 1985, Krook, et al., 1977). Neither black bears nor grizzly bears display disuse-associated decreases in cortical geometry, cortical thickness, intracortical porosity, cortical strength, bone mineral content, or trabecular bone volume fraction after an extended 
period of disuse (Donahue, et al., 2006, Donahue, et al., 2006, McGee, et al., 2008, McGeeLawrence, et al., 2009, McGee-Lawrence, et al., 2009). Additionally, in contrast to humans (Specker, et al., 2010), black bears show a decrease in intracortical porosity with age (McGee, et al., 2007). Black bear parathyroid hormone may be even more promising as a treatment of osteoporosis since bbPTH is positively correlated with bone formation markers during hibernation in these animals (Donahue, et al., 2006).

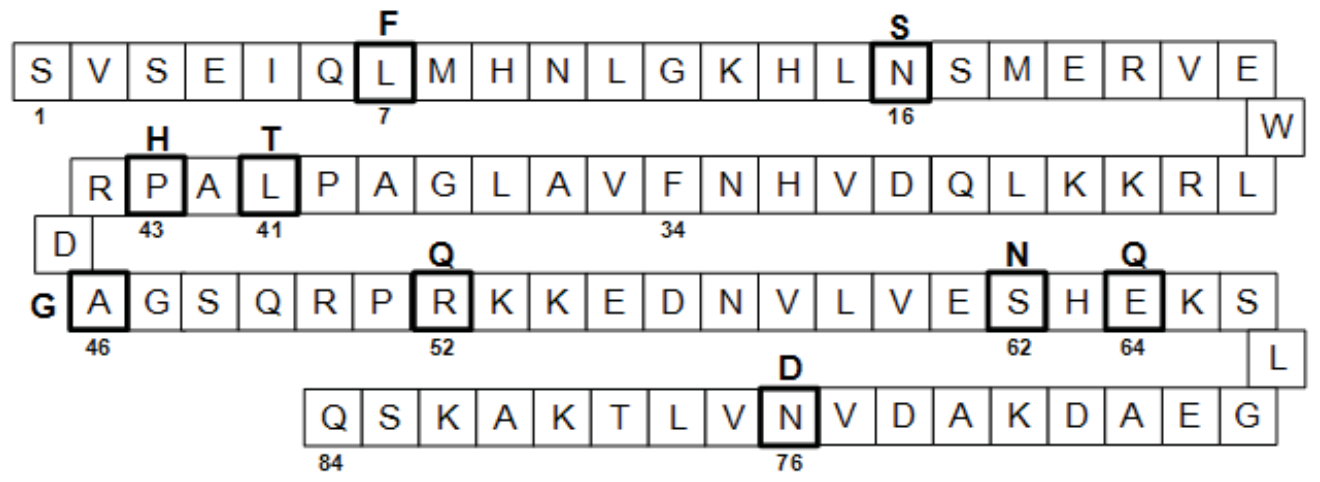

Figure 1.1 Amino acid sequence of human PTH 1-84. Amino acid substitutions in bear PTH 1-84 are highlighted next to the corresponding amino acid in the human sequence.

\subsection{DMD Models}

Duchenne muscular dystrophy is modeled in only a few species including dogs, chickens, and most commonly, mice (Askanas, et al., 1971, Bandman, 1985, Crowe and Baskin, 1979, DeMichele, et al., 1986, Saito, et al., 2007). These animals have been engineered to display 
deficiencies in the dystrophin gene at locus Xp21 of the X chromosome. Animal models of DMD display the characteristic muscular weakness, myopathic lesions, and muscular fibrosis observed in DMD patients, along with associated declines in bone properties, as well as elevated levels of serum creatine kinase and pyruvate kinase (Ryder-Cook, et al., 1988, Sicinski, et al., 1989, Bulfield, et al., 1984, Call, et al., 2010).

\subsubsection{The $m d x$ Mouse}

Osteoporosis in the $m d x$ mouse, a dystrophin-deficient rodent model, has not been extensively studied. Available literature indicates these animals experience bone losses associated with dystrophin deficiency in a similar pattern as observed in DMD-induced osteoporosis. Even without glucocorticoid exposure, these mice demonstrate decreased bone mineral density in load bearing bones including the pelvis, femur, tibia, and lumbar vertebrae (Nakagaki and Camilli, 2012). In the first four months of life, $m d x$ mice lose muscle and bone in the degenerative pattern of DMD. They display larger body sizes and limb muscles, though these muscles are heavily fibrosed and less capable of high muscular forces. In 4 month old female $m d x$ mice, Montgomery et al observed increases in femur bone mineral density, bone mineral content, force to failure in 3-point bending, and spinal BMD (Montgomery, et al., 2005). However, when normalized by the increased body mass of the mice, no significant changes were observed in skeletal properties (Novotny, et al., 2011). In a study comparing musculoskeletal properties of $m d x$ mice over age, it was concluded that the first four weeks of life are characterized by progressive muscle weakness and associated skeletal declines, and by 12 weeks of age, the mice begin recovery of lost muscle, being fully recovered to wild type 
force production by 18 weeks. At four weeks, increased cortical porosity and decreased bone density were observed in the tibia of $m d x$ mice compared to wild type controls. Breaking force, and deformation at fracture were significantly decreased in $m d x$ mice regardless of age, supporting the idea that even though muscle is regained, bone takes much longer to recover (Anderson, et al., 1993). In 4-week old male $m d x$ mice, micro-CT of the mid-diaphysis and metaphysis of the tibia showed decreases in bone volume fraction (BV/TV) of $35 \%$, with an associated decrease in trabecular number and increase in trabecular spacing. Ultimate load and stiffness of the tibia were significantly lower than that of wild type controls (Novotny, et al., 2011). Nakagaki et al showed decreases in mineral density at the hip, lower limbs, and lumbar vertebrae in $m d x$ mice. At 3 weeks of age, $m d x$ femurs displayed decreased trabecular area, trabecular area fraction, and trabecular thickness of $\sim 40 \%$. Static histomorphometry revealed decreases in both osteoblast and osteoclast surface area, with greater decreases in osteoblast surface. Cortical area and thickness of the femur was also significantly reduced in the femur of the $m d x$ mouse. No change in body weight between $m d x$ and wild type was observed at this young age (Nakagaki, et al., 2010).

\subsection{DMD and Osteoporosis Treatments}

Duchenne muscular dystrophy patients and other pediatric osteoporosis patients have historically been treated with nutritional supplementation. High doses of vitamin D and calcium in this population have shown only modest maintenance of skeletal properties (Bianchi, 2005, Bianchi, et al., 2010). A single study in 2003 administered alendronate to DMD patients. These patients were treated with the bisphosphonate therapy for a two year period, during which their 
bone mineral densities and z-scores were evaluated using dual-energy X-ray absorptiometry. At the conclusion of the study, it was found that alendronate had prevented the expected decreases in bone mineral density that have been observed in untreated patients. However, as would be expected in a bisphosphonate therapy, no anabolic outcomes were observed (Hawker, et al., 2005). An anabolic treatment for osteoporosis in DMD, such as intermittent administration of bbPTH could serve as an improved treatment to attenuate the fractures observed in this population. Indeed, PTH has been shown to reverse bone losses in both disuse (hindlimb suspension) and in glucocorticoid-treated scenarios better than bisphosphonates (Saag, et al., 2009, Cavanagh, et al., 2005). 


\section{Specific Aims and Hypotheses}

Aim 1: Establish black bear PTH as an effective anabolic treatment for osteoporosis in a mouse model of Duchenne muscular dystrophy

Administer high dose bbPTH to $m d x$ mice and measure bone histomorphometric and strength properties after treatment compared to vehicle-treated $m d x$ mice

Hypotheses: High dose bbPTH will improve bone properties in both mdx and wild type mice.

High dose bbPTH will restore bone properties in mdx mice to untreated wild type values.

Aim 2: Determine black bear PTH's relative potency as an osteoporosis treatment compared to human PTH in the $m d x$ mouse

Administer multiple doses (vehicle, low, medium, and high) of bbPTH or hPTH to separate groups of $m d x$ mice. Evaluate skeletal outcomes including bone histomorphometric and strength properties associated with each dose. Determine relative potency by regressing bone properties against dose for each treatment, and use relative potency analyses to determine which is more effective to reach wild type vehicle-treated values.

Hypotheses: $\quad$ bbPTH and hPTH will improve bone properties in a dose-responsive manner. 
bbPTH will be more anabolic than $h P T H$, therefore, it will require a lower dose of bbPTH to reach untreated wild type values in $m d x$ mice than hPTH to reach the same value 


\section{Chapter 2: Black Bear Parathyroid Hormone has Greater Anabolic Effects on Trabecular Bone in Dystrophin- deficient Mice than in Wild Type Mice ${ }^{1}$}

\subsection{Introduction}

Boys with Duchenne muscular dystrophy (DMD) progressively lose muscle strength and between the ages of 12-15 years are usually confined to a wheelchair (Nair, et al., 2001). The condition is typically fatal by $20-25$ years due to respiratory or cardiac muscle failure (Bianchi, et al., 2003). DMD induced muscular necrosis and fibrosis are treated with glucocorticoids (e.g., prednisone or deflazacort) (Bianchi, et al., 2010, Straathof, et al., 2009). DMD patients treated with glucocorticoids demonstrate a $30-50 \%$ decrease in bone mineral content and bone mineral density in the lumbar spine, hip, and long bones of the lower limbs as compared with healthy age-matched controls (Bianchi, et al., 2010, Soderpalm, et al., 2007, Larson and Henderson, 2000, Aparicio, et al., 2002, Crabtree, et al., 2009). Greater losses occur in trabecular bone than cortical bone due to its greater surface area for remodeling activity (Bianchi, et al., 2010). Fracture risk increases as a result. One study found that $44 \%$ of 71 boys with DMD sustained at least one fracture; of boys over the age of 16 years, $67 \%$ sustained at least one fracture (Larson and Henderson, 2000). The majority of fractures occur in the proximal and distal femur in DMD patients (Hsu and Garcia-Ariz, 1981, Hsu, 1979, Gray, et al., 1992).

\footnotetext{
${ }^{1}$ Reprinted from BONE, 51 (3), Gray, McGee-Lawrence, Sanders, Condon, Tsai, Donahue, Black bear parathyroid hormone has greater anabolic effects on trabecular bone in dystrophin-deficient mice than in wild type mice, 578-585, 2012 with permission from Elsevier.
} 
Like boys with DMD, $m d x$ mice lack dystrophin (Ryder-Cook, et al., 1988, King, et al., 2007, Sicinski, et al., 1989). These animals exhibit myopathic lesions characteristic of those seen in DMD patients (Bulfield, et al., 1984, Call, et al., 2010). $M d x$ mice display larger body sizes and limb muscles, though these muscles are heavily fibrosed and less capable of high muscular forces (Montgomery, et al., 2005). At 3 weeks of age, $m d x$ femurs display $40 \%$ reductions in trabecular area, trabecular area fraction, and trabecular thickness as compared to age-matched wild type mice. They show decreases in osteoblast surface and increases in osteoclast surface area, leading to increased resorption and decreased formation (Rufo, et al., 2011). In 4 week old male $m d x$ mice, the metaphysis of the tibia showed decreases in bone volume fraction of $35 \%$, with a decrease in trabecular number and increase in trabecular spacing. One study found no difference between $m d x$ and wild type cortical thickness in the femur at 4 months of age (Montgomery, et al., 2005). However, at 6 months, $m d x$ mice have decreased cortical bone properties relative to wild type mice and increased osteoclast number (Rufo, et al., 2011). Whole bone breaking force and deformation at fracture are reduced in $m d x$ mice regardless of age (Anderson, et al., 1993). At 24 months of age, $m d x$ mice show greater declines (relative to wild type mice) in trabecular and cortical properties in the tibia than at 7 weeks of age (Novotny, et al., 2011).

Treatments for DMD-related osteoporosis have not been widely explored. Treating DMD patients with the bisphosphonate alendronate prevented further decreases in bone mineral density over a two year period (Hawker, et al., 2005). The impaired osteoblast function seen in both DMD patients and $m d x$ mice suggests that an anabolic treatment for osteoporosis (i.e., PTH therapy) would be an effective therapeutic for increasing bone mass in these patients. Indeed, PTH treatment leads to greater reductions in fracture risk than alendronate in patients 
with glucocorticoid-induced osteoporosis (Saag, et al., 2009). Our laboratory has been investigating a novel PTH analogue linked to preservation of bone during disuse. Black bears (Ursus americanus) hibernate for 6 months of the year, and do not experience disuse-related osteoporosis (Donahue, et al., 2006, McGee-Lawrence, et al., 2009, McGee-Lawrence, et al., 2009). Black bear parathyroid hormone (bbPTH) has been positively correlated to bone formation markers during hibernation and is implicated in the mechanism of bone preservation during disuse (McGee-Lawrence, et al., 2009, Donahue, et al., 2006, Donahue, et al., 2006). Furthermore, bbPTH 1-34 causes greater reductions in serum starved induced caspase activity in osteoblasts than hPTH 1-34 (McGee-Lawrence, 2009). Thus, bbPTH may be well suited to improve bone mass in cases of dystrophin deficiency that impair mobility. We hypothesized that bbPTH treatment in $m d x$ mice would demonstrate improved bone properties compared to vehicle treated mice, and that bbPTH treatment would restore $m d x$ bone properties to wild type levels.

\subsection{Materials and Methods}

\subsubsection{PCR cloning and sequencing of bbPTH}

Genomic DNA was extracted from black bear whole blood samples using the GenomicPrep Blood DNA Isolation Kit (Amersham Biosciences, Piscataway, NJ). The genomic DNA was used for PCR amplification of PTH using consensus primers designed based on alignment of eight full-length mammalian PTH sequences available in GenBank including bovine (Bos 
taurus, AAA30749), cat (Felis catus, Q9GL67), dog (Canis familiaris, P52212), human (Homo sapiens, NP_000306), macaque (Macaca fascicularis, Q9XT35), mouse (Mus musculus, NP_065648), pig (Sus scrofa, NP_999566), and rat (Rattus norvegicus, NP_058740). PCR amplification was performed using 10-15 ng genomic DNA, $100 \mu \mathrm{M}$ dNTPs, $0.2 \mu \mathrm{M}$ each primer, and 1 unit REDTaq (Sigma, St. Louis, MO) in $20 \mu \mathrm{L}$ reaction volume. PCR products were gel-purified using the UltraClean GelSpin Kit (MoBio Carlsbad, CA) and cloned into the pCRII vector using the TA cloning kit (Invitrogen, Carlsbad, CA). DNA sequencing was performed using the DTCS Quick Start kit and the CEQ8000 Genetic Analysis System (Beckman Coulter, Fullerton, CA). Nucleotide sequences were searched against the GenBank protein database using BlastX (Altschul, et al., 1997) to confirm their putative identity as PTH. Multiple sequence alignment was performed by ClustalW version 1.82 (Chenna, et al., 2003). The sequence obtained for mature black bear PTH (bbPTH; GenBank \#GU563375) is shown in Figure 1.1.

Proteos (Kalamazoo, MI) recombinantly produced bbPTH 1-84 in E. coli. The purified protein were characterized by analytical HPLC and mass spectroscopy and subjected to quantitative amino acid analysis to determine exact protein concentration. Lyophilized protein aliquots were stored at $-80^{\circ} \mathrm{C}$. 


\subsection{2 cAMP Assay}

The PKA/cAMP pathway is primarily responsible for PTH's anabolic effects on osteoblasts, and previous work suggests that small changes in the amino acid sequence of human PTH can produce a peptide that induces greater cyclic adenosine monophosphate (cAMP) production than the hormone's native version (Langsetmo, et al., 2007). Thus, bbPTH peptide bioactivity was investigated via quantification of cAMP production. PTH receptor expression and PTH-stimulated cAMP production are temporally regulated during osteoblast differentiation (Bellido, et al., 2003, Schiller, et al., 1999), where maximal PTH-stimulated cAMP production in MC3T3 cells occurs in cells incubated for 5-10 days in osteogenic medium; therefore, this time frame was chosen for our studies. MC3T3-subclone 4 cells were seeded at 10,000 cells $/ \mathrm{cm}^{2}$ in 6 well plates in basal medium ( $\alpha$-MEM, 10\% FBS, $1 \%$ penicillinstreptomycin). Cells were allowed to attach overnight, before medium was changed to osteogenic medium (basal medium supplemented with $50 \mu \mathrm{g} / \mathrm{ml}$ ascorbic acid and $10 \mathrm{mM} \beta$ glycerophosphate) (Day 0). The medium was replaced with fresh osteogenic medium on Day 3, and the cAMP assay was performed on Day 5.

For the cAMP assay, the medium was aspirated and confluent cells were washed with PBS. The cells were stimulated with vehicle (1 mM acetic acid) or bbPTH $(1-84)(10,30$, or $100 \mathrm{nM})$ in PBS containing $1 \mathrm{mM}$ isobutylmethylxanthine (IBMX) for $10 \mathrm{~min}$ at $37^{\circ} \mathrm{C}$ with $\mathrm{N}=3$ wells per treatment. At the end of the treatment period, the PBS was collected and samples were prepared and assayed in triplicate without acetylation as per the manufacturer's instructions 
(Cayman Chemical, Ann Arbor, MI). Cell culture supernatants were assayed directly; samples were diluted as necessary in cAMP EIA buffer.

\subsubsection{Caspase-3/7 Activity Assay}

We performed a caspase-3/7 assay because human PTH has been shown to have an antiapoptotic effect on osteoblasts (Bellido, et al., 2003). MC3T3-S4 cells were seeded at 20,000 cells/well in 96 well, tissue culture-treated white-walled plates. The cells were seeded in basal medium and allowed to attach overnight. The next day, the medium was aspirated, cells were washed with PBS, and then pretreated with vehicle (1 mM acetic acid) or bbPTH (1-84) (30 or $100 \mathrm{nM}$ ) in basal medium for $1 \mathrm{hr}$ with $\mathrm{N}=6$ wells per treatment. At the end of the pretreatment period, the medium was aspirated, the cells were washed with PBS, and either basal medium (unstarved cells) or $\alpha$-MEM alone (serum-starved cells) was added to each well. After 6 hours, the medium was aspirated, the cells were washed with PBS, and $50 \mu 1$ of both PBS and a luminogenic caspase-3/7 substrate (Caspase-Glo 3/7 Assay, Promega, Madison, WI) were added to each well. After 1 hour, luminescence was quantified using a Synergy HT MultiDetection Microplate Reader (Bio-Tek, Winooski, VT). Luminescence was converted to international units $(\mathrm{U})$ of caspase-3/7 activity using a standard curve generated with human recombinant caspase-3 (Enzo Life Sciences, Farmingdale, NY). 


\subsubsection{Animals}

Twenty 4-week old male C57BL/10ScSn/DMD-mdx and 10 wild type control C57BL/10Sn mice were obtained from Jackson Laboratories (Bar Harbor, ME). Mice were co-housed six per cage in a 12 -h dark, 12 -h light environment at $20^{\circ} \mathrm{C}$. Mice were fed a standard rodent diet containing 0.95\% calcium (Purnia LabDiet Autoclavable Rodent Diet \#5010) and given water ad libitum. All mice were euthanized at 10 weeks of age, after 6 weeks of PTH treatment, using carbon dioxide asphyxiation. Three mice ( $1 \mathrm{mdx}$ bbPTH, $1 \mathrm{mdx}$ vehicle and 1 wild type vehicle) died during the study and were not included in subsequent data analysis. This study was approved by the Michigan Tech Animal Care and Use Committee protocol L0206.

\subsubsection{PTH Treatment}

Mice were given daily subcutaneous injections of bbPTH 1-84 or an acidic vehicle solution. Vehicle injections were prepared with $0.15 \mathrm{M} \mathrm{NaCl}$ and $0.001 \mathrm{~N} \mathrm{HCl}$. bbPTH solutions were prepared by dissolving PTH in the acidic saline solution. Mice were injected once daily, 5 times per week with $28 \mathrm{nmol} / \mathrm{kg}$ bbPTH 1-84. After six weeks of daily injection, mice were euthanized and their long bones were removed. At 1 and 4 days prior to sacrifice, mice were given calcein injections to label bone formation surfaces $(10 \mathrm{mg} / \mathrm{kg})$. 


\subsubsection{Isolation, Culture, and Mineralization of Bone Marrow Stromal Cells (BMSCs)}

Bone marrow was flushed from the humeri of vehicle- and bbPTH-treated wild type and $m d x$ mice. Cells were pooled by treatment group. Cells were seeded into 6 well plates $\left(10^{7}\right.$ cells/well) in osteogenic culture medium ( $\alpha$-MEM, 20\% FBS, $1 \%$ antibiotic-antimycotic, $1 \%$ non-essential amino acids, $50 \mu \mathrm{g} / \mathrm{ml}$ ascorbic acid and $10 \mathrm{mM} \beta$-glycerophosphate). BMSCs were identified by adherence; after 72 hrs, non-adherent cells were removed. Media changes continued every 3 days. BMSCs were cultured in osteogenic medium for 21 days to promote calcified matrix production. At the end of this period, BMSCs were fixed $(10 \%$ neutral-buffered formalin) and stained (2\% alizarin red). Calcified matrix was quantified as the percentage of alizarin red-positive area over total well area using image analysis software (Bioquant Osteo, Nashville, TN).

\subsubsection{Trabecular Bone Properties}

Proximal tibial and distal femoral metaphyses were scanned using micro-computed tomography ( $\mu \mathrm{CT}$ ) (SCANCO 35, SCANCO Medical, Switzerland) to determine trabecular properties. The scan region started $0.5 \mathrm{~mm}$ from the physis and was 100 slices $(0.7 \mathrm{~mm})$ thick (Figure 2.1). From these data, trabecular number (Tb.n), trabecular spacing (Tb.sp), trabecular thickness (Tb.th), and bone volume/tissue volume (BV/TV) were calculated. Dynamic histomorphometry was evaluated in the same region of the proximal tibia $(0.5 \mathrm{~mm}$ from the 
physis and the endosteal surface) (Phaner, et al., 2004) by determining the distance between calcein labels on the trabecular surface and the lengths of single- and double-labeled surfaces using Bioquant Osteo software (Nashville, TN) (Figure 2.4). Static histomorphometry was evaluated by measuring osteoid surface, osteoid thickness, and eroded surface in slides stained in von Kossa with MacNeal's tetrachrome stain (Figure 2.2). Osteoblast and osteoclast surfaces were measured in decalcified proximal tibia segments stained in toluidine blue and tartrateresistant acid phosphatase (TRAP) (Figure 2.3).

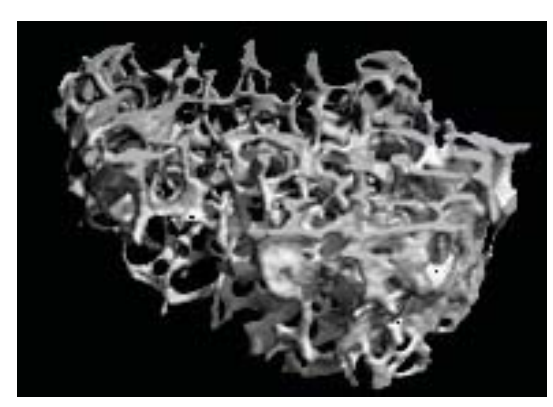

Figure 2.1: Micro-CT image of the distal femur trabeculae

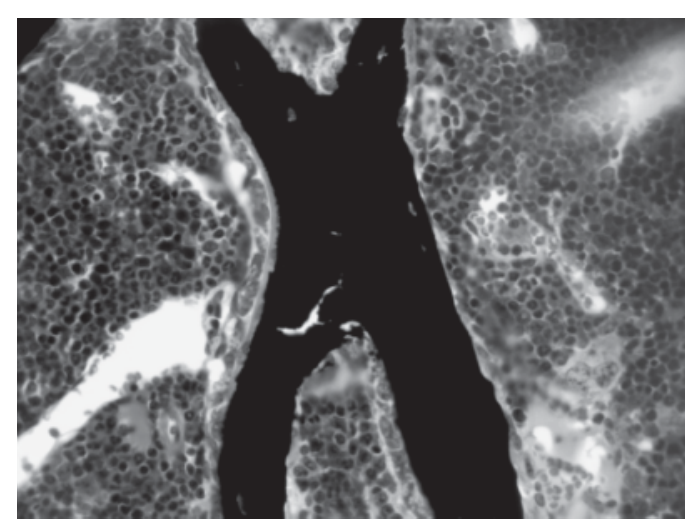

Figure 2.2: Von Kossa MacNeal staining of trabecular bone was used to determine osteoid surface and thickness. Osteoid appears as a light blue seam surrounding black trabecular struts. 


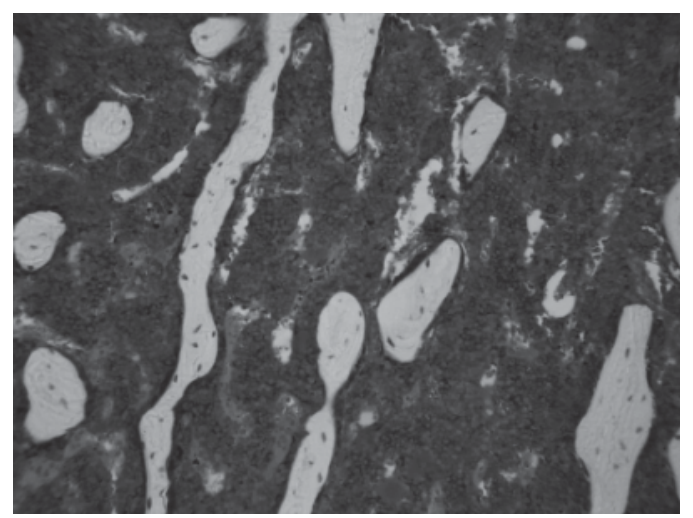

Figure 2.3: Tartrate-resistant acid phosphatase (TRAP) stained trabecular bone was used to measure osteoclast and osteoblast surface. Osteoclasts appear as pink streaks along the white trabecular struts, and osteoblasts appear as blue cuboidal cells along the trabeculae.

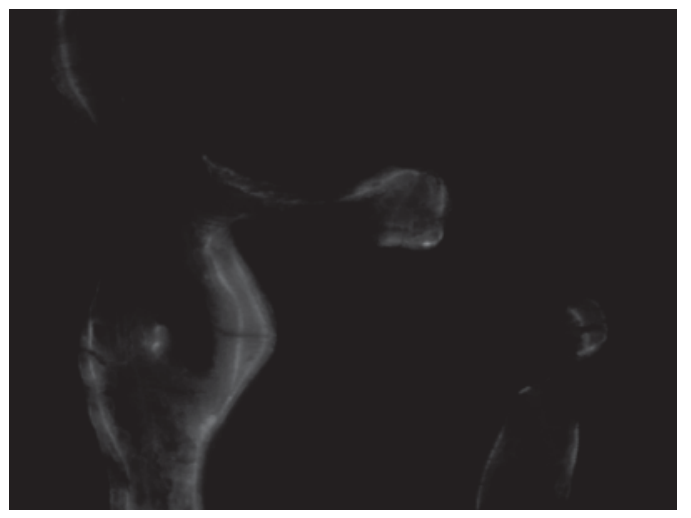

Figure 2.4: Calcein-labeled trabecular bone was used to determine mineralizing surface/bone surface (MS/BS) and mineral apposition rate (MAR) based on label distance.

\subsubsection{Cortical Bone Properties}

The right femoral diaphysis was embedded in methylmethacrylate. A cross-section was cut at the midpoint using an Isomet diamond wafering blade (Beuhler, Lake Bluff, IL), ground to a thickness of $<90 \mu \mathrm{m}$ and mounted on a microscope slide. Cross-sections were digitized at 40X 
magnification using a SPOT Insight camera (Diagnostic Instruments, Sterling Heights, MI). A custom macro and Scion Image software (Scion Corp., Frederick, ME) were used to quantify cross-sectional properties including medio-lateral $\left(\mathrm{I}_{\mathrm{ml}}\right)$, anterio-posterior $\left(\mathrm{I}_{\mathrm{ap}}\right)$, and maximum $\left(I_{\max }\right)$ moments of inertia (Figure 2.5). Mineral apposition rate was determined by measuring the distance between calcein labels using Bioquant software. Mineralizing surface was determined by measuring the ratio of single- and double-labeled surfaces to the total cortical surface (Figure 2.6). Cortical thickness was measured as the average distance between the endosteal and periosteal surfaces.

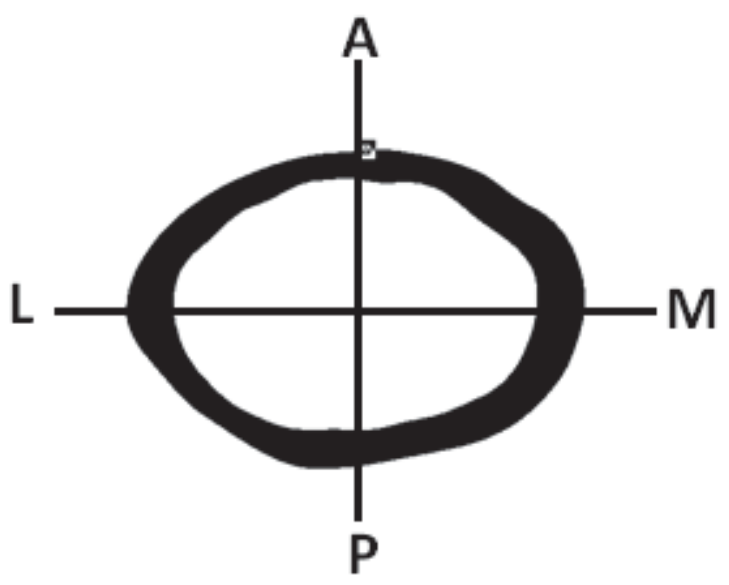

Figure 2.5: A custom macro and Scion Image were used to determine cortical geometrical properties including Iml, Iap, and Imax, and cortical area. Anatomical axes are indicated. Bioquant was used to calculate cortical thickness. 


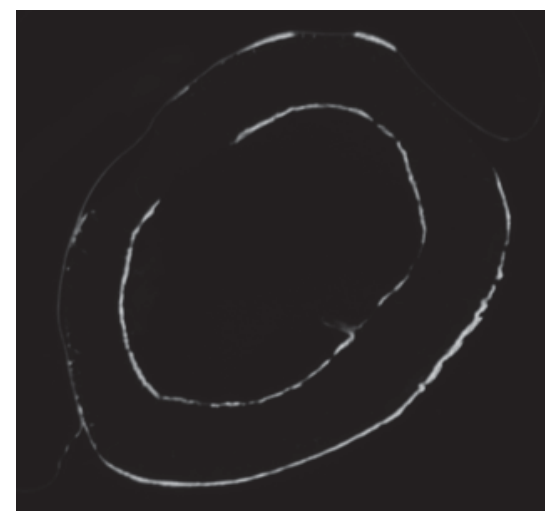

Figure 2.6: Calcein-labeled cortical cross sections were evaluated to measure single- and doublelabeled surfaces to determine mineralizing surface and mineral apposition rate on the periosteal and endosteal surfaces.

\subsubsection{Mechanical Properties}

Bending properties of the left femur were determined by a 3-point bend test at a rate of 1 $\mathrm{mm} / \mathrm{min}$. The testing fixtures had a span of $10 \mathrm{~mm}$ and a radius of $1 \mathrm{~mm}$ (Figure 2.7). Mechanical testing was performed using an Instron test machine (Norwood, MA). Stress-strain plots were determined using asymmetric beam theory (Levenston, 1995), and used to calculate ultimate stress and modulus of toughness. Load-displacement plots were used to determine ultimate load and energy to failure in bending for each sample (Figure 2.8). 


$$
\text { Ultimate stress: } \quad \sigma=\left(\frac{P L\left(I_{a p} y-I_{p} x\right.}{4\left(I_{m l} I_{a p}-I_{p}{ }^{2}\right.}\right)
$$

$$
\text { Modulus of toughness: } \quad u=\frac{U_{f}\left(3 c^{2}\right)}{I_{m l} L}
$$

$$
\begin{aligned}
& \sigma=\text { Ultimate stress (MPa) } \\
& \mathrm{P}=\text { Load }(\mathrm{N}) \\
& \mathrm{L}=\text { Length of span }(\mathrm{mm}) \\
& \mathrm{x}=\text { Anterior distance furthest from neutral axis } \\
& \mathrm{y}=\text { Medio-lateral distance furthest from neutral axis } \\
& \mathrm{u}=\text { Modulus of Toughness } \\
& \mathrm{Uf}=\text { Energy to failure } \\
& \mathrm{c}=\text { Distance from point of zero deflection }
\end{aligned}
$$

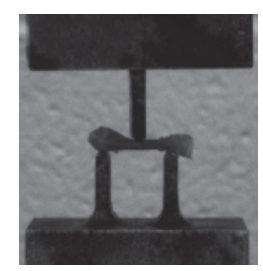

Figure 2.7: Three-point bending setup with anterior surface in tension 


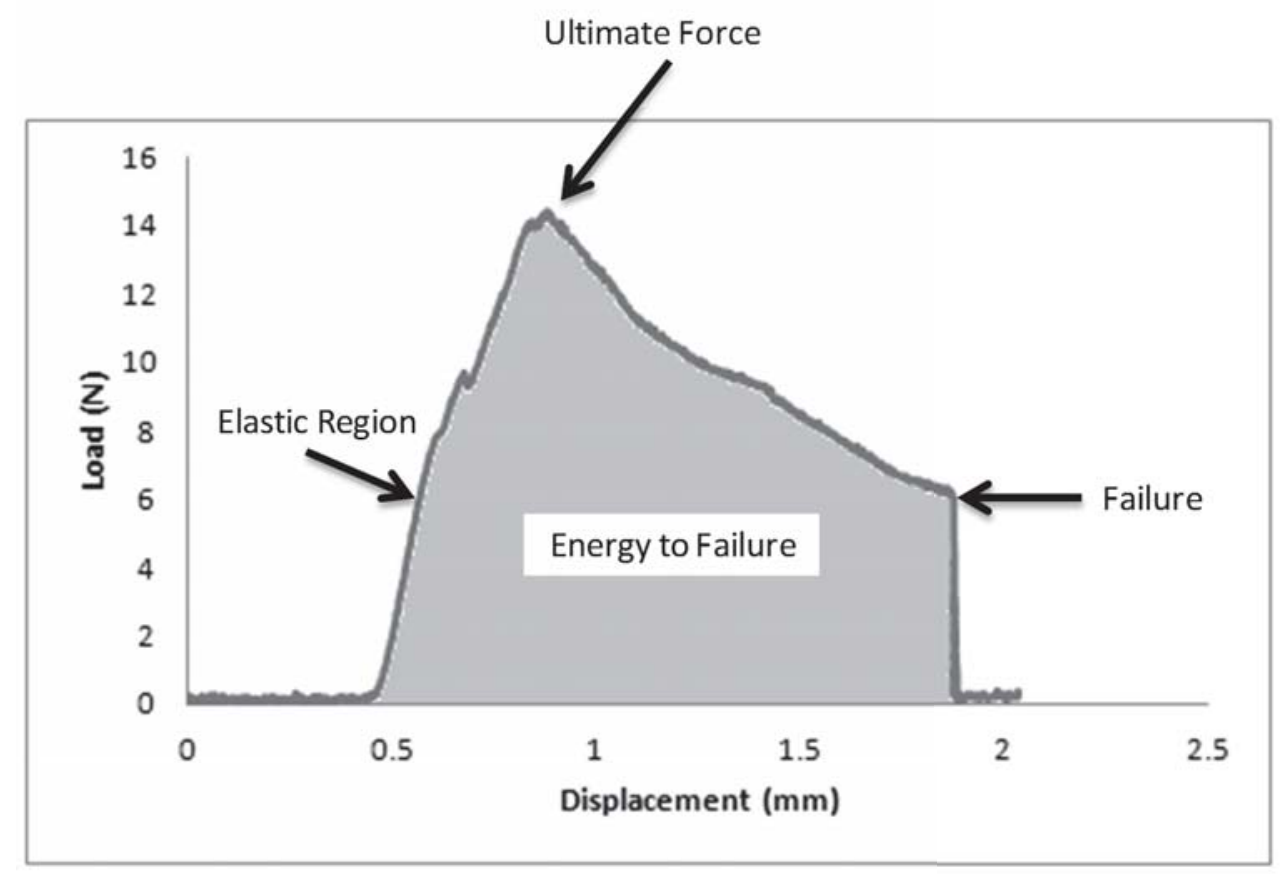

Figure 2.8: Load-displacement plot for 3-pt bending of a mouse femur

\subsubsection{Mineral Content}

Mineral content was determined through ashing. After mechanical testing, femoral diaphyses were cleaned of marrow, placed in a furnace at $100^{\circ} \mathrm{C}$ for 24 hours to remove all water, and weighed to obtain dry mass. Samples were returned to the furnace for 48 hours at $600^{\circ} \mathrm{C}$ to burn off all organic material. Bones were again weighed to determine relative mineral content, defined as the ratio of ash mass to dry mass. 


\subsubsection{Statistics}

Bone properties and cell parameters were compared between bbPTH- and vehicle-treated animals using one-way ANOVA and Tukey's post hoc analysis.

\subsection{Results}

\subsubsection{Cell Studies}

All three concentrations of bbPTH increased cAMP production in MC3T3 cells compared to vehicle controls $(\mathrm{p}<0.0001)$. No difference was observed between $10 \mathrm{nM}$ bbPTH and $30 \mathrm{nM}$ bbPTH, but 100 $\mathrm{nM}$ bbPTH increased cAMP production more than the lower doses $(\mathrm{p}<0.0001)$ (Figure 2.9). Caspase 3/7

activity was reduced $(\mathrm{p}<0.0001)$ in serum starved MC3T3 cells treated with both concentrations of bbPTH, with $100 \mathrm{nM}$ bbPTH decreasing caspase 3/7 to unstarved control values (Figure 2.10). 


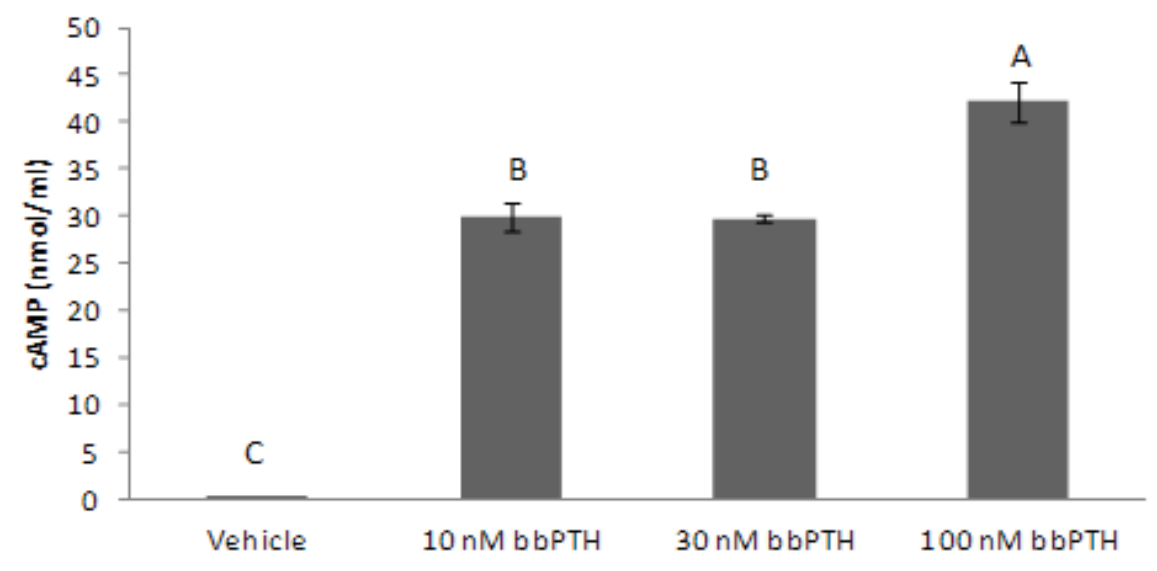

Figure 2.9: bbPTH increased cAMP production in a dose-responsive manner $(\mathrm{p}<0.0001)$.

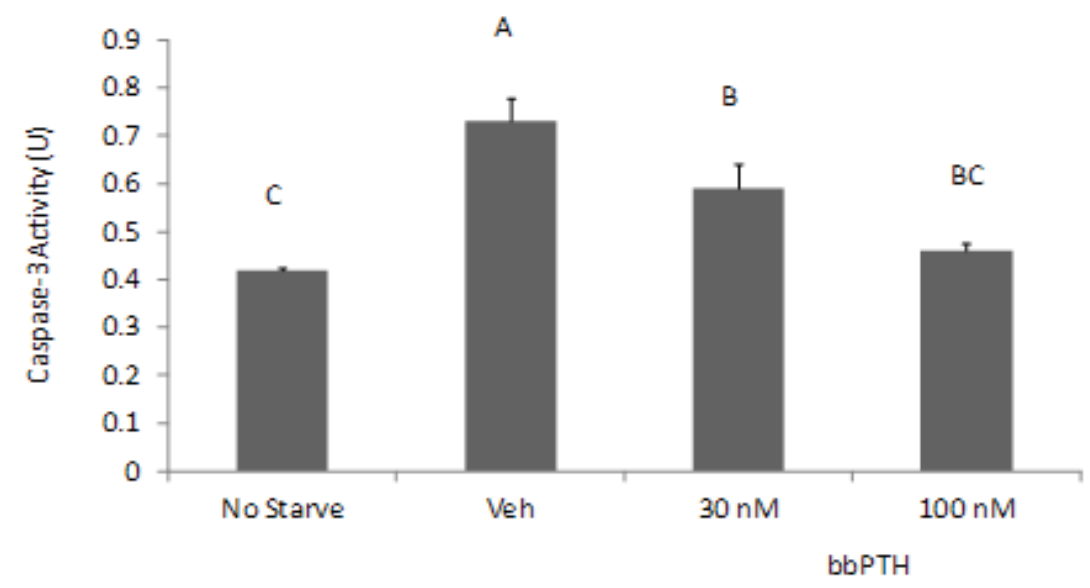

Figure 2.10: bbPTH was antiapoptotic in serum starved MC3T3 cells $(\mathrm{p}<0.0001)$. Groups with different letters are significantly different from one another. 


\subsubsection{Bone Marrow Stromal Cells}

Alizarin red staining showed greater $(p=0.0021)$ mineralized matrix in BMSC cultures from vehicle-treated $m d x$ mice than in cultures from bbPTH-treated $m d x$ mice (Figure 2.11-A). In wild type mice, the difference $(p=0.09)$ between vehicle and bbPTH treatments was not as large (Figure 2.11-B).

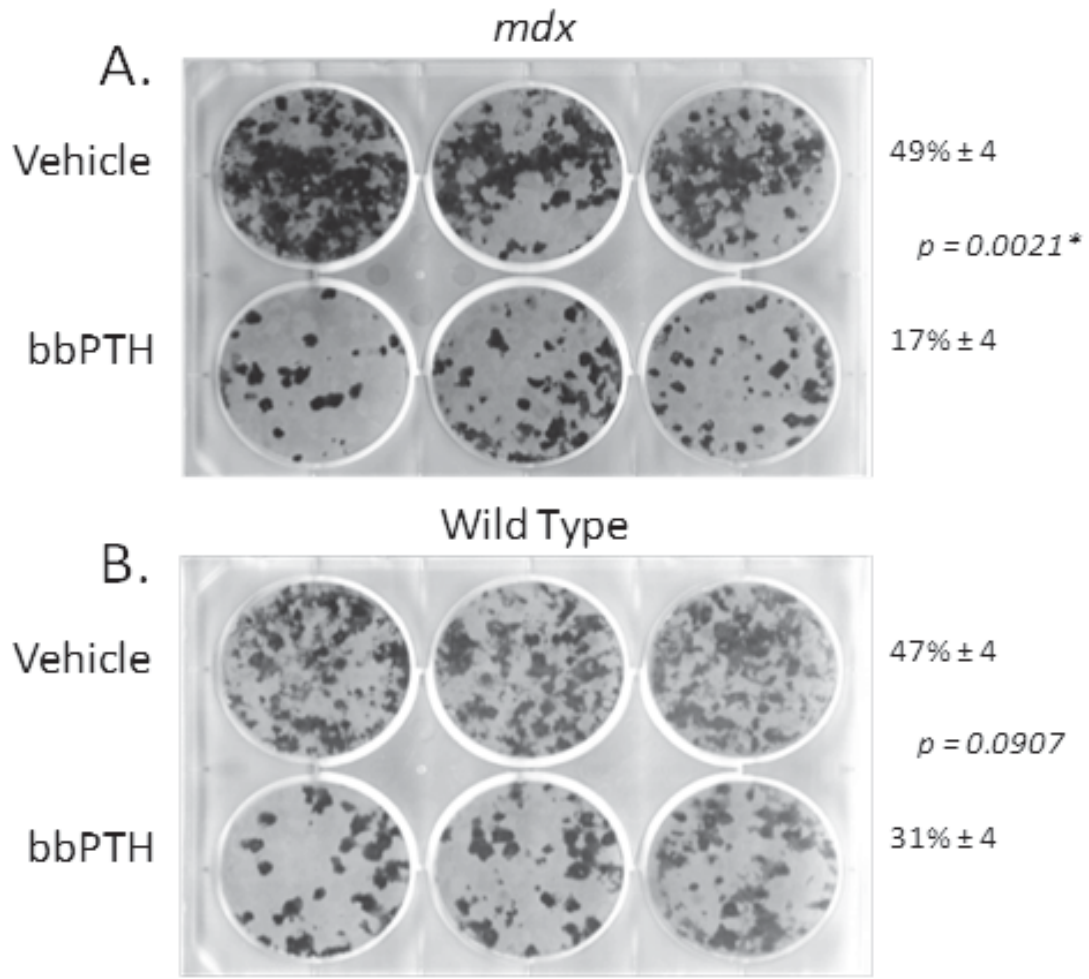

Figure 2.11: Alizarin red stained mineralized matrix in 21 day BMSC cultures from the humeri of A) $m d x$ and B) wild type mice. The percentage of well area stained for mineralized matrix was quantified. 


\subsubsection{Trabecular Bone}

Trabecular bone volume fraction was lower in the distal femoral and proximal tibial metaphyses of vehicle-treated $m d x$ mice compared to wild type mice $(\mathrm{p}=0.0024)$ (Figure 2.12A). Treatment with bbPTH improved trabecular bone volume in both the distal femur and proximal tibia in both $m d x$ and wild type mice, but to a much greater degree in $m d x$ mice (Figure 2.13). The increase in femoral bone volume fraction in $m d x$ mice with bbPTH treatment was 7-fold, compared to a 2-fold change in wild type mice (Figure 2.12-A), with similar magnitude responses in the tibia (Table 2.1).

Vehicle-treated wild type mice demonstrated greater trabecular thickness in the distal femur and proximal tibia than $m d x$ mice $(\mathrm{p}>0.0212)$. Trabecular spacing $(\mathrm{p}>0.7780)$, trabecular number $(\mathrm{p}>0.9813)$, and apparent mineral density $(\mathrm{p}>0.7733)$ were not different between vehicle-treated $m d x$ and wild type mice.

Both trabecular number (Figure 2.12-B) and trabecular thickness (Table 2.1) increased ( $<$ 0.0001 ) with bbPTH treatment in $m d x$ distal femurs and proximal tibias, but not in wild type mice. Trabecular spacing decreased $(\mathrm{p}<0.0001)$ in $m d x$ femurs, but not in wild type mice. 
In the proximal tibia there was no difference in mineralizing surface between any groups ( $p$ $=0.7437)$. Trabecular mineral apposition rate increased with bbPTH in wild type mice $(\mathrm{p}=$ 0.0202), but there was no difference in mineral apposition rate between vehicle- and bbPTHtreatment in $m d x$ mice $(\mathrm{p}=0.6628)$. There were no differences in mineral apposition rate treatments between $m d x$ and wild type mice in either treatment group $(\mathrm{p}>0.245)$ (Table 2.1).

Despite the observed anabolic effect of bbPTH on trabecular bone volume fraction, no differences were found between groups in osteoid thickness $(p=0.4047)$ or osteoid surface $(p=$ 0.966). However, bbPTH-treated $m d x$ mice had increased osteoblast surface $(\mathrm{p}=0.0435)$ and decreased osteoclast surface $(\mathrm{p}=0.0336)$, compared to vehicle treatment. These changes likely contributed to the increased trabecular bone volume fraction that occurred with bbPTH treatment in $m d x$ mice. Similar changes were seen in wild type mice treated with bbPTH, but the differences were not significant for osteoblast surface $(p=0.0711)$ or osteoclast surface $(p=$ 0.1242) (Table 2.2). Normally, PTH treatment increases both osteoblast and osteoclast surfaces (Wu, et al., 2011). Increased osteoblast surface and decreased osteoclast surface, as seen in the bbPTH treated mdx mice, may be a feature unique to bbPTH. 
A.

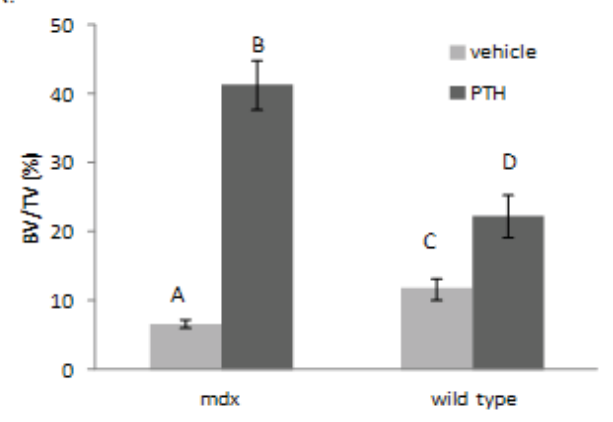

B.

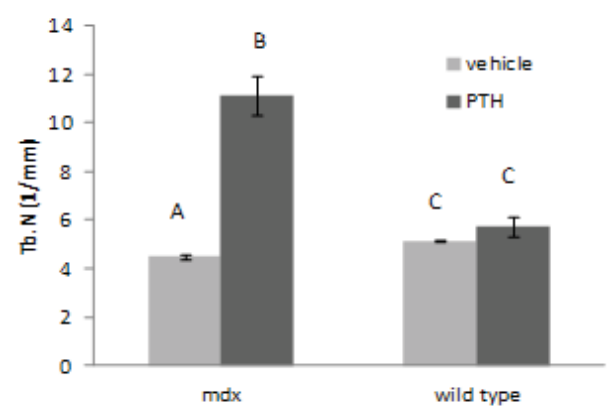

Figure 2.12: A) Bone volume fraction was lower in vehicle-treated $m d x$ femurs compared to wild type femurs. Mdx femurs showed greater response to PTH treatment than wild type femurs. B) Vehicle-treated $m d x$ mice had lower trabecular number in the femur compared to wild type mice (p $=0.0028)$. Trabecular number increased with PTH treatment in $m d x$ mice $(p<0.0001)$, but not wild type $(p=0.2047)$. Mean values with standard error bars. Groups with different letters are significantly different $(p<0.05)$ from each other.

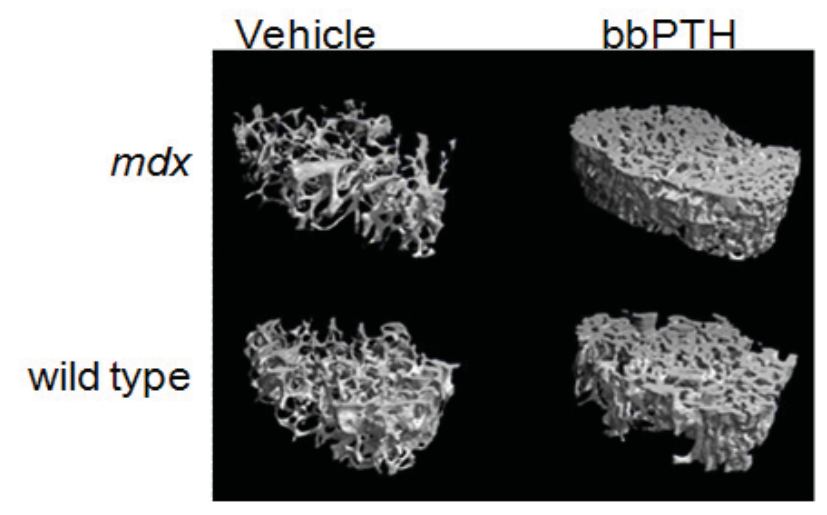

Figure 2.13: Micro-CT images of distal femoral metaphyses show compromised trabecular architecture in $m d x$ mice compared to wild type mice and improved trabecular architecture with PTH treatment, particularly in $m d x$ mice. 
Table 2.1

The distal femur and proximal tibia trabecular regions show 1) compromised trabecular architectural parameters in $m d x$ mice vs. wild type; 2) an anabolic effect of bbPTH in $m d x$ and wild type mice, with a stronger effect in $m d x ; 3$ ) bbPTH treatment increased $m d x$ trabecular microarchitecture beyond vehicle-treated wild type values. Average \pm SE.

$* \mathrm{p}<0.05$ vs. vehicle-treated; ** $\mathrm{p}<0.005$ vs. vehicle-treated $\dagger p<0.05$ vs. wild type vehicle; $\dagger \dagger p<0.005$ vs. wild type vehicle

\begin{tabular}{|c|c|c|c|c|}
\hline & $m d x$ Vehicle & $m d x$ bbPTH & Wild Type Vehicle & $\begin{array}{l}\text { Wild Type } \\
\text { bbPTH }\end{array}$ \\
\hline \multicolumn{5}{|l|}{ Distal Femur $\mu \mathrm{CT}$} \\
\hline $\mathrm{BV} / \mathrm{TV}(\%)$ & $6.6 \pm 2.2+$ & $41.3 \pm 2.2^{*++}$ & $11.7 \pm 3.2$ & $22.3 \pm 3.2 *$ \\
\hline Tb.Th $(\mathrm{mm})$ & $0.03 \pm 0.001+$ & $0.05 \pm 0.001^{* *}$ & $0.04 \pm 0.002$ & $0.05 \pm 0.002$ \\
\hline Tb.Sp (mm) & $0.22 \pm 0.008$ & $0.08 \pm 0.008^{* *++}$ & $0.19 \pm 0.001$ & $0.18 \pm 0.001$ \\
\hline Tb.N $(1 / \mathrm{mm})$ & $4.5 \pm 0.4^{+}$ & $11.1 \pm 0.5 * *+\dagger$ & $5.1 \pm 0.7$ & $5.7 \pm 0.7$ \\
\hline \multicolumn{5}{|l|}{ Proximal Tibia $\mu \mathrm{CT}$} \\
\hline $\mathrm{BV} / \mathrm{TV}(\%)$ & $5.7 \pm 0.03$ & $39.0 \pm 0.03^{* *+\dagger}$ & $9.2 \pm 0.04$ & $20.6 \pm 0.04 * *$ \\
\hline Tb.Th $(\mathrm{mm})$ & $0.032 \pm 0.001+$ & $0.044 \pm 0.001 * *+$ & $0.037 \pm 0.001$ & $0.044 \pm 0.001$ \\
\hline Tb.Sp $(\mathrm{mm})$ & $0.23 \pm 0.02$ & $0.11 \pm 0.02 * *+$ & $0.20 \pm 0.03$ & $0.22 \pm 0.02$ \\
\hline Tb.N $(1 / \mathrm{mm})$ & $4.3 \pm 0.8$ & $10.5 \pm 1.8^{* *++}$ & $4.8 \pm 1.17$ & $5.1 \pm 1.0$ \\
\hline \multicolumn{5}{|c|}{ Proximal Tibia Dynamic Histomorphometry } \\
\hline MS/BS & $0.19 \pm 0.03$ & $0.19 \pm 0.03$ & $0.20 \pm 0.04$ & $0.15 \pm 0.04$ \\
\hline $\operatorname{MAR}(\mu \mathrm{m} /$ day $)$ & $2.66 \pm 0.09$ & $2.81 \pm 0.09$ & $2.31 \pm 0.15$ & $2.97 \pm 0.15^{*}$ \\
\hline \multicolumn{5}{|c|}{ Proximal Tibia Static Histomorphometry } \\
\hline Osteoid Thickness $(\mu \mathrm{m})$ & $2.51 \pm 0.54$ & $3.27 \pm 0.54$ & $1.59 \pm 0.82$ & $2.60 \pm 0.82$ \\
\hline Osteoid Surface (\%) & $22.39 \pm 5.00$ & $24.67 \pm 5.00$ & $31.09 \pm 8.61$ & $21.42 \pm 6.67$ \\
\hline Bone Surface (mm) & $17.38 \pm 3.86$ & $48.48 \pm 3.86^{* *+}$ & $23.29 \pm 5.79$ & $34.57 \pm 5.79$ \\
\hline Eroded Surface (\%) & $0.04 \pm 0.014$ & $0.05 \pm 0.014$ & $0.05 \pm 0.022$ & $0.04 \pm 0.019$ \\
\hline Osteoblast Surface/Bone Surface & $0.10 \pm 0.04$ & $0.32 \pm 0.05 *$ & $0.13 \pm 0.06$ & $0.39 \pm 0.06$ \\
\hline Osteoclast Surface/Bone Surface & $0.13 \pm 0.01$ & $0.04 \pm 0.02 *+$ & $0.16 \pm 0.02$ & $0.09 \pm 0.02$ \\
\hline
\end{tabular}

\subsubsection{Cortical Bone}

No differences were found in femur length for either treatment or mouse type $(p>0.22)$. $M d x$ mice appeared to have an altered femoral cross-section, with a more prominent linea aspera than wild type mice, regardless of bbPTH treatment (Figure 2.14). No differences were 
detected between $m d x$ and wild type, or bbPTH and vehicle-treated mice for cortical thickness $(p=0.2803), I_{\max }(p=0.4344)$, or $I_{a p}(p=0.4492)$. However, moment of inertia about the bending axis $\left(\mathrm{I}_{\mathrm{ml}}\right)$ was greater in bbPTH-treated $m d x$ mice than vehicle-treated $m d x$ mice $(\mathrm{p}=$ 0.0097) (Table 2.2).

No differences were detected in cortical bone mineralizing surface on the fluorescently labeled endosteal surface, either when analyzed by quadrant, or by total endosteal area $(\mathrm{p}>$ 0.2579). Mineral apposition rate was not different between any groups, though bbPTHtreatment tended to decrease endosteal mineral apposition rate $(p=0.0776)$. Similarly, no differences were found between any groups for periosteal mineralizing surface on the calcein labeled periosteal surface $(\mathrm{p}>0.1970)$. bbPTH-treated $m d x$ mice tended to have greater periosteal mineral apposition than vehicle-treated controls $(\mathrm{p}=0.0764)$, unlike wild type mice $(\mathrm{p}=0.8890)$. No other differences were detected in cortical bone mineral apposition rate between groups $(\mathrm{p}>0.1492)$ (Table 2).

Three-point bend testing of the femur showed no differences $(p>0.1314)$ between ultimate load or energy to failure between bbPTH- and vehicle-treated mice or between $m d x$ and wild type mice. Normalizing by body weight had no effect $(p>0.1086)$. Similarly, no differences were found in ultimate stress $(\mathrm{p}=0.9231)$ or modulus of toughness $(\mathrm{p}=0.5541)($ Table 2.2).

Mineral content in the femoral diaphysis, as determined by ash fraction, was not different for $m d x$ vs. wild type or PTH vs. vehicle-treated animals $(\mathrm{p}=0.8516)($ Table 2.2). 


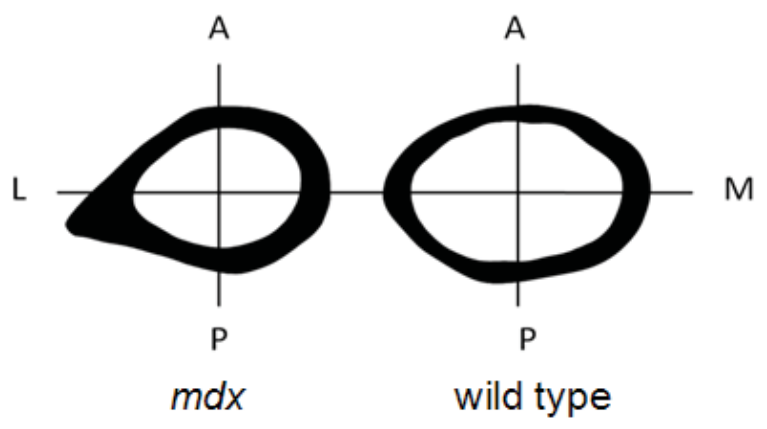

Figure 2.14: $m d x$ femoral cross-sections (left) had a more prominent linea aspera than wild type mice (right). Images are femoral cross-sections of vehicle-treated animals, but are representative of all samples treated or untreated. 
Table 2.2:

bbPTH did not change mechanical properties of cortical bone in $m d x$ or wild type, or strongly affect geometric values. The only change in geometry was $I_{m l}$, the moment of inertia about the bending axis in PTH-treated $m d x$ animals. Average \pm SE.

$* * \mathbf{p}=0.0097$ vs. vehicle-treated

\begin{tabular}{|c|c|c|c|c|}
\hline & $m d x$ Vehicle & $m d x$ bbPTH & $\begin{array}{l}\text { Wild Type } \\
\text { Vehicle }\end{array}$ & $\begin{array}{l}\text { Wild Type } \\
\text { bbPTH }\end{array}$ \\
\hline \multicolumn{5}{|l|}{ Cortical Geometry } \\
\hline Cortical Thickness $(\mu \mathrm{m})$ & $440.2 \pm 25.2$ & $446.7 \pm 25.2$ & $363.2 \pm 37.8$ & $369.1 \pm 37.8$ \\
\hline Cortical Area $\left(\mathrm{mm}^{2}\right)$ & $0.96 \pm 0.06$ & $1.06 \pm 0.06$ & $0.85 \pm 0.10$ & $0.93 \pm 0.10$ \\
\hline$I_{m ! l}\left(\mathrm{~mm}^{4}\right)$ & $0.17 \pm 0.01$ & $0.22 \pm 0.01 * *$ & $0.19 \pm 0.02$ & $0.21 \pm 0.02$ \\
\hline $\mathrm{I}_{\mathrm{ap}}\left(\mathrm{mm}^{4}\right)$ & $0.37 \pm 0.03$ & $0.44 \pm 0.03$ & $0.36 \pm 0.06$ & $0.44 \pm 0.06$ \\
\hline$I_{\max }\left(m^{4}\right)$ & $0.37 \pm 0.04$ & $0.45 \pm 0.04$ & $0.37 \pm 0.06$ & $0.44 \pm 0.06$ \\
\hline \multicolumn{5}{|c|}{ Endosteal Dynamic Histomorphometry } \\
\hline $\operatorname{MAR}(\mu \mathrm{m} /$ day $)$ & $1.36 \pm 0.23$ & $1.19 \pm 0.23$ & $1.59 \pm 0.34$ & $1.62 \pm 0.34$ \\
\hline MS/BS & $0.61 \pm 0.05$ & $0.42 \pm 0.05$ & $0.59 \pm 0.08$ & $0.44 \pm 0.08$ \\
\hline \multicolumn{5}{|c|}{ Periosteal Dynamic Histomorphometry } \\
\hline $\operatorname{MAR}(\mu \mathrm{m} / \mathrm{day})$ & $2.09 \pm 0.17$ & $2.31 \pm 0.17$ & $1.49 \pm 0.26$ & $1.76 \pm 0.26$ \\
\hline MS/BS & $0.61 \pm 0.04$ & $0.61 \pm 0.04$ & $0.49 \pm 0.06$ & $0.48 \pm 0.06$ \\
\hline \multicolumn{5}{|l|}{ Ash Fraction } \\
\hline Ash Fraction & $0.65 \pm 0.03$ & $0.67 \pm 0.02$ & $0.66 \pm 0.04$ & $0.64 \pm 0.03$ \\
\hline \multicolumn{5}{|l|}{ Mechanical Testing } \\
\hline Ultimate Force $(\mathrm{N})$ & $15.4 \pm 0.82$ & $16.7 \pm 0.89$ & $16.2 \pm 0.23$ & $17.1 \pm 0.95$ \\
\hline Energy to Failure $(\mathrm{m} J)$ & $15.0 \pm 2.1$ & $17.1 \pm 2.3$ & $10.0 \pm 1.0$ & $13.3 \pm 2.6$ \\
\hline Ultimate Stress(MPa) & $179.7 \pm 11.2$ & $147.7 \pm 11.3$ & $166.3 \pm 18.4$ & $162.0 \pm 18.4$ \\
\hline Modulus of Toughness $\left(\mathrm{m} J / \mathrm{mm}^{3}\right)$ & $16.9 \pm 3.1$ & $14.6 \pm 3.1$ & $9.1 \pm 5.0$ & $12.7 \pm 5.0$ \\
\hline
\end{tabular}

\subsection{Discussion}

We cloned the gene for black bear PTH and found nine amino acid residues were different from human PTH 1-84. We recombinantly produced bbPTH 1-84 and found it activates cAMP production as has been previously reported for human PTH (Koh, et al., 1999). The 
cAMP/protein kinase A pathway is belived to be responsible for the majority of PTH induced increases in histological and serum indices of bone formation (Fujimori, et al., 1991, Rixon, et al., 1994, Hilliker, et al., 1996). PTH also produces osteoanabolic activity via anti-apoptosis mechanisms in osteoblasts (Jilka, et al., 1999). We also found that treating osteoblasts with bbPTH prior to serum starvation reduces caspase 3/7 activity. Previously we found bbPTH 1-34 causes greater reductions in serum starved induced caspase activity than hPTH 1-34 (McGeeLawrence, 2009). Here we demonstrate the ability of bbPTH 1-84 to have a greater osteoanabolic effect in dystrophin deficient mice than in wild type mice.

Though a strong anabolic response to bbPTH treatment (i.e., increased trabecular bone volume fraction) was observed in both $m d x$ and wild type mice, the relative effect was much greater in $m d x$ mouse bone. The lower mineralization in BMSC cultures from $m d x$ mice treated with bbPTH suggests that the majority of osteoblast precursors were differentiated and removed from the marrow to participate in bone formation during the course of treatment. Dystrophin deficiency alters calcium signaling and calcium reuptake in muscle cells, and calcium signaling is also an important biological mechanism in osteoblasts (Zayzafoon, 2006). Thus, there is potential that the $m d x$ mouse also features differences in calcium signaling in osteoblasts in response to PTH and mechanical loading (Lansman and Franco-Obregon, 2006). These differences may help explain the low bone volume in $m d x$ mice and the differential response to PTH treatment between $m d x$ and wild type mice. $M d x$ mice display a low bone mass phenotype at 3 weeks of age, which precedes the onset of muscle weakness (Nakagaki, et al., 2010). Dystrophin deficiency may also affect primary spongiosa formation and the development of hypertrophic chondrocytes during development due to aberrant calcium signaling (Silbermann and Kadar, 1977). No connection between PTH and dystrophin has been established previously, but the marked difference in anabolic response to bbPTH in $m d x$ as compared to wild type 
mouse trabecular bone suggests that dystrophin or associated altered calcium signaling due to dystrophin deficiency plays a role in trabecular bone formation. However, surprisingly there is no difference in serum calcium concentrations between 2 month old $m d x$ and wild type mice (Kikkawa, et al., 2009). Bone losses attributed to the $m d x$ phenotype may be due to decreased muscular force as well. Though mouse behavior was not markedly different by gross observation during this study, previous work has shown decreased muscle forces despite increased muscle size in $m d x$ mice from ages 4 weeks to 24 months (Anderson, et al., 1993, Novotny, et al., 2011, Montgomery, et al., 2005). Notably, PTH has been shown to attenuate bone loss in disuse scenarios, such as hind limb suspension (Cavanagh, et al., 2005).

The bone volume fraction increases with bbPTH treatment were based on increases in trabecular thickness and coincident decreases in trabecular spacing in $m d x$ mice. bbPTH increased bone volume fraction to a greater degree than has been observed in previous studies administering $\mathrm{hPTH}$ to mice, with a $91 \%$ increase in bone volume fraction in wild type mice in this study, compared to $14-38 \%$ increases in bone volume fraction in mice administered with high dose hPTH (Kanis, et al., 1994, Lippuner, et al., 2004). Trabecular number was also increased in $m d x$ bones, contributing to a large increase in bone volume fraction (Figure 5B). A possibility for the increase in trabecular number, since dystrophin deficiency leads to aberrant calcium signaling in muscle cells, and possibly other musculoskeletal cells, is that $m d x$ mice have a greater number of hypertrophic chondrocytes or increased primary spongiosa since hypertrophic chondrocyte proliferation is regulated by a calcium signaling pathway (Li, et al., 2011). Higher values of these parameters in $m d x$ mice at the start of the PTH treatment period could lead to increases in trabecular number and bone volume fraction with PTH treatment (Silbermann and Kadar, 1977, Silbermann and Kadar, 1977). The increases in bone volume fraction and trabecular number lead to large increases in bone surface (BS) compared to vehicle 
treated animals. The substantial increase in bone surface in the bbPTH treated mice may explain the lack of change in mineralizing surface (MS/BS), which is normally seen with PTH treatment. Furthermore, in vitro data suggest that bbPTH has an anti-apoptotic effect in osteoblasts, which would increase osteoblast survival, consistent with the increased osteoblast surface we observed histologically in bbPTH treated $m d x$ mice.

Cortical bone did not display the marked changes with bbPTH treatment that were observed in trabecular bone. This is similar to studies with PTH in other mouse models, which show approximately a 10\% increase in cortical bone ultimate force with PTH (Washimi, et al., 2010, Zhou, et al., 2003). Our study showed a comparable increase in femoral ultimate force of approximately $8 \%$, though the difference was not significant, and no change was detected in stress or modulus of toughness. PTH did not have the expected effect on endosteal mineralizing surface, possibly because the majority of osteoblast precursors were mobilized in the heavily affected trabecular bone. However, bbPTH did significantly increase medio-lateral moment of inertia in $m d x$ mice. This is important because the medio-lateral axis is the primary bending axis in the femur (Margolis, et al., 2004). This raises the possibility that bbPH may have a moderate effect on $m d x$ cortical bone, which may improve with longer duration treatment.

The potent osteoanabolic response to bbPTH in $m d x$ trabecular bone is clinically relevant to DMD patients, as the majority of fractures occur in the highly trabecularized regions of bone including the distal femur, proximal tibia, and vertebrae (Gray, et al., 1992, Hsu, 1979, Hsu and Garcia-Ariz, 1981, Bothwell, et al., 2003). An increase in trabecular bone volume, as occurs with parathyroid hormone treatment, could greatly reduce fracture risk due to compression by increasing trabecular bone density in DMD patients (Fields, et al., 2009). Additionally, a longer duration PTH treatment in DMD patients could have beneficial effects on cortical bone. 
However, the potential of PTH to increase the risk of osteosarcoma in pediatric patients is a concern that would need further investigation. Decreasing fracture prevalence in DMD patients could improve overall quality of life by allowing greater mobility for a longer period of time, even with the use of glucocorticoids. Parathyroid hormone is effective in the treatment of glucocorticoid-induced osteoporosis (Weinstein, et al., 2010, Saag, et al., 2009). Therefore, treating DMD patients with parathyroid hormone could reduce the probability of fractures and prolong the amount of time these patients are independently mobile. Our data support the idea that $\mathrm{bbPTH}$ is an effective therapeutic to combat bone loss in cases of dystrophin deficiency. However, this study administered only high dose bbPTH. Future work comparing the dose responses of bbPTH and hPTH in $m d x$ mice are needed to further elucidate the mechanisms by which PTH improves bone properties in the $m d x$ model of Duchenne muscular dystrophy.

\subsection{Acknowledgements}

The authors gratefully acknowledge Dr. Mike Vaughan for the black bear blood samples, Matt Nelsen and Yinan Yuan for assistance with bbPTH cloning, and funding from Aursos Inc. and NIH (DK078407). 


\section{Chapter 3: Black Bear PTH is more Potent than Human PTH in a Dose-Responsive Manner in Trabecular Bone in Dystrophin-Deficient Mice ${ }^{2}$}

\subsection{Introduction}

Duchenne muscular dystrophy (DMD) is a fatal X-linked disease that leads to wasting of skeletal and cardiac muscle. Glucocorticoids, the main treatment modality in DMD, have deleterious effects on the skeleton through the inhibition of osteoblast formation and the promotion of osteoclastic resorption (Cohran, et al., 2008). In addition to skeletal losses due to glucocorticoid treatments, DMD patients experience bone loss due to inactivity (lack of mechanical stresses) as they lose mobility.

Fracture risk is elevated in DMD patients treated with glucocorticoids, and these boys experience a $30-50 \%$ reduction in bone mineral content in the lumbar spine, hip, femur, and tibia, with greater losses observed in trabecular bone (Bianchi, et al., 2010, Soderpalm, et al., 2007, Aparicio, et al., 2002, Larson and Henderson, 2000, Crabtree, et al., 2009). When treated with glucocorticoids, one study found that $44-67 \%$ of boys experienced at least one osteoporosis-related fracture. Many of these fractures occurred after the loss of ambulation and resulted from low-trauma falls from a wheelchair or standing height (Larson and Henderson, 2000). Even when glucocorticoid treatment is not taken into account, over $20 \%$ of DMD

\footnotetext{
${ }^{2}$ This chapter consists of a paper prepared for peer-reviewed publication, but has not yet been submitted. Copyrights retained by author.
} 
patients sustained at least one fracture (versus $<4 \%$ fracture rate in healthy boys of similar age) (McDonald, et al., 2002). The majority of fractures occur in the long bones of the lower limb in both ambulatory and wheelchair-bound boys, with more fractures occurring in the femur than the tibia (McDonald, et al., 2002, Siegel, 1977, Gray, et al., 1992, Hsu, 1982, Hsu, 1979, Hsu and Garcia-Ariz, 1981). In addition to long bone fractures, vertebral fractures occur commonly in DMD patients, but are often asymptomatic, leading to underestimated occurrence. One study looked at glucocorticoid treatment time and risk of vertebral fractures and found that fracture risk increases with age and with time on glucocorticoids, and by 100 months of glucocorticoid treatment, $75 \%$ of DMD patients will have sustained a vertebral fracture (Bothwell, et al., 2003).

The dystrophin-deficient $m d x$ mouse is a model for DMD that demonstrates the myopathic lesions observed in human DMD (Ryder-Cook, et al., 1988, King, et al., 2007, Sicinski, et al., 1989, Bulfield, et al., 1984, Call, et al., 2010). Regardless of glucocorticoid treatment, $m d x$ mice display increasing indices of osteoporosis including decreased trabecular bone volume fraction, decreased osteoblast surface area, decreased cortical area, increased cortical porosity, and decreased force to failure and deformation at fracture from ages 3 weeks to 24 months (Novotny, et al., 2011, Nakagaki, et al., 2010, Anderson, et al., 1993, Rufo, et al., 2011).

Anabolic treatments have not been widely explored. Human parathyroid hormone (hPTH) reduces fracture risk more effectively than alendronate in glucocorticoid-induced osteoporosis and attenuates osteoblast apoptosis (Saag, et al., 2009, Bellido, et al., 2003, Jilka, et al., 1999, Weinstein, et al., 2010). Even slight variations in amino acid reside sequence of the PTH 
peptide can cause large changes in target organ cAMP response (Hilliker, et al., 1996, Langsetmo, et al., 2007). In a comparative dose-response study of rat and bovine PTH (1-34) in ovariectomized rats, relative potency analyses showed that bovine PTH, with 6 amino acid residues different from rat $\mathrm{PTH}$, was 2-5 times more potent in trabecular and cortical bone volume and thickness indices ( $\mathrm{Li}$, et al., 2001). Black bear parathyroid hormone (bbPTH), with 9 amino acid residue differences from hPTH, could be even more beneficial, since black bears hibernate for half the year, yet experience no disuse-related declines in bone properties (Donahue, et al., 2006, Donahue, et al., 2006, McGee, et al., 2008, McGee, et al., 2007, McGeeLawrence, et al., 2009, McGee-Lawrence, et al., 2009). High dose black bear PTH has been shown previously to be anabolic in the trabecular bone of the $m d x$ mouse (Gray et al, ASBMR 2011; Gray et al, ORS 2011). In this study, we administered 3 doses of bbPTH or hPTH to $m d x$ mice to determine dose response and relative potency. We hypothesized that $m d x$ mice treated with either PTH analogue would demonstrate an increasing osteoanabolic response with increased PTH, and that bbPTH would be more osteoanabolic (higher relative potency) at similar doses.

\subsection{Materials and Methods}

\subsubsection{Animals}

Forty-nine 4-week old male C57BL/10ScSn/DMD- $m d x$ and 24 wild type control C57BL/10Sn mice were obtained from Jackson Laboratories (Bar Harbor, ME). Mice were cohoused six or seven per cage in a 12 -h dark, $12-\mathrm{h}$ light environment at $20^{\circ} \mathrm{C}$. Mice were fed a 
standard rodent diet containing $0.95 \%$ calcium (Purina LabDiet Autoclavable Rodent Diet \#5010) and given water ad libitum. All mice were euthanized at 10 weeks of age, after 6 weeks of PTH or vehicle treatment, using carbon dioxide asphyxiation. Two $m d x$ mice died during the study and were not included in subsequent data analysis. This study was approved by the Michigan Tech Animal Care and Use Committee protocol L0206.

\subsubsection{PTH Treatment}

Mice were given daily subcutaneous injections of bbPTH 1-84, hPTH 1-84 (Proteos, Kalamazoo, MI) or an acidic vehicle solution. Vehicle injections were prepared with $0.15 \mathrm{M}$ $\mathrm{NaCl}$ and $0.001 \mathrm{~N} \mathrm{HCl}$. PTH solutions were prepared by dissolving bbPTH or hPTH in the acidic saline solution. Mice were injected once daily, 5 times per week with either 2.6, 8.7, or $26.0 \mathrm{nmol} / \mathrm{kg} \mathrm{hPTH} 1-84$, or $3.5,11.8$, or $35.4 \mathrm{nmol} / \mathrm{kg}$ bbPTH $1-84$, or an equal volume $(0.05$ $\mathrm{ml} / \mathrm{g}$ ) of acidic saline. hPTH and bbPTH doses were different due to a discovered error in original mass measurements by the peptide supplier. After six weeks of daily injection, mice were euthanized and their femurs, humeri, and lumbar vertebrae were removed. Right hindlimbs and lumbar vertebrae were fixed in $70 \%$ ethanol and left hindlimbs were placed in $0.15 \mathrm{M}$ saline and frozen at $-24 \mathrm{C}$. At 1 and 4 days prior to sacrifice, mice were given calcein injections to label bone formation surfaces $(10 \mathrm{mg} / \mathrm{kg})$. 


\subsubsection{Trabecular Bone Properties}

Distal right femoral metaphyses and L4 lumbar vertebrae were scanned using microcomputed tomography ( $\mu \mathrm{CT}$ ) (SCANCO 35, SCANCO Medical, Switzerland) to determine trabecular properties. The femoral scan region started $0.5 \mathrm{~mm}$ proximal to the physis and was 100 slices $(0.7 \mathrm{~mm})$ thick. The vertebral scan region began $0.5 \mathrm{~mm}$ from the proximal cortical shell and spanned to $0.5 \mathrm{~mm}$ above the distal cortical shell. From these data, trabecular number (Tb.n), trabecular spacing (Tb.sp), trabecular thickness (Tb.th), and bone volume/tissue volume (BV/TV) were calculated. The distal femur and L4 were thin sliced to a thickness of $5 \mu \mathrm{m}$, and mounted on glass slides. Dynamic histomorphometry was evaluated in the region evaluated by $\mu \mathrm{CT}$ in the distal femur and L4 by determining the distance between calcein labels on the trabecular surface and the lengths of single- and double-labeled surfaces using Bioquant Osteo

software (Nashville, TN). Static histomorphometry was evaluated by measuring osteoid surface, osteoid thickness, and eroded surface in slides stained in von Kossa with MacNeal's tetrachrome stain. Osteoblast and osteoclast surfaces were measured in decalcified proximal tibia segments stained in toluidine blue and tartrate-resistant acid phosphatase (TRAP).

\subsubsection{Cortical Bone Properties}

The right femoral diaphysis was embedded in methylmethacrylate. A cross-section was cut at the midpoint using an Isomet diamond wafering blade (Beuhler, Lake Bluff, IL), ground to a thickness of $<90 \mu \mathrm{m}$ and mounted on a microscope slide. Cross-sections were digitized at 40X magnification using a Leitz fluorescence microscope (Leica, Germany) and a SPOT Insight 
camera (Diagnostic Instruments, Sterling Heights, MI). A custom macro and Scion Image software (Scion Corp., Frederick, ME) were used to quantify cross-sectional properties including medio-lateral $\left(\mathrm{I}_{\mathrm{ml}}\right)$, anterio-posterior $\left(\mathrm{I}_{\mathrm{ap}}\right)$, and maximum $\left(\mathrm{I}_{\max }\right)$ moments of inertia. Mineral apposition rate was determined by measuring the distance between calcein labels using Bioquant software on both the periosteal and endosteal surfaces Mineralizing surface was determined by measuring the ratio of single- and double-labeled surfaces to the total cortical surface on both the periosteal and endosteal surfaces. Cortical thickness was measured as the average distance between the endosteal and periosteal surfaces around the entire cortex at $5 \mu \mathrm{m}$ increments.

Vertebral cortical thickness and bone volume fraction were determined from $\mu \mathrm{CT}$ images of the entirety of L4, subtracting the region (described previously) evaluated as trabecular bone.

\subsubsection{Mechanical Properties}

Bending properties of the left femur were determined by a 3-point bend test at a rate of 1 $\mathrm{mm} / \mathrm{min}$. The testing fixtures had a span of $10 \mathrm{~mm}$ and a radius of $1 \mathrm{~mm}$. Mechanical testing was performed using an Instron test machine (Norwood, MA). Stress-strain plots were determined using asymmetric beam theory (Levenston, 1995), and used to calculate ultimate stress and modulus of toughness. Load-displacement plots were used to determine ultimate load and energy to failure for each sample. 


\subsubsection{Mineral Content}

Mineral content was determined through ashing. After mechanical testing, femoral diaphyses were cleaned of marrow, placed in a furnace at $100^{\circ} \mathrm{C}$ for 24 hours to remove all water, and weighed to obtain dry mass. Samples were returned to the furnace for 48 hours at $600^{\circ} \mathrm{C}$ to burn off all organic material. Bones were again weighed to determine relative mineral content, defined as the ratio of ash mass to dry mass.

\subsubsection{Statistics}

Bone properties were regressed against dose were compared between bbPTH- and hPTH treated $m d x$ mice using Analysis of Covariance (ANCOVA) with treatment and dose as covariates. Relative potency was determined through relative potency analysis as described previously (Li, et al., 2001). Confidence intervals were established using the Delta Method (Hogg, et al., 2005). Since ANCOVA regresses outcome variables against dose, the plot line was used to determine p-values. Since individual data points were not used, the difference in hPTH and bbPTH doses does not affect statistical outcomes. 


\subsection{Results}

\subsection{1 mdx vs. Wild Type: Vehicle Treatment}

Vehicle-treated $m d x$ mice were significantly heavier $(\mathrm{p}=0.019)$ at sacrifice than wild type mice treated with vehicle, but no differences were detected in femur length $(\mathrm{p}=0.341)$ between these mice. Differences in cortical properties included increased periosteal surface $(p=0.042)$, increased cortical area $(p=0.033)$, increased $\operatorname{Imax}(p=0.045)$, as well as tendencies toward increase in Iap and $\operatorname{Iml}(\mathrm{p}=0.051$ and 0.057 , respectively) in $m d x$ mice. No changes were observed $(\mathrm{p}>0.1)$ in mechanical testing parameters including ultimate stress and energy to failure. Trabecular properties, including bone volume fraction (Figure 3.1), trabecular number, trabecular thickness, trabecular spacing, osteoclast surface, and osteoblast surface were not

different $(\mathrm{p}>0.2)$ between $m d x$ and wild type mice. However, trabecular mineralizing surface/bone surface was increased $(\mathrm{p}=0.033)$ in $m d x$ mice (Table 3.1). 
Table 3.1:

\section{Bone parameters for vehicle treated $m d x$ and wild type mice}

\begin{tabular}{|c|c|c|c|c|c|c|}
\hline & \multicolumn{2}{|c|}{$m d x$} & \multicolumn{2}{|c|}{ wild type } & \multirow[b]{2}{*}{ p-value } & \multirow[b]{2}{*}{$\%$ Change in $m d x$} \\
\hline & average & standard error & average & standard error & & \\
\hline Femur Length (mm) & $\begin{array}{r}15.282 \\
\end{array}$ & \begin{tabular}{|l|}
0.049 \\
\end{tabular} & $\begin{array}{r}15.192 \\
\end{array}$ & $\begin{array}{r}0.071 \\
\end{array}$ & \begin{tabular}{|l|}
0.341 \\
\end{tabular} & 0.59 \\
\hline Sac Weight (g) & 30.500 & 0.253 & 28.333 & 0.272 & 0.019 & 7.65 \\
\hline Fmax/BW (N/g) & 0.468 & 0.011 & 0.447 & 0.012 & 0.308 & 4.72 \\
\hline Energy/BW (N*mm) & 0.444 & 0.039 & 0.493 & 0.041 & 0.637 & -10.08 \\
\hline stress & 208.549 & 5.642 & 207.564 & 1.524 & 0.472 & 0.47 \\
\hline $\bmod$ tough $\left(\mathrm{mj} / \mathrm{mm}^{\wedge} 3\right)$ & 5.626 & 0.332 & 7.376 & 0.603 & 0.838 & -23.73 \\
\hline lap, $\mu \mathrm{m}^{\wedge} 4$ & 41655834.574 & 1668677.647 & 33604006.551 & 760028.298 & 0.051 & 23.96 \\
\hline $\mathrm{Iml}, \mu \mathrm{m}^{\wedge} 4$ & 22456921.326 & 816445.951 & 18487381.229 & 515566.652 & 0.057 & 21.47 \\
\hline $\operatorname{Imax}, \mu \mathrm{m}^{\wedge} 4$ & 42373911.264 & 1701669.113 & 33736459.084 & 774805.762 & 0.045 & 25.60 \\
\hline Ash Fraction & 0.632 & 0.015 & 0.633 & 0.008 & 0.504 & -0.07 \\
\hline Cortical Thickness $(\mu \mathrm{m})$ & 206.677 & 3.928 & 191.622 & 2.891 & 0.119 & 7.86 \\
\hline Cortical Area $(\mu \mathrm{m})$ & 10019.378 & 236.133 & 8631.853 & 150.191 & 0.033 & 16.07 \\
\hline endosteal MS/BS & 0.389 & 0.011 & 0.464 & 0.011 & 0.958 & -16.11 \\
\hline periosteal MS/BS & 0.475 & 0.025 & 0.506 & 0.011 & 0.669 & -6.06 \\
\hline endosteal MAR ( $\mu \mathrm{m} / \mathrm{day})$ & 2.399 & 0.051 & 2.388 & 0.139 & 0.488 & 0.46 \\
\hline periosteal MAR ( $\mu \mathrm{m} /$ day) & 3.934 & 0.134 & 3.322 & 0.109 & 0.091 & 18.41 \\
\hline Trabecular MAR ( $\mu \mathrm{m} / \mathrm{day})$ & 1.115 & 0.028 & 1.003 & 0.093 & 0.327 & 11.16 \\
\hline Femur BV/TV & 0.145 & 0.008 & 0.171 & 0.009 & 0.820 & -15.67 \\
\hline Femur Tb.N (1/mm) & 5.675 & 0.094 & 5.865 & 0.079 & 0.729 & -3.23 \\
\hline Femur Tb.Th (mm) & 0.039 & 0.001 & 0.043 & 0.002 & 0.800 & -9.20 \\
\hline Femur Tb.Sp (mm) & 0.175 & 0.003 & 0.170 & 0.002 & 0.286 & 3.35 \\
\hline LV BV/TV & 0.102 & 0.001 & 0.123 & 0.007 & 0.867 & -16.78 \\
\hline LV Tb.N (1/mm) & 4.233 & 0.032 & 4.322 & 0.024 & 0.806 & -2.06 \\
\hline LV Tb.Th (mm) & 0.040 & 0.000 & 0.046 & 0.001 & 0.912 & -12.85 \\
\hline LV Tb.Sp (mm) & 0.236 & 0.002 & 0.228 & 0.002 & 0.105 & 3.82 \\
\hline Cort BV/TV & 0.650 & 0.002 & 0.667 & 0.010 & 0.749 & -2.64 \\
\hline LV Cort SMI & 0.791 & 0.024 & 0.826 & 0.018 & 0.680 & -4.24 \\
\hline LV Cortical Thickness (mm) & 0.829 & 0.020 & 0.904 & 0.023 & 0.827 & -8.28 \\
\hline LV Cort AMD (g/mm^3) & 673.763 & 2.968 & 690.856 & 8.080 & 0.777 & -2.47 \\
\hline LV Cort MMD (g/mm^3) & 925.586 & 4.952 & 931.164 & 4.420 & 0.631 & -0.60 \\
\hline OC Surf./Bone Surf. & 0.157962495 & 0.0098 & 0.152906397 & 0.0062 & 0.376 & 3.31 \\
\hline OB Surf./Bone Surf. & 0.168343818 & 0.0149 & 0.156473564 & 0.005 & 0.333 & 7.59 \\
\hline
\end{tabular}




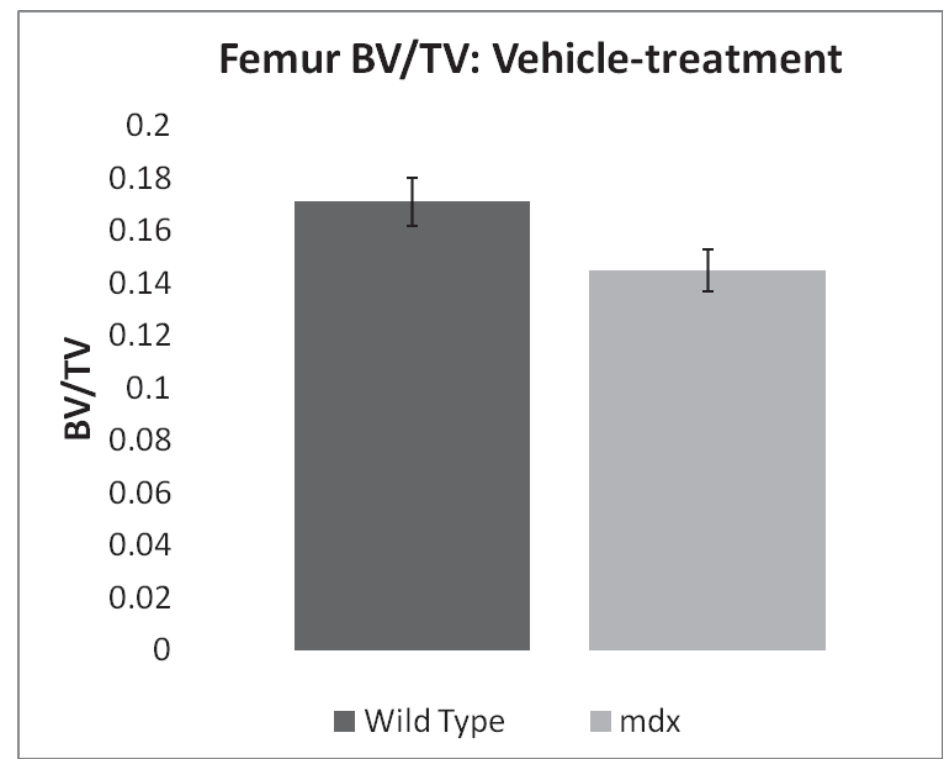

Figure 3.1: Bone volume fraction was not greater in wild type mice compared to $m d x$ mice

\subsection{2 bbPTH vs. Vehicle: Wild Type Mice}

bbPTH treatment increased maximum force to failure $(\mathrm{p}=0.0192)$ as well as Fmax normalized by body weight $(\mathrm{p}=0.0032)$ in wild type mice. Iap and Imax increased in bbPTH treated wild type mice $(\mathrm{p}=0.0027$ and 0.0482 , respectively) and Iml showed a tendency $(\mathrm{p}=0.0645)$ toward increase with bbPTH. In trabecular bone, bbPTH increased femoral bone volume fraction $(\mathrm{p}=$ 0.0238) (Figure 3.2) and femoral trabecular thickness $(\mathrm{p}=0.0402)$, with no changes noted in osteoblast or osteoclast surface $(\mathrm{p}>0.3)$ (Table 3.2). Table 0.2 lists regression values (determined through ANCOVA) of bbPTH treatment values, compared to vehicle treatment (single value). 
Table 3.2:

Bone parameters in bbPTH-treated and vehicle-treated wild type mice

\begin{tabular}{|c|c|c|c|c|c|}
\hline & vehicle value & slope & intercept & stderr & p-value \\
\hline Femur Length (mm) & 15.19 & -0.006 & 15.25 & 0.091 & 0.82 \\
\hline Sac Weight (g) & 28.33 & 0.28 & 27.13 & 0.36 & 0.32 \\
\hline Fmax (N) & 12.62 & 0.25 & 14.2 & 0.39 & 0.01 \\
\hline Energy $\left(\mathrm{N}^{*} \mathrm{~mm}\right)$ & 14.03 & 0.07 & 17.9 & 1.14 & 0.26 \\
\hline Fmax/BW (N/g) & 0.44 & 0.0003 & 0.52 & 0.01 & 0.003 \\
\hline Energy/BW ( $\left.{ }^{*} \mathrm{~mm} / \mathrm{g}\right)$ & 0.49 & -0.003 & 0.66 & 0.04 & 0.19 \\
\hline stress & 207.5 & -0.38 & 218.2 & 4.04 & 0.60 \\
\hline mod tough $\left(\mathrm{mj} / \mathrm{mm}^{\wedge} 3\right)$ & 7.37 & -0.06 & 8.84 & 0.62 & 0.79 \\
\hline lap, $\mu m^{\wedge} 4$ & 18487381 & 112500 & $2 \mathrm{E}+07$ & 822.91 & 0.064 \\
\hline $\operatorname{Iml}, \mu \mathrm{m}^{\wedge} 4$ & 43778945 & 0 & $4 \mathrm{E}+07$ & 0 & 0.002 \\
\hline $\operatorname{Imax}, \mu m^{\wedge} 4$ & 33736460 & 144078 & $4 \mathrm{E}+07$ & 1396513 & 0.048 \\
\hline Ash Fraction & 0.63 & 0.0006 & 0.63 & 0.0141 & 0.73 \\
\hline Cortical Thickness $(\mu \mathrm{m})$ & 191.6 & 0.29 & 195.28 & 3.47 & 0.22 \\
\hline Cortical Area $(\mu \mathrm{m})$ & 8631.8 & 22.41 & 9107.9 & 227.3 & 0.07 \\
\hline endosteal MS/BS & 0.46 & 0.002 & 0.35 & 0.02 & 0.17 \\
\hline periosteal MS/BS & 0.50 & -0.002 & 0.53 & 0.02 & 0.96 \\
\hline endosteal MAR ( $\mu \mathrm{m} / \mathrm{day})$ & 2.38 & 0.02 & 2.10 & 0.17 & 0.81 \\
\hline periosteal MAR ( $\mu \mathrm{m} /$ day) & 3.32 & 0.013 & 3.38 & 0.18 & 0.41 \\
\hline Trabecular MAR ( $\mu \mathrm{m} /$ day) & 1.00 & 0.001 & 1.06 & 0.09 & 0.69 \\
\hline Femur BV/TV & 0.17 & 0.0062 & 0.17 & 0.021 & 0.023 \\
\hline Femur Tb.N (1/mm) & 5.86 & 0.14 & 4.95 & 0.47 & 0.11 \\
\hline Femur Tb.Th (mm) & 0.04 & 0 & 0.04 & 0.001 & 0.04 \\
\hline Femur Tb.Sp (mm) & 0.16 & -0.02 & 0.19 & 0.009 & 0.18 \\
\hline LV BV/TV & 0.12 & 0.001 & 0.11 & 0.008 & 0.2025 \\
\hline LV Tb.N (1/mm) & 4.32 & 0.0068 & 4.07 & 0.089 & 0.4566 \\
\hline LV Tb.Th (mm) & 0.04 & 0.0003 & 0.04 & 0.001 & 0.1688 \\
\hline LV Tb.Sp (mm) & 0.22 & -0.0004 & 0.24 & 0.005 & 0.222 \\
\hline Cort BV/TV & 0.66 & 0.0008 & 0.62 & 0.01 & 0.21 \\
\hline LV Cort SMI & 0.82 & 0.0007 & 0.82 & 0.03 & 0.93 \\
\hline LV Cortical Thickness (mm) & 0.90 & 0.003 & 0.83 & 0.05 & 0.89 \\
\hline LV Cort AMD (g/mm^3) & 690.8 & 0.45 & 656.26 & 8.10 & 0.11 \\
\hline LV Cort MMD (g/mm^3) & 931.1 & -0.4 & 915.89 & 5.29 & 0.048 \\
\hline OC Surf./Bone Surf. & 0.15 & -0.001 & 0.19 & 0.009 & 0.33 \\
\hline OB Surf./Bone Surf. & 0.15 & 0.0002 & 0.16 & 0.008 & 0.36 \\
\hline
\end{tabular}




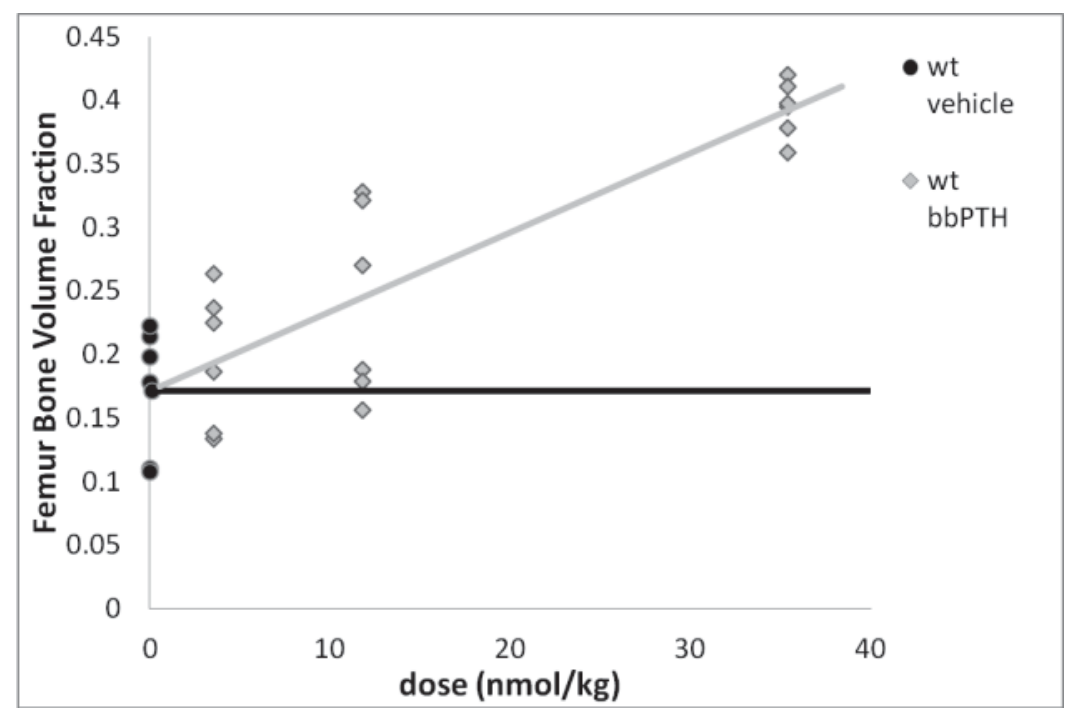

Figure 3.2: bbPTH increased BV/TV in a dose-responsive manner in wild type mice

\subsection{3 bbPTH vs. hPTH in mdx Mice: Relative Potency Analysis}

In the $m d x$ mouse, no differences were observed $(\mathrm{p}>0.3)$ in general properties including weight at sacrifice and femur length comparing bbPTH and hPTH treatment. In cortical bone, $\mathrm{hPTH}$ tended $(\mathrm{p}=0.0805$, relative potency $\mathrm{bbPTH}$ dose $/ \mathrm{hPTH}$ dose $=0.55)$ to mildly increase periosteal mineralizing surface/bone surface in the femur hPTH increased cortical shell thickness in the lumbar vertebrae $(\mathrm{p}=0.0187$, relative potency $=0.32)$, and bbPTH increased Iap compared to hPTH $(\mathrm{p}=0.0001$, relative potency $=1.09)$, but no other differences $(\mathrm{p}>0.1)$ were detected for cortical bone properties including mechanical testing values in either the femur or the lumbar vertebrae. In trabecular bone, bbPTH increased bone volume fraction $(\mathrm{p}=$ 0.001 , relative potency $=2.03)($ Figure 3.3$)$, trabecular number $(\mathrm{p}=0.0003$, relative potency $=$ 
$2.06)$ and decreased trabecular spacing $(\mathrm{p}=0.0384$, relative potency $=1.87)$ in the femur, and tended to increase trabecular number in L4 $(\mathrm{p}=0.09925$, relative potency $=1.01)$ (Table 3.3 and Table 3.4). Table 3.3 lists the slopes and intercepts of the linear regression against dose, as determined by ANCOVA, of bbPTH and hPTH parameters, respectively. Table 3.4 lists PTH doses required to reach wild type vehicle values as determined from the regression lines, along with calculated relative potency analyses for each variable. In cases where dose was determined to be negative (i.e. requiring extrapolation of the dose beyond the y-axis), potency and p-values are not listed. No differences between bbPTH and hPTH were detected for any of these parameters. 
Table 3.3:

Dose response curves for PTH treated $m d x$ mice. Slopes and intercepts correspond to regression determined by ANCOVA.

\begin{tabular}{|c|c|c|c|c|c|}
\hline & \multicolumn{2}{|c|}{ bbPTH } & \multicolumn{2}{|c|}{ hPTH } & \multirow[b]{2}{*}{ stderr } \\
\hline & slope & intercept & slope & intercept & \\
\hline Femur Length (mm) & 0.0085 & 14.9 & -0.0034 & 15.0 & 0.09 \\
\hline Sac Weight (g) & 0.0826 & 27.2 & -0.065 & 29.2 & 0.49 \\
\hline $\operatorname{Fmax}(N)$ & 0.0753 & 12.6 & 0.024 & 14.0 & 0.47 \\
\hline Energy $\left(\mathrm{N}^{*} \mathrm{~mm}\right)$ & -0.0166 & 16.6 & -0.013 & 16.3 & 1.11 \\
\hline Fmax/BW (N/g) & 0.0011 & 0.46 & 0.002 & 0.48 & 0.012 \\
\hline Energy/BW $(\mathrm{N} * \mathrm{~mm} / \mathrm{g})$ & -0.0025 & 0.61 & 0.0006 & 0.56 & 0.041 \\
\hline stress & -0.0077 & 7.91 & -0.015 & 8.4275 & 7.71 \\
\hline $\bmod$ tough $\left(\mathrm{mj} / \mathrm{mm}^{\wedge} 3\right)$ & 2.19 & 103.93 & 5.09 & 85.03 & 0.77 \\
\hline lap, $\mu \mathrm{m}^{\wedge} 4$ & 120126 & 20000000 & 101241 & 20000000 & 824773 \\
\hline $\mathrm{Iml}, \mu \mathrm{m}^{\wedge} 4$ & 398669 & 30000000 & 302654 & 30000000 & 650925.1 \\
\hline Imax, $\mu \mathrm{m}^{\wedge} \mathbf{4}$ & 13225 & 3000000 & 59748 & 2000000 & 1687754.3 \\
\hline Ash Fraction & -0.0014 & 0.69 & 0.0006 & 0.65 & 0.013 \\
\hline Cortical Thickness $(\mu \mathrm{m})$ & 0.09 & 8.44 & 0.16 & 8.28 & 0.56 \\
\hline Cortical Area $(\mu \mathrm{m})$ & 0.59 & 195.34 & -0.0031 & 223.56 & 237.0 \\
\hline endosteal MS/BS & -0.0009 & 0.40 & -0.0044 & 0.48 & 0.02 \\
\hline periosteal MS/BS & 0.0015 & 0.43 & 0.0019 & 0.45 & 0.03 \\
\hline endosteal MAR ( $\mu \mathrm{m} / \mathrm{day})$ & -0.0013 & 2.44 & -0.026 & 2.76 & 0.20 \\
\hline periosteal MAR ( $\mu \mathrm{m} / \mathrm{day})$ & 0.024 & 3.41 & 0.0071 & 3.53 & 0.22 \\
\hline Trabecular MAR ( $\mu \mathrm{m} /$ day) & 0.0051 & 0.97 & -0.0089 & 1.06 & 0.11 \\
\hline Femur BV/TV & 0.009 & 0.11 & 0.0037 & 0.12 & 0.014 \\
\hline Femur Tb.N (1/mm) & 0.19 & 4.14 & 0.054 & 4.85 & 0.24 \\
\hline Femur Tb.Th (mm) & 0.0001 & 0.04 & 0.0001 & 0.043 & 0.001 \\
\hline Femur Tb.Sp (mm) & -0.004 & 0.22 & -0.0014 & 0.20 & 0.0073 \\
\hline LV BV/TV & 0.0018 & 0.08 & 0.0012 & 0.083 & 0.004 \\
\hline LV Tb.N (1/mm) & 0.0062 & 3.76 & 0.0086 & 3.74 & 0.063 \\
\hline LV Tb.Th (mm) & 0.0003 & 0.03 & 0.0002 & 0.03 & 0.0006 \\
\hline LV Tb.Sp (mm) & -0.0004 & 0.26 & -0.0004 & 0.26 & 0.0042 \\
\hline Cort BV/TV & 0.0008 & 0.60 & 0.0007 & 0.61 & 0.0086 \\
\hline LV Cort SMI & 0.0065 & 0.73 & -0.003 & 0.93 & 0.04 \\
\hline LV Cortical Thickness (mm) & 0.0012 & 0.79 & -0.0028 & 0.98 & 0.042 \\
\hline LV Cort AMD (g/mm^^3) & 0.7381 & 633.18 & 0.73 & 638.54 & 6.43 \\
\hline LV Cort MMD (g/mm^3) & 0.5379 & 889.86 & 9314 & 894.5 & 4.97 \\
\hline OC Surf./Bone Surf. & -0.0027 & 0.19 & -0.0006 & 0.17 & 0.0097 \\
\hline OB Surf./Bone Surf. & -0.0022 & 0.26 & 0.0003 & 0.19 & 0.0152 \\
\hline
\end{tabular}


Table 3.4:

Relative potencies of bbPTH and hPTH in $m d x$ mice. Relative potency determined as dose bbPTH/dose hPTH to achieve wild type vehicle-treated values.

\begin{tabular}{|c|c|c|c|c|c|c|}
\hline Variable & wild type value & $\begin{array}{c}\text { bbPTH dose } \\
\text { (nmol/kg) }\end{array}$ & $\begin{array}{r}\text { hPTH dose } \\
\text { (nmol/kg) }\end{array}$ & Potency & $\begin{array}{c}95 \% \mathrm{Cl} \text { for dose } \\
( \pm \mathrm{nmol} / \mathrm{kg})\end{array}$ & p-value \\
\hline Femur Length & $15.19 \mathrm{~mm}$ & 24.50 & -49.8 & -- & -- & 0.30 \\
\hline Sac Weight & $28.3 \mathrm{~g}$ & 12.52 & 13.9 & 1.11 & 0.046 & 0.78 \\
\hline F Max & $12.62 \mathrm{~N}$ & -0.48 & -57.1 & -- & -- & 0.28 \\
\hline F Max/Body Weight & $0.44 \mathrm{~N} / \mathrm{g}$ & -16.91 & -17.1 & -- & -- & 0.11 \\
\hline Energy to Failure & $14.03 \mathrm{~N} * \mathrm{~mm}$ & 155.49 & 165.2 & 1.06 & 0.89 & 0.84 \\
\hline Energy/BW & $0.4934 \mathrm{~N}^{*} \mathrm{~mm} / \mathrm{g}$ & 50.52 & -111.4 & -- & -- & 0.78 \\
\hline Ultimate Stress & $207.563 \mathrm{Mpa}$ & 21.36 & -14900 & -- & -- & 0.09 \\
\hline Modulus of Toughness & $7.3761 \mathrm{~mJ} / \mathrm{mm}^{\wedge} 3$ & 87.25 & 78.73 & 0.90 & 0.81 & 0.77 \\
\hline lap & $4.37\left(10^{\wedge} 7\right) \mu \mathrm{m}^{\wedge} 4$ & 30.52 & 33.39 & 1.09 & 475.8 & 0.0001 \\
\hline $\mathrm{Iml}$ & $1.84\left(10^{\wedge} 7\right) \mu m^{\wedge} 4$ & -9.27 & -4.25 & -- & -- & 0.62 \\
\hline Imax & $3.37\left(10^{\wedge} 7\right) \mu \mathrm{m}^{\wedge} 4$ & -1.12 & -1.85 & -- & -- & 0.77 \\
\hline Ash Fraction & 0.63 & 40.46 & -32.63 & -- & -- & 0.57 \\
\hline Cortical Thickness & $191.6 \mu \mathrm{m}$ & -7.72 & -5.32 & -- & -- & 0.43 \\
\hline Cortical Area & $8630 \mu \mathrm{m}^{\wedge} 2$ & -8.56 & -6.07 & -- & -- & 0.75 \\
\hline endosteal MS/BS & 0.46 & -64.75 & 4.08 & -- & -- & 0.54 \\
\hline periosteal MS/BS & 0.50 & 47.24 & 26.02 & 0.55 & 1.63 & 0.08 \\
\hline endosteal MAR & $2.38 \mu \mathrm{m} /$ day & 42.13 & 14.16 & 0.33 & 0.087 & 0.99 \\
\hline periosteal MAR & $3.32 \mu \mathrm{m} / \mathrm{day}$ & -3.84 & -29.37 & -- & -- & 0.62 \\
\hline Trabecular MAR & $1.00 \mu \mathrm{m} /$ day & 5.36 & 7.17 & 1.33 & 1.55 & 0.77 \\
\hline Femur BV/TV & 0.17 & 6.50 & 13.27 & 2.03 & 4.29 & 0.001 \\
\hline Femur Tb.N & $5.861 / \mathrm{mm}$ & 8.91 & 18.42 & 2.06 & 0.05 & 0.0003 \\
\hline Femur Tb.Th & $0.42 \mathrm{~mm}$ & -9.96 & -2.8 & -- & -- & 0.50 \\
\hline Femur Tb.Sp & $0.16 \mathrm{~mm}$ & 12.94 & 24.32 & 1.87 & 1.55 & 0.038 \\
\hline LV BV/TV & 0.12 & 20.68 & 32.22 & 1.55 & 3.55 & 0.12 \\
\hline LV Tb.N & $4.321 / \mathrm{mm}$ & 65.68 & 66.66 & 1.01 & 0.29 & 0.09 \\
\hline LV Tb.Th & $0.04 \mathrm{~mm}$ & 21.59 & 30.10 & 1.39 & 3.23 & 0.19 \\
\hline LV Tb.Sp & $0.22 \mathrm{~mm}$ & 73.18 & 99.09 & 1.35 & 1.01 & 0.94 \\
\hline LV Cortical BV/TV & 0.66 & 74.79 & 83.64 & 1.11 & 0.6 & 0.84 \\
\hline LV Cortical SMI & 0.82 & 14.50 & 34.88 & 2.40 & 1.2 & 0.22 \\
\hline LV Cortical Thickness & $0.90 \mathrm{~mm}$ & 89.09 & 28.92 & 0.32 & 1.19 & 0.018 \\
\hline LV Cortical App.M.Dn & $690.85 \mathrm{~g} / \mathrm{mm}^{\wedge} 3$ & 78.13 & 71.48 & 0.91 & 1.64 & 0.52 \\
\hline LV Cortical Mat.M.Dn & $931.16 \mathrm{~g} / \mathrm{mm}^{\wedge} 3$ & 76.77 & 39.36 & 0.05 & 1.44 & 0.11 \\
\hline OC Surf./Bone Surf. & 0.15 & 13.89 & 28.93 & 2.08 & 2.38 & 0.005 \\
\hline OB Surf./Bone Surf. & 0.16 & 51.81 & 71.93 & 1.33 & 1.91 & 0.003 \\
\hline
\end{tabular}




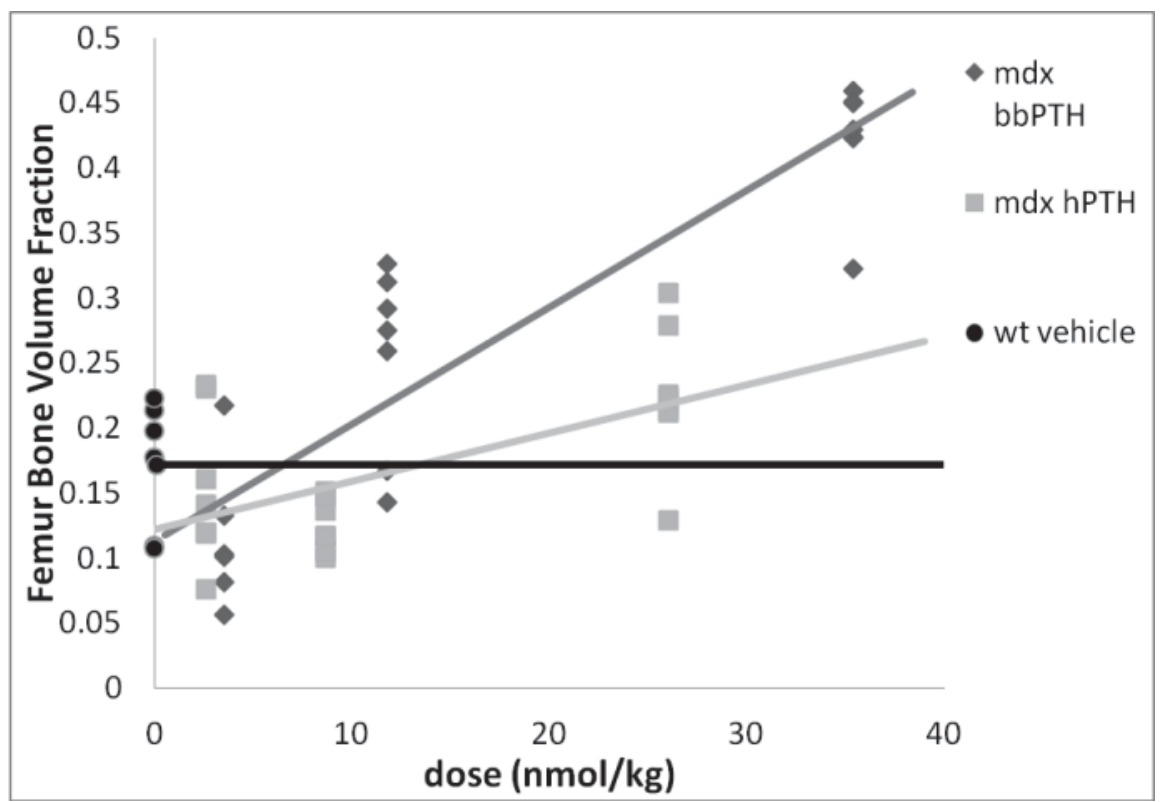

Figure 3.3: Dose-response of PTH treatments in $m d x$ mice showed greater BV/TV in bbPTHtreated animals

No significant differences were detected comparing relative changes compared to vehicle treatment with bbPTH in $m d x$ and wild type mice. This is in contrast to the findings from our previous study where bbPTH increased bone volume fraction in the femur and tibia to a greater degree in $m d x$ mice compared to wild type mice. This could be due to seasonality in bone properties in each mouse genotype (Kruczek and Gruca 1990), which may affect $m d x$ mice to a greater or lesser degree compared to wild type mice. 


\subsection{Discussion}

\subsection{1 mdx vs. Wild Type: Vehicle Treatment}

The increase in weight at sacrifice for $m d x$ mice is consistent with previous literature indicating that $m d x$ mice have larger body size and muscle mass, despite lessened forcegenerating capacity (Novotny, et al., 2011). However, it was hypothesized that $m d x$ mice would have weaker bones (evidenced by decreased Fmax, ultimate stress, energy to failure, and modulus of toughness) as seen previously (Novotny, et al., 2011), which was not the case in this study. We observed no change in this occurrence previously (Almeida, et al., 2004), so it is not entirely surprising that we again saw no decrease in strength parameters. In addition, we saw a changed femoral morphometry in $m d x$ mice leading to increased cortical area and moments of inertia, which could contribute to the lack of change in ultimate stress and energy to failure, combined with the lack of change in ash fraction in either type of mouse. More surprisingly, the $m d x$ mice in this study did not show significant decreases in any trabecular parameters, which disagrees with previously observed phenomena (Novotny, et al., 2011, Nakagaki, et al., 2010). In addition, $m d x$ mice also showed an increase in trabecular mineralizing surface/bone surface,

which is not supported by literature. This could be due to seasonality on the part of the mice, depending on such factors as photoperiod and birth month (Gerardin, et al., 2010). 


\subsection{2 bbPTH vs. Vehicle: Wild Type Mice}

As expected, bbPTH improved many skeletal outcomes in wild type mice as compared to vehicle-treated wild type mice, consistent with literature administering PTH analogs to healthy mice (Washimi, et al., 2010, Lippuner, et al., 2004, Frost, 1999, Kanis, et al., 1994, Lane and Yao, 2010). bbPTH treated mice showed improvements in force to failure, and moments of inertia, indicating an improved cortical structure consistent with increased strength. The lack of change in ultimate stress and modulus of toughness suggests these morphometric changes adapted to maintain a constant physiologic strain consistent with the mechanostat theory (Bartel, et al., 2006). Femoral trabecular bone properties improved with bbPTH treatment, including bone volume fraction and trabecular thickness. The bone volume fraction increase is especially important, since bone volume fraction is linked to overall compressive strength of bone tissue (Fields, et al., 2009, Keaveny, et al., 2008). In addition, the improvements in femoral bone volume fraction were measured in the distal femur, an important location where many fractures occur in boys with DMD (Gray, et al., 1992, Hsu, 1979, Hsu and Garcia-Ariz, 1981). No significant improvements were observed in the lumbar vertebrae in bbPTH treated mice compared to vehicle treatment. This is not unexpected, since, though PTH is expected to improve these properties, the effects are very mild compared to the changes in long bone trabecular bone which experiences a greater loading scheme (Iida-Klein, et al., 2007). The lack of change in osteoblast and osteoclast surface is of particular note, since hPTH analogs have been previously observed to increase both osteoblast and osteoclast surface leading to increased bone turnover (Hilliker, et al., 1996, Jilka, et al., 2006, Sheehan, et al., Weinstein, et al., 2010). This lack of change, especially in osteoclasts, may suggest that bbPTH may have a slightly altered method in promoting bone formation, particularly in trabecular bone. 


\subsection{3 bbPTH vs. hPTH in mdx Mice: Relative Potency Analysis}

As hypothesized, bbPTH was shown to be more anabolic than hPTH in the $m d x$ mouse, particularly in trabecular bone. Interestingly, the mild differences detected in cortical bone were in $m d x$ mice treated with hPTH. Thickness of the cortical shell of L4 was improved at a greater rate in $\mathrm{hPTH}$ treated $m d x$ mice compared to bbPTH treated mice, leading to a relative potency (bbPTH/hPTH determined at daily injection volume to achieve wild type vehicle-treatment levels) of 0.3246 , as well as a mild increase in periosteal mineralizing surface. However, none of these changes resulted in a difference in mechanical testing parameters, indicating no significant increases in resistance to fracture in the femur. In the lumbar vertebrae, the cortical shell makes up a smaller proportion of the bone, leading to a larger contribution of the trabecular bone to overall vertebral strength. The mild (but insignificant) increases in trabecular properties observed with bbPTH treatment may be enough to offset, or even surpass the added strength gained from a thicker cortical shell in hPTH treated $m d x$ mice. This is an important finding, as a large proportion of boys with DMD sustain vertebral compression fractures (Bothwell, et al., 2003), so restoring vertebral strength is a desirable outcome for an osteoporosis treatment in this population. Significant increases with bbPTH occurred in the trabecular bone of the distal femur contributing to an increase in femoral bone volume fraction with a relative potency of 2.039 , indicating it requires over twice as much hPTH as bbPH injected daily to achieve wild type values for this parameter. In addition, bbPTH here demonstrates an ability to decrease, in a dose-responsive manner, osteoclast surface area in $m d x$ trabecular bone (potency $=2.0827$ ). This may indicate that increasing doses of bbPTH actually 
downregulate osteoclast proliferation, leading to decreased bone resorption, and the greater gains in trabecular bone volume fraction we observed here. 


\section{Conclusion}

The marked anabolic response to bbPTH in $m d x$ mouse trabecular bone is a positive indication that bbPTH may be an effective treatment for DMD-induced osteoporosis. An anabolic treatment for osteoporosis in boys with Duchenne muscular dystrophy could greatly improve quality of life for these patients. A reduction in fractures associated with bbPTH therapy could eliminate extra hospitalizations, unnecessary pain, and disability associated with broken bones. In many DMD patients, long bone fractures are the transition point from being independently mobile or uprightly mobile with assist devices (braces, walkers, etc.) to being permanently wheelchair bound.

Since muscle and bone, like most biological tissues, employ a "use it or lose it" philosophy, reduced mobility allows DMD muscular degradation to accelerate to eventual cardiac or respiratory muscle failure. From a seated position, the body's demand for oxygen decreases due to lessened demand from postural muscles, eventually reducing cardiac muscle tone. Additionally, when seated in a wheelchair, DMD patients with moderate to severe kyphoscoliosis are in a position where it is more difficult for the diaphragm to efficiently contract and for the lungs to fully expand, increasing the probability of a respiratory emergency or death due to respiratory arrest. DMD patients, due to glucocorticoid use, also experience delayed fracture healing (Mann, et al., 2007). Therefore, a fracture that may take six to eight weeks to heal in a healthy boy may take several months to heal in a boy with DMD, or healing may not take place at all. Black bear PTH, a more potent anabolic osteoporosis treatment in murine trabecular bone, could greatly benefit DMD patients through fracture reduction, ultimately improving overall quality of life and perhaps even prolonging life span. 
However, before this drug can be administered to human patients, much work remains to be done. Future work could explore drug interactions of glucocorticoids and bbPTH in a rodent model in a dose-response study. In vitro drug interactions also need exploring, as well as in vitro testing to further elucidate the mechanisms behind bone anabolism due to bbPTH administration. Rodent bone is not a perfect analogue to human bone, however, as rodent cortical bone does not undergo intracortical remodeling like the bones of larger animals, including humans and bears does. bbPTH therapies may be explored in additional DMD models including dogs and chickens before safety and efficacy should be tested in a human pediatric population. 


\section{References}

Almeida, M., L. Han, E. Ambrogini, S. M. Bartell, and S. C. Manolagas. "Oxidative Stress Stimulates Apoptosis and Activates Nf-Kappab in Osteoblastic Cells Via a Pkcbeta/P66shc Signaling Cascade: Counter Regulation by Estrogens or Androgens." [In eng]. Molecular Endocrinology 24, no. 10 (Oct 2004): 2030-7.

Almeida, M., M. Martin-Millan, E. Ambrogini, R. Bradsher, 3rd, L. Han, X. D. Chen, P. K. Roberson, et al. "Estrogens Attenuate Oxidative Stress and the Differentiation and Apoptosis of Osteoblasts by DNA-Binding-Independent Actions of the Eralpha." [In eng]. Journal of Bone and Mineral Research 25, no. 4 (Apr 2007): 769-81.

Altschul, S. F., T. L. Madden, A. A. Schaffer, J. Zhang, Z. Zhang, W. Miller, and D. J. Lipman. "Gapped Blast and Psi-Blast: A New Generation of Protein Database Search Programs." [In eng]. Nucleic Acids Research 25, no. 17 (Sep 1 1997): 3389-402.

"Gapped Blast and Psi-Blast: A New Generation of Protein Database Search Programs." Nucleic Acids Res 25, no. 17 (Sep 1 1997): 3389-402.

Anderson, J. E., D. L. Lentz, and R. B. Johnson. "Recovery from Disuse Osteopenia Coincident to Restoration of Muscle Strength in Mdx Mice." [In eng]. Bone 14, no. 4 (Jul-Aug 1993): 625-34.

Antonarakis, S. E., J. A. Phillips, 3rd, R. L. Mallonee, H. H. Kazazian, Jr., E. R. Fearon, P. G. Waber, H. M. Kronenberg, A. Ullrich, and D. A. Meyers. "Beta-Globin Locus Is Linked to the Parathyroid Hormone (Pth) Locus and Lies between the Insulin and Pth Loci in Man." [In eng]. Proceedings of the National Academy of Sciences USA 80, no. 21 (Nov 1983): 6615-9.

Aparicio, L. F., M. Jurkovic, and J. DeLullo. "Decreased Bone Density in Ambulatory Patients with Duchenne Muscular Dystrophy." [In eng]. Journal of Pediatric Orthopedics 22, no. 2 (Mar-Apr 2002): 179-81.

Askanas, V., S. A. Shafiq, and A. T. Milhorat. "Normal and Dystrophic Chicken Muscle at Successive Stages in Tissue Culture." [In eng]. Archives of Neurology 24, no. 3 (Mar 1971): 259-65.

Aslan, D., M. D. Andersen, L. B. Gede, T. K. de Franca, S. R. Jorgensen, P. Schwarz, and N. R. Jorgensen. "Mechanisms for the Bone Anabolic Effect of Parathyroid Hormone Treatment in Humans." [In eng]. Scandinavian Journal of Clinical Laboratory Investigation 72, no. 1 (Feb 2001): 14-22.

Balaban, B., D. J. Matthews, G. H. Clayton, and T. Carry. "Corticosteroid Treatment and Functional Improvement in Duchenne Muscular Dystrophy: Long-Term Effect." [In eng]. American Journal of Physical Medical Rehabilitation 84, no. 11 (Nov 2005): 843-50.

Bandman, E. "Distribution of Slow Myosin in Dystrophic Chicken Muscle." [In eng]. Advances in Experimental Biology 182 (1985): 63-72.

Bartel, D.L., T.D. Davy, and T.M. Keaveny. Orthopaedic Biomechanics: Mechanics and Design in Musculoskeletal Systems. Upper Saddle River, NJ: Pearson Prentice Hall, 2006. 
Bellido, T., A. A. Ali, L. I. Plotkin, Q. Fu, I. Gubrij, P. K. Roberson, R. S. Weinstein, et al. "Proteasomal Degradation of Runx2 Shortens Parathyroid Hormone-Induced Anti-Apoptotic Signaling in Osteoblasts. A Putative Explanation for Why Intermittent Administration Is Needed for Bone Anabolism." [In eng]. Journal of Biological Chemistry 278, no. 50 (Dec 12 2003): 50259-72.

Bianchi, M. L. "How to Manage Osteoporosis in Children." [In eng]. Best Practices Research in Clinical Rheumatology 19, no. 6 (Dec 2005): 991-1005.

Bianchi, M. L., A. Mazzanti, E. Galbiati, S. Saraifoger, A. Dubini, F. Cornelio, and L. Morandi. "Bone Mineral Density and Bone Metabolism in Duchenne Muscular Dystrophy." [In eng]. Osteoporosis International 14, no. 9 (Sep 2003): 761-7.

Bianchi, M. L., L. Morandi, E. Andreucci, S. Vai, J. Frasunkiewicz, and R. Cottafava. "Low Bone Density and Bone Metabolism Alterations in Duchenne Muscular Dystrophy: Response to Calcium and Vitamin D Treatment." [In eng]. Osteoporosis International 22, no. 2 (Feb 2010): 529-39.

Bikle, D. D., and B. P. Halloran. "The Response of Bone to Unloading." [In eng]. Journal of Bone Mineral Metabolism 17, no. 4 (1999): 233-44.

Bikle, D. D., T. Sakata, and B. P. Halloran. "The Impact of Skeletal Unloading on Bone Formation." [In eng]. Gravitational Space Biology Bulletin 16, no. 2 (Jun 2003): 45-54.

Bothwell, J. E., K. E. Gordon, J. M. Dooley, J. MacSween, E. A. Cummings, and S. Salisbury. "Vertebral Fractures in Boys with Duchenne Muscular Dystrophy." [In eng]. Clinical Pediatrics 42, no. 4 (May 2003): 353-6.

Brennan, O., O. D. Kennedy, T. C. Lee, S. M. Rackard, and F. J. O'Brien. "Effects of Estrogen Deficiency and Bisphosphonate Therapy on Osteocyte Viability and Microdamage Accumulation in an Ovine Model of Osteoporosis." [In eng]. Journal of Orthopedic Research 29, no. 3 (Mar 2010): 419-24.

Bulfield, G., W. G. Siller, P. A. Wight, and K. J. Moore. "X Chromosome-Linked Muscular Dystrophy (Mdx) in the Mouse." [In eng]. Proceedings of the National Academy of Sciences USA 81, no. 4 (Feb 1984): 1189-92.

Burger, E. H., and J. Klein-Nulen. "Responses of Bone Cells to Biomechanical Forces in Vitro." [In eng]. Advances in Dental Research 13 (Jun 1999): 93-8.

Call, J. A., J. N. McKeehen, S. A. Novotny, and D. A. Lowe. "Progressive Resistance Voluntary Wheel Running in the Mdx Mouse." [In eng]. Muscle Nerve 42, no. 6 (Dec 2010): 871-80.

Carmeliet, G., L. Vico, and R. Bouillon. "Space Flight: A Challenge for Normal Bone Homeostasis." [In eng]. Critical Reviews in Eukaryotic Gene Expression 11, no. 1-3 (2001): 131-44.

Cavanagh, P. R., A. A. Licata, and A. J. Rice. "Exercise and Pharmacological Countermeasures for Bone Loss During Long-Duration Space Flight." [In eng]. Gravitational Space Biology Bulletin 18, no. 2 (Jun 2005): 39-58.

Chenna, R., H. Sugawara, T. Koike, R. Lopez, T. J. Gibson, D. G. Higgins, and J. D. Thompson. "Multiple Sequence Alignment with the Clustal Series of Programs." Nucleic Acids Res 31, no. 13 (Jul 1 2003): 3497-500.

Clarke, B. L., and S. Khosla. "Physiology of Bone Loss." [In eng]. Radiological Clinical North America 48, no. 3 (May 2010): 483-95. 
Cohran, V. C., M. Griffiths, and J. E. Heubi. "Bone Mineral Density in Children Exposed to Chronic Glucocorticoid Therapy." [In eng]. Clinical Pediatrics 47, no. 5 (Jun 2008): 469-75.

Crabtree, N. J., H. Roper, H. McMurchie, and N. J. Shaw. "Regional Changes in Bone Area and Bone Mineral Content in Boys with Duchenne Muscular Dystrophy Receiving Corticosteroid Therapy." [In eng]. Journal of Pediatrics 156, no. 3 (Mar 2009): 450-5.

Crowe, L. M., and R. J. Baskin. "Stereologic Analysis of Dystrophic Chicken Muscle." [In eng]. American Journal of Pathology 95, no. 2 (May 1979): 295-315.

DeMichele, S. J., M. T. Atallah, P. R. Sweeny, and R. G. Brown. "Connective Tissue Metabolism in Muscular Dystrophy. Early Amino Acid Changes in Collagen Types Isolated from the Gastrocnemius Muscle of Developing Dystrophic Chicken Embryos." [In eng]. Computed Biochemistry and Physiology 84, no. 2 (1986): 225-33.

Donahue, S. W., S. A. Galley, M. R. Vaughan, P. Patterson-Buckendahl, L. M. Demers, J. L. Vance, and M. E. McGee. "Parathyroid Hormone May Maintain Bone Formation in Hibernating Black Bears (Ursus Americanus) to Prevent Disuse Osteoporosis." [In eng]. Journal of Experimental Biology 209, no. Pt 9 (May 2006): 1630-8.

Donahue, S. W., M. E. McGee, K. B. Harvey, M. R. Vaughan, and C. T. Robbins. "Hibernating Bears as a Model for Preventing Disuse Osteoporosis." [In eng]. Journal of Biomechanics 39, no. 8 (2006): 1480-8.

Doty, S. B., and E. A. Nunez. "Activation of Osteoclasts and the Repopulation of Bone Surfaces Following Hibernation in the Bat, Myotis Lucifugus." [In eng]. Anatomy 213, no. 4 (Dec 1985): 481-95.

Elias, A. N., and G. Gwinup. "Immobilization Osteoporosis in Paraplegia." [In eng]. Journal of the American Paraplegia Society 15, no. 3 (Jul 1992): 163-70.

Emery, A. E. "Population Frequencies of Inherited Neuromuscular Diseases--a World Survey." [In eng]. Neuromuscular Disorders 1, no. 1 (1991): 19-29.

Fields, A. J., S. K. Eswaran, M. G. Jekir, and T. M. Keaveny. "Role of Trabecular Microarchitecture in Whole-Vertebral Body Biomechanical Behavior." [In eng]. Journal of Bone and Mineral Research 24, no. 9 (Sep 2009): 1523-30.

Frost, H. M. "On the Estrogen-Bone Relationship and Postmenopausal Bone Loss: A New Model." [In eng]. Journal of Bone and Mineral Research 14, no. 9 (Sep 1999): 1473-7.

Fujimori, A., S. L. Cheng, L. V. Avioli, and R. Civitelli. "Dissociation of Second Messenger Activation by Parathyroid Hormone Fragments in Osteosarcoma Cells." [In eng]. Endocrinology 128, no. 6 (Jun 1991): 3032-9.

Gallet, M., and J. M. Vanacker. "Err Receptors as Potential Targets in Osteoporosis." [In eng]. Trends in Endocrinology and Metabolism 21, no. 10 (Oct 2001): 63741.

Gerardin, P., R. El Amrani, B. Cyrille, M. Gabriele, P. Guillermin, M. Boukerrou, B. Boumahni, et al. "Low Clinical Burden of 2009 Pandemic Influenza a (H1n1) Infection During Pregnancy on the Island of La Reunion." [In eng]. PLoS One 5, no. 5 (2010): e10896. 
Gray, B., J. D. Hsu, and J. Furumasu. "Fractures Caused by Falling from a Wheelchair in Patients with Neuromuscular Disease." [In eng]. Developmental Medical Child Neurology 34, no. 7 (Jul 1992): 589-92.

Hawker, G. A., R. Ridout, V. A. Harris, C. C. Chase, L. J. Fielding, and W. D. Biggar. "Alendronate in the Treatment of Low Bone Mass in Steroid-Treated Boys with Duchennes Muscular Dystrophy." [In eng]. Archives of Physical Medical Rehabilitation 86, no. 2 (Feb 2005): 284-8.

Hilliker, S., J. E. Wergedal, H. E. Gruber, P. Bettica, and D. J. Baylink. "Truncation of the Amino Terminus of Pth Alters Its Anabolic Activity on Bone in Vivo." [In eng]. Bone 19, no. 5 (Nov 1996): 469-77.

Hogg, R.V., J.W. McKean, and A.T. Craig. Introduction to Mathematical Statistics. Seventh ed.: Pearson Education, 2005.

Hsu, J. D. "Extremity Fractures in Children with Neuromuscular Disease." [In eng]. Johns Hopkins Medical Journal 145, no. 3 (Sep 1979): 89-93.

"Skeletal Changes in Children with Neuromuscular Disorders." [In eng]. Progress in Clinical Biological Research 101 (1982): 553-7.

Hsu, J. D., and M. Garcia-Ariz. "Fracture of the Femur in the Duchenne Muscular Dystrophy Patient." [In eng]. Journal of Pediatric Orthopedics 1, no. 2 (1981): 203-7.

Iida-Klein, A., S. S. Lu, F. Cosman, R. Lindsay, and D. W. Dempster. "Effects of Cyclic Vs. Daily Treatment with Human Parathyroid Hormone (1-34) on Murine Bone Structure and Cellular Activity." [In eng]. Bone 40, no. 2 (Feb 2007): 391-8.

Jiang, S. D., L. S. Jiang, and L. Y. Dai. "Mechanisms of Osteoporosis in Spinal Cord Injury." [In eng]. Clinical Endocrinology (Oxford) 65, no. 5 (Nov 2006): 55565.

Jilka, R. L. "Molecular and Cellular Mechanisms of the Anabolic Effect of Intermittent Pth." [In eng]. Bone 40, no. 6 (Jun 2007): 1434-46.

Jilka, R. L., M. Almeida, E. Ambrogini, L. Han, P. K. Roberson, R. S. Weinstein, and S. C. Manolagas. "Decreased Oxidative Stress and Greater Bone Anabolism in the Aged, When Compared to the Young, Murine Skeleton with Parathyroid Hormone Administration." [In eng]. Aging Cell 9, no. 5 (Oct 2010): 851-67.

Jilka, R. L., C. A. O'Brien, A. A. Ali, P. K. Roberson, R. S. Weinstein, and S. C. Manolagas. "Intermittent Pth Stimulates Periosteal Bone Formation by Actions on Post-Mitotic Preosteoblasts." [In eng]. Bone 44, no. 2 (Feb 2009): 275-86.

Jilka, R. L., C. A. O'Brien, S. M. Bartell, R. S. Weinstein, and S. C. Manolagas. "Continuous Elevation of Pth Increases the Number of Osteoblasts Via Both Osteoclast-Dependent and -Independent Mechanisms." [In eng]. Journal of Bone and Mineral Research 25, no. 11 (Nov 2006): 2427-37.

Jilka, R. L., R. S. Weinstein, T. Bellido, P. Roberson, A. M. Parfitt, and S. C. Manolagas. "Increased Bone Formation by Prevention of Osteoblast Apoptosis with Parathyroid Hormone." [In eng]. Journal of Clinical Investigation 104, no. 4 (Aug 1999): 439-46. 
Kanis, J. A., L. J. Melton, 3rd, C. Christiansen, C. C. Johnston, and N. Khaltaev. "The Diagnosis of Osteoporosis." [In eng]. Journal of Bone and Mineral Research 9, no. 8 (Aug 1994): 1137-41.

Keaveny, T. M., P. F. Hoffmann, M. Singh, L. Palermo, J. P. Bilezikian, S. L. Greenspan, and D. M. Black. "Femoral Bone Strength and Its Relation to Cortical and Trabecular Changes after Treatment with Pth, Alendronate, and Their Combination as Assessed by Finite Element Analysis of Quantitative Ct Scans." [In eng]. J Bone Miner Res 23, no. 12 (Dec 2008): 1974-82.

Khosla, S. "Update on Estrogens and the Skeleton." [In eng]. Journal of Clinical Endocrinology and Metabolism 95, no. 8 (Aug 2010): 3569-77.

Kikkawa, N., T. Ohno, Y. Nagata, M. Shiozuka, T. Kogure, and R. Matsuda. "Ectopic Calcification Is Caused by Elevated Levels of Serum Inorganic Phosphate in Mdx Mice." [In eng]. Cell Structure and Function 34, no. 2 (2009): 77-88.

King, W. M., R. Ruttencutter, H. N. Nagaraja, V. Matkovic, J. Landoll, C. Hoyle, J. R. Mendell, and J. T. Kissel. "Orthopedic Outcomes of Long-Term Daily Corticosteroid Treatment in Duchenne Muscular Dystrophy." [In eng]. Neurology 68, no. 19 (May 8 2007): 1607-13.

Koh, A. J., C. A. Beecher, T. J. Rosol, and L. K. McCauley. "3',5'-Cyclic Adenosine Monophosphate Activation in Osteoblastic Cells: Effects on Parathyroid Hormone-1 Receptors and Osteoblastic Differentiation in Vitro." [In eng]. Endocrinology 140, no. 7 (Jul 1999): 3154-62.

Krook, L., W. A. Wimsatt, J. P. Whalen, I. MacIntyre, and E. A. Nunez. "Calcitonin and Hibernation Bone Loss in the Bat (Myotis Lucifugus)." [In eng]. Cornell Veterinarian 67, no. 2 (Apr 1977): 265-71.

Lane, N. E., and W. Yao. "Glucocorticoid-Induced Bone Fragility." [In eng]. Annals of the New York Academy of Sciences 1192 (Mar 2010): 81-3.

Langsetmo, L., T. V. Nguyen, N. D. Nguyen, C. S. Kovacs, J. C. Prior, J. R. Center, S. Morin, et al. "Independent External Validation of Nomograms for Predicting Risk of Low-Trauma Fracture and Hip Fracture." [In eng]. Canadian Medical Association Journal 183, no. 2 (Feb 8 2007): E107-14.

Lansman, J. B., and A. Franco-Obregon. "Mechanosensitive Ion Channels in Skeletal Muscle: A Link in the Membrane Pathology of Muscular Dystrophy." [In eng]. Clinical Experimental Pharmacology and Physiology 33, no. 7 (Jul 2006): 64956.

Larson, C. M., and R. C. Henderson. "Bone Mineral Density and Fractures in Boys with Duchenne Muscular Dystrophy." [In eng]. Journal of Pediatric Orthopedics 20, no. 1 (Jan-Feb 2000): 71-4.

Levenston, M. E. "Periosteal Bone Formation Stimulated by Externally Induced Bending Strains." [In eng]. Journal of Bone and Mineral Research 10, no. 4 (Apr 1995): 671-2.

Li, M., D. R. Healy, Y. Li, H. A. Simmons, F. Gao, H. Z. Ke, B. Lu, T. A. Owen, and D. D. Thompson. "A Comparison of the Anabolic Effects of Rat and Bovine Parathyroid Hormone (1-34) in Ovariectomized Rats." [In eng]. Journal of Musculoskeletal and Neuronal Interactions 2, no. 1 (Sep 2001): 77-83. 
Li, Y., M. J. Ahrens, A. Wu, J. Liu, and A. T. Dudley. "Calcium/CalmodulinDependent Protein Kinase Ii Activity Regulates the Proliferative Potential of Growth Plate Chondrocytes." [In eng]. Development 138, no. 2 (Jan 2011): 35970.

Lippuner, K., A. W. Popp, P. Schwab, M. Gitlin, T. Schaufler, C. Senn, and R. Perrelet. "Fracture Hospitalizations between Years 2000 and 2007 in Switzerland: A Trend Analysis." [In eng]. Osteoporosis International 22, no. 9 (Sep 2004): 2487-97.

Lord, J., B. Behrman, N. Varzos, D. Cooper, J. S. Lieberman, and W. M. Fowler. "Scoliosis Associated with Duchenne Muscular Dystrophy." [In eng]. Archives of Physical Medical Rehabilitation 71, no. 1 (Jan 1990): 13-7.

Lyritis, G. P., T. Georgoulas, and C. P. Zafeiris. "Bone Anabolic Versus Bone Anticatabolic Treatment of Postmenopausal Osteoporosis." [In eng]. Annals of the New York Academy of Sciences 1205 (Sep 2010): 277-83.

Mallya, S. M., H. I. Wu, E. A. Saria, K. R. Corrado, and A. Arnold. "Tissue-Specific Regulatory Regions of the Pth Gene Localized by Novel Chromosome 11 Rearrangement Breakpoints in a Parathyroid Adenoma." [In eng]. Journal of Bone and Mineral Research 25, no. 12 (Dec 2010): 2606-12.

Mann, V., C. Huber, G. Kogianni, F. Collins, and B. Noble. "The Antioxidant Effect of Estrogen and Selective Estrogen Receptor Modulators in the Inhibition of Osteocyte Apoptosis in Vitro." [In eng]. Bone 40, no. 3 (Mar 2007): 674-84.

Manolagas, S. C. "From Estrogen-Centric to Aging and Oxidative Stress: A Revised Perspective of the Pathogenesis of Osteoporosis." [In eng]. Endocrinology Review 31, no. 3 (Jun 2010): 266-300.

Margolis, D. S., Y. H. Lien, L. W. Lai, and J. A. Szivek. "Bilateral Symmetry of Biomechanical Properties in Mouse Femora." [In eng]. Medicine, Engineering, Physics 26, no. 4 (May 2004): 349-53.

Marieb, E.N, and K. Hoehn. Human Anatomy and Physiology. Seventh ed. San Francisco, CA: Pearson Benjamin Cummings, 2007.

McDonald, D. G., M. Kinali, A. C. Gallagher, E. Mercuri, F. Muntoni, H. Roper, P. Jardine, D. H. Jones, and M. G. Pike. "Fracture Prevalence in Duchenne Muscular Dystrophy." [In eng]. Developmental Medical Child Neurology 44, no. 10 (Oct 2002): 695-8.

McGee-Lawrence, M. E. "Relative Anti-Apoptotic and Osteogenic Effects of Black Bear Pth 1-34 Compared to Human Pth 1-34." Paper presented at the ASBMR Annual Meeting, Denver, CO, 2009.

McGee-Lawrence, M. E., D. M. Stoll, E. R. Mantila, B. K. Fahrner, H. V. Carey, and S. W. Donahue. "Thirteen-Lined Ground Squirrels (Ictidomys Tridecemlineatus) Show Microstructural Bone Loss During Hibernation but Preserve Bone Macrostructural Geometry and Strength." [In eng]. Journal of Experimental Biology 214, no. Pt 8 (Apr 15 2010): 1240-7.

McGee-Lawrence, M. E., S. J. Wojda, L. N. Barlow, T. D. Drummer, K. Bunnell, J. Auger, H. L. Black, and S. W. Donahue. "Six Months of Disuse During Hibernation Does Not Increase Intracortical Porosity or Decrease Cortical Bone 
Geometry, Strength, or Mineralization in Black Bear (Ursus Americanus) Femurs." [In eng]. Journal of Biomechanics 42, no. 10 (Jul 22 2009): 1378-83.

McGee-Lawrence, M. E., S. J. Wojda, L. N. Barlow, T. D. Drummer, A. B. Castillo, O. Kennedy, K. W. Condon, et al. "Grizzly Bears (Ursus Arctos Horribilis) and Black Bears (Ursus Americanus) Prevent Trabecular Bone Loss During Disuse (Hibernation)." [In eng]. Bone 45, no. 6 (Dec 2009): 1186-91.

McGee, M. E., A. J. Maki, S. E. Johnson, O. L. Nelson, C. T. Robbins, and S. W. Donahue. "Decreased Bone Turnover with Balanced Resorption and Formation Prevent Cortical Bone Loss During Disuse (Hibernation) in Grizzly Bears (Ursus Arctos Horribilis)." [In eng]. Bone 42, no. 2 (Feb 2008): 396-404.

McGee, M. E., D. L. Miller, J. Auger, H. L. Black, and S. W. Donahue. "Black Bear Femoral Geometry and Cortical Porosity Are Not Adversely Affected by Ageing Despite Annual Periods of Disuse (Hibernation)." [In eng]. Journal of Anatomy 210, no. 2 (Feb 2007): 160-9.

Montgomery, E., C. Pennington, C. M. Isales, and M. W. Hamrick. "Muscle-Bone Interactions in Dystrophin-Deficient and Myostatin-Deficient Mice." [In eng]. Discoveries in Molecular and Cell Evolutionary Biology 286, no. 1 (Sep 2005): 814-22.

Nair, K. P., A. Vasanth, M. Gourie-Devi, A. B. Taly, S. Rao, N. Gayathri, and T. Murali. "Disabilities in Children with Duchenne Muscular Dystrophy: A Profile." [In eng]. Journal of Rehabilitational Medicine 33, no. 4 (Jul 2001): 147-9.

Nakagaki, W. R., C. A. Bertran, C. Y. Matsumura, H. Santo-Neto, and J. A. Camilli. "Mechanical, Biochemical and Morphometric Alterations in the Femur of Mdx Mice." [In eng]. Bone 48, no. 2 (Feb 1 2010): 372-9.

Nakagaki, W. R., and J. A. Camilli. "Bone Tissue and Muscle Dystrophin Deficiency in Mdx Mice." [In eng]. Joint Bone Spine 79, no. 2 (Mar 2012): 129-33.

"National Osteoporosis Foundation." http://www.nof.org/.

Novotny, S. A., G. L. Warren, A. S. Lin, R. E. Guldberg, K. A. Baltgalvis, and D. A. Lowe. "Bone Is Functionally Impaired in Dystrophic Mice but Less So Than Skeletal Muscle." [In eng]. Neuromuscular Disorders 21, no. 3 (Mar 2011): 183-93.

"Bone Is Functionally Impaired in Dystrophic Mice but Less So Than Skeletal Muscle." [In eng]. Neuromuscul Disord 21, no. 3 (Mar 2011): 183-93.

Oli, M.H., H.A. Jacobson, and B.D. Leopold. "Denning Ecology of Black Bears in the White River National Wildlife Refuge, Arkansas." Journal of Wildlife Management 61 (1997): 700-06.

Parfitt, A. M. "Parathyroid Hormone and Periosteal Bone Expansion." [In eng]. Journal of Bone and Mineral Research 17, no. 10 (Oct 2002): 1741-3.

Phaner, V., C. Charmetant, A. Condemine, I. Fayolle-Minon, M. H. Lafage-Proust, and P. Calmels. "[Osteoporosis in Spinal Cord Injury. Screening and Treatment. Results of a Survey of Physical Medicine and Rehabilitation Physician Practices in France. Proposals for Action to Be Taken Towards the Screening and the Treatment]." [In fre]. Annals of Physical Rehabilitation Medicine 53, no. 10 (Dec 2004): 615-20. 
Pinkerton, J. V., and D. W. Stovall. "Reproductive Aging, Menopause, and Health Outcomes." [In eng]. Annals of the New York Academy of Sciences 1204 (Aug 2010): 169-78.

Reidhaar-Olson, J. F., R. M. Davis, J. A. De Souza-Hart, and H. E. Selick. "Active Variants of Human Parathyroid Hormone (1-34) with Multiple Amino Acid Substitutions." [In eng]. Molecular and Cell Endocrinology 160, no. 1-2 (Feb 25 2000): 135-47.

Riggs, B. L., S. Khosla, and L. J. Melton, 3rd. "A Unitary Model for Involutional Osteoporosis: Estrogen Deficiency Causes Both Type I and Type Ii Osteoporosis in Postmenopausal Women and Contributes to Bone Loss in Aging Men." [In eng]. Journal of Bone and Mineral Research 13, no. 5 (May 1998): 763-73.

Rixon, R. H., J. F. Whitfield, L. Gagnon, R. J. Isaacs, S. Maclean, B. Chakravarthy, J. P. Durkin, et al. "Parathyroid Hormone Fragments May Stimulate Bone Growth in Ovariectomized Rats by Activating Adenylyl Cyclase." [In eng]. Journal of Bone and Mineral Research 9, no. 8 (Aug 1994): 1179-89.

Rufo, A., A. Del Fattore, M. Capulli, F. Carvello, L. De Pasquale, S. Ferrari, D. Pierroz, et al. "Mechanisms Inducing Low Bone Density in Duchenne Muscular Dystrophy in Mice and Humans." [In eng]. Journal of Bone and Mineral Research 26, no. 8 (Aug 2011): 1891-903.

Ryder-Cook, A. S., P. Sicinski, K. Thomas, K. E. Davies, R. G. Worton, E. A. Barnard, M. G. Darlison, and P. J. Barnard. "Localization of the Mdx Mutation within the Mouse Dystrophin Gene." [In eng]. European Molecular Biology Organization Journal 7, no. 10 (Oct 1988): 3017-21.

Saag, K. G., J. R. Zanchetta, J. P. Devogelaer, R. A. Adler, R. Eastell, K. See, J. H. Krege, K. Krohn, and M. R. Warner. "Effects of Teriparatide Versus Alendronate for Treating Glucocorticoid-Induced Osteoporosis: Thirty-SixMonth Results of a Randomized, Double-Blind, Controlled Trial." [In eng]. Arthritis and Rheumatism 60, no. 11 (Nov 2009): 3346-55.

Saito, T., A. Nakamura, Y. Aoki, T. Yokota, T. Okada, M. Osawa, and S. Takeda. "Antisense Pmo Found in Dystrophic Dog Model Was Effective in Cells from Exon 7-Deleted Dmd Patient." [In eng]. PLoS One 5, no. 8 (2007): e12239.

Schiller, P. C., G. D'Ippolito, B. A. Roos, and G. A. Howard. "Anabolic or Catabolic Responses of Mc3t3-E1 Osteoblastic Cells to Parathyroid Hormone Depend on Time and Duration of Treatment." [In eng]. Journal of Bone and Mineral Research 14, no. 9 (Sep 1999): 1504-12.

Schooley, R.L., C.R. MacLaughlin, G.J. Matula Jr., W.B. Krohn. "Denning Chronology of Female Black Bears: Effects of Food, Weather, and Reproduction." Journal of Mammalogy 75 (1994): 466-77.

Sheehan, S., A. Muthusamy, E. Paul, R. A. Sikes, and R. R. Gomes, Jr. "Short-Term Intermittent Pth 1-34 Administration Enhances Bone Formation in Scid/Beige Mice." [In eng]. Endocr J 57, no. 5 (373-82.

Sicinski, P., Y. Geng, A. S. Ryder-Cook, E. A. Barnard, M. G. Darlison, and P. J. Barnard. "The Molecular Basis of Muscular Dystrophy in the Mdx Mouse: A Point Mutation." [In eng]. Science 244, no. 4912 (Jun 30 1989): 1578-80. 
Siegel, I. M. "Fractures of Long Bones in Duchenne Muscular Dystrophy." [In eng]. Journal of Trauma 17, no. 3 (Mar 1977): 219-22.

Silbermann, M., and T. Kadar. "Age-Related Changes in the Cellular Population of the Growth Plate of Normal Mouse." [In eng]. Acta Anatomy (Basel) 97, no. 4 (1977): 459-68.

"Quantitative Changes in the Cellular Population of the Growth Plate of Triamcinolone-Treated Mice." [In eng]. Acta Anatomy (Basel) 98, no. 4 (1977): 396-400.

Skerry, T. M., and L. J. Suva. "Investigation of the Regulation of Bone Mass by Mechanical Loading: From Quantitative Cytochemistry to Gene Array." [In eng]. Cell Biochemistry and Function 21, no. 3 (Sep 2003): 223-9.

Smith, A. D., J. Koreska, and C. F. Moseley. "Progression of Scoliosis in Duchenne Muscular Dystrophy." [In eng]. Journal of Bone Joint Surgery 71, no. 7 (Aug 1989): 1066-74.

Soderpalm, A. C., P. Magnusson, A. C. Ahlander, J. Karlsson, A. K. Kroksmark, M. Tulinius, and D. Swolin-Eide. "Low Bone Mineral Density and Decreased Bone Turnover in Duchenne Muscular Dystrophy." [In eng]. Neuromuscular Disorders 17, no. 11-12 (Dec 2007): 919-28.

Specker, B. L., H. E. Wey, and E. P. Smith. "Rates of Bone Loss in Young Adult Males." [In Eng]. International Journal of Clinical Rheumatology 5, no. 2 (Apr 1 2010): 215-28.

Srinivasan, S., B. J. Ausk, J. Prasad, D. Threet, S. D. Bain, T. S. Richardson, and T. S. Gross. "Rescuing Loading Induced Bone Formation at Senescence." [In eng]. PLoS Computed Biology 6, no. 9 (2010).

Straathof, C. S., W. C. Overweg-Plandsoen, G. J. van den Burg, A. J. van der Kooi, J. J. Verschuuren, and I. J. de Groot. "Prednisone 10 Days on/10 Days Off in Patients with Duchenne Muscular Dystrophy." [In eng]. Journal of Neurology 256, no. 5 (May 2009): 768-73.

Syed, F. A., J. Iqbal, Y. Peng, L. Sun, and M. Zaidi. "Clinical, Cellular and Molecular Phenotypes of Aging Bone." [In eng]. Interdisciplinary Topics in Gerontology 37 (2010): 175-92.

Washimi, Y., H. Chen, A. Ito, R. Takao, T. Uzawa, Y. Yamamoto, H. Yamada, and S. Shoumura. "Effect of Intermittent Treatment with Human Parathyroid Hormone 1-34 in Samp6 Senescence-Accelerated Mice." [In eng]. Journal of Endocrinology Investigation 33, no. 6 (Jun 2010): 395-400.

Weinstein, R. S., R. L. Jilka, M. Almeida, P. K. Roberson, and S. C. Manolagas. "Intermittent Parathyroid Hormone Administration Counteracts the Adverse Effects of Glucocorticoids on Osteoblast and Osteocyte Viability, Bone Formation, and Strength in Mice." [In eng]. Endocrinology 151, no. 6 (Jun 2010): 2641-9.

Wu, X., L. Pang, W. Lei, W. Lu, J. Li, Z. Li, F. J. Frassica, et al. "Inhibition of Sca-1Positive Skeletal Stem Cell Recruitment by Alendronate Blunts the Anabolic Effects of Parathyroid Hormone on Bone Remodeling." [In eng]. Cell Stem Cell 7, no. 5 (Nov 5 2011): 571-80. 
Yasuma, F., and M. Sakai. "Scoliosis in Duchenne Muscular Dystrophy." [In eng]. Respiration 66, no. 5 (1999): 463.

Zayzafoon, M. "Calcium/Calmodulin Signaling Controls Osteoblast Growth and Differentiation." [In eng]. Journal of Cellular Biochemistry 97, no. 1 (Jan 1 2006): 56-70.

Zhou, H., A. Iida-Klein, S. S. Lu, M. Ducayen-Knowles, L. R. Levine, D. W. Dempster, and R. Lindsay. "Anabolic Action of Parathyroid Hormone on Cortical and Cancellous Bone Differs between Axial and Appendicular Skeletal Sites in Mice." [In eng]. Bone 32, no. 5 (May 2003): 513-20. 


\section{Appendices}

\subsection{A1 MATLAB ANCOVA Plots}

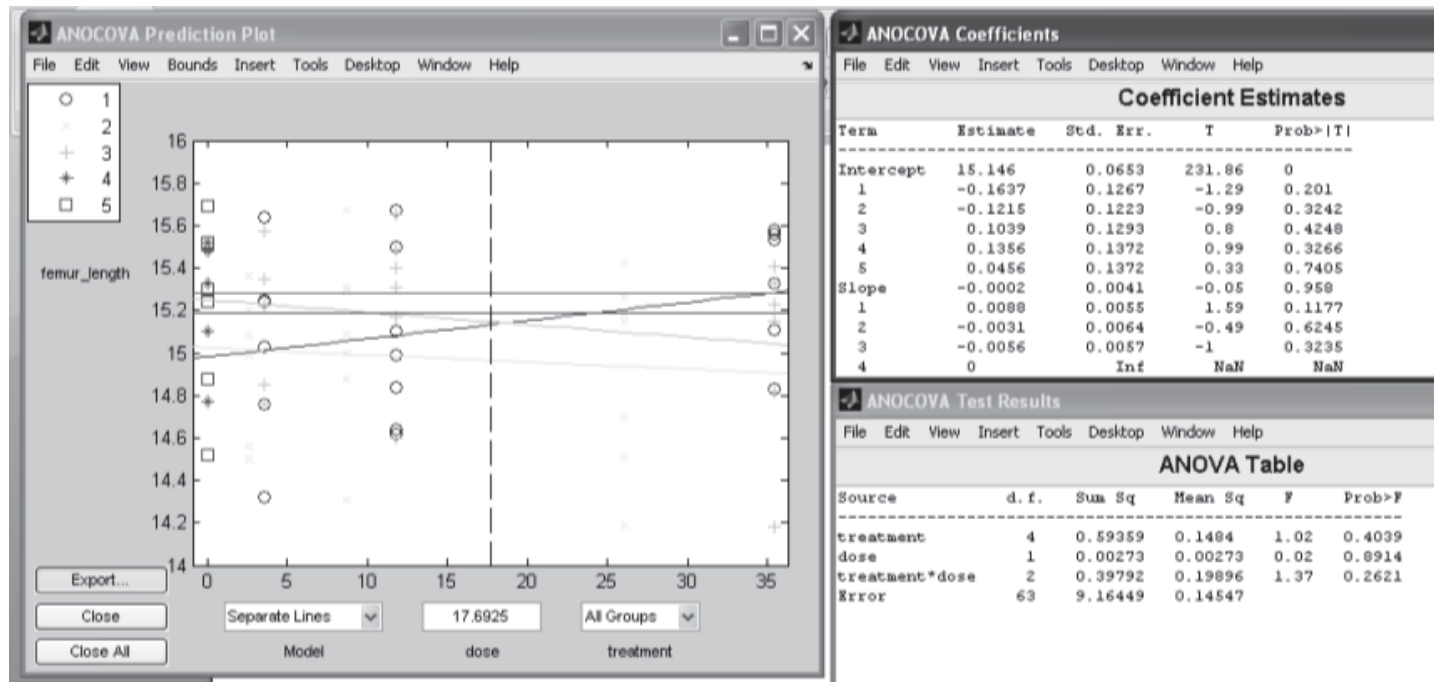

Figure 5.1: Dose response for femur length 


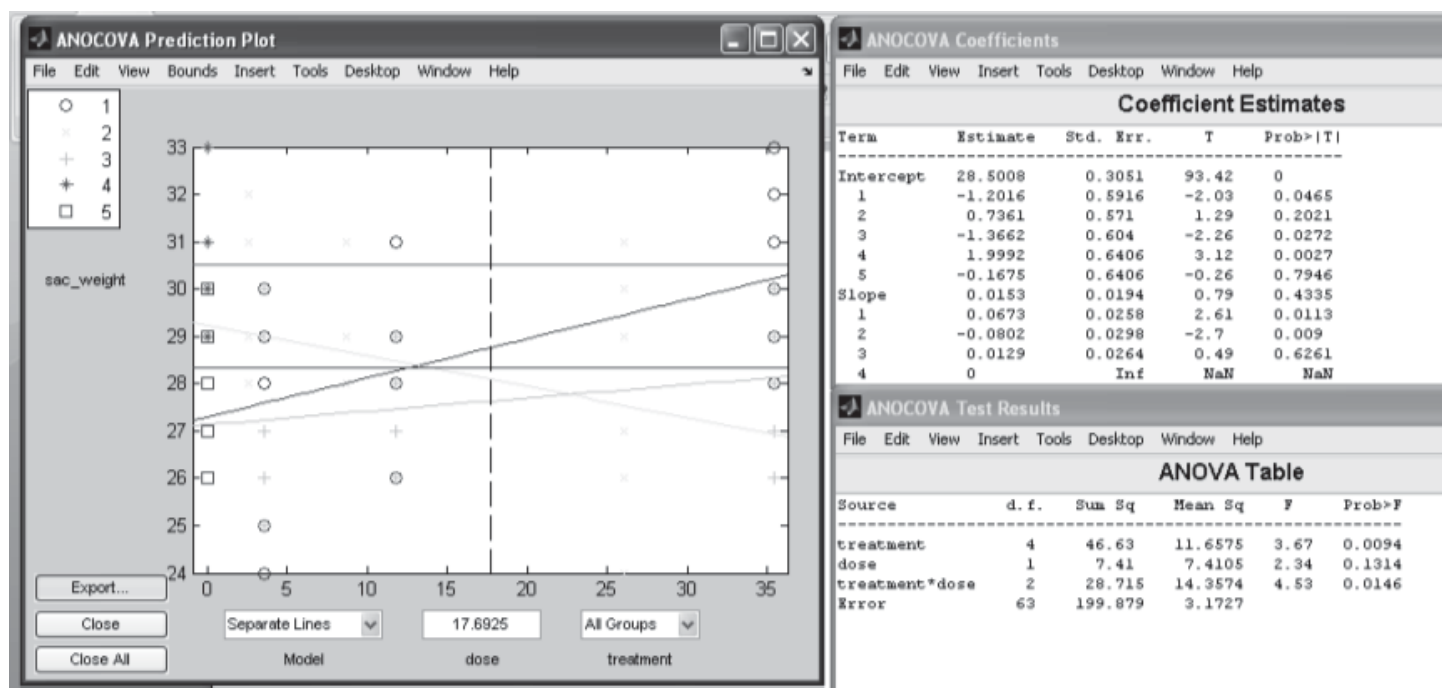

Figure 5.2: Dose response for weight at sacrifice

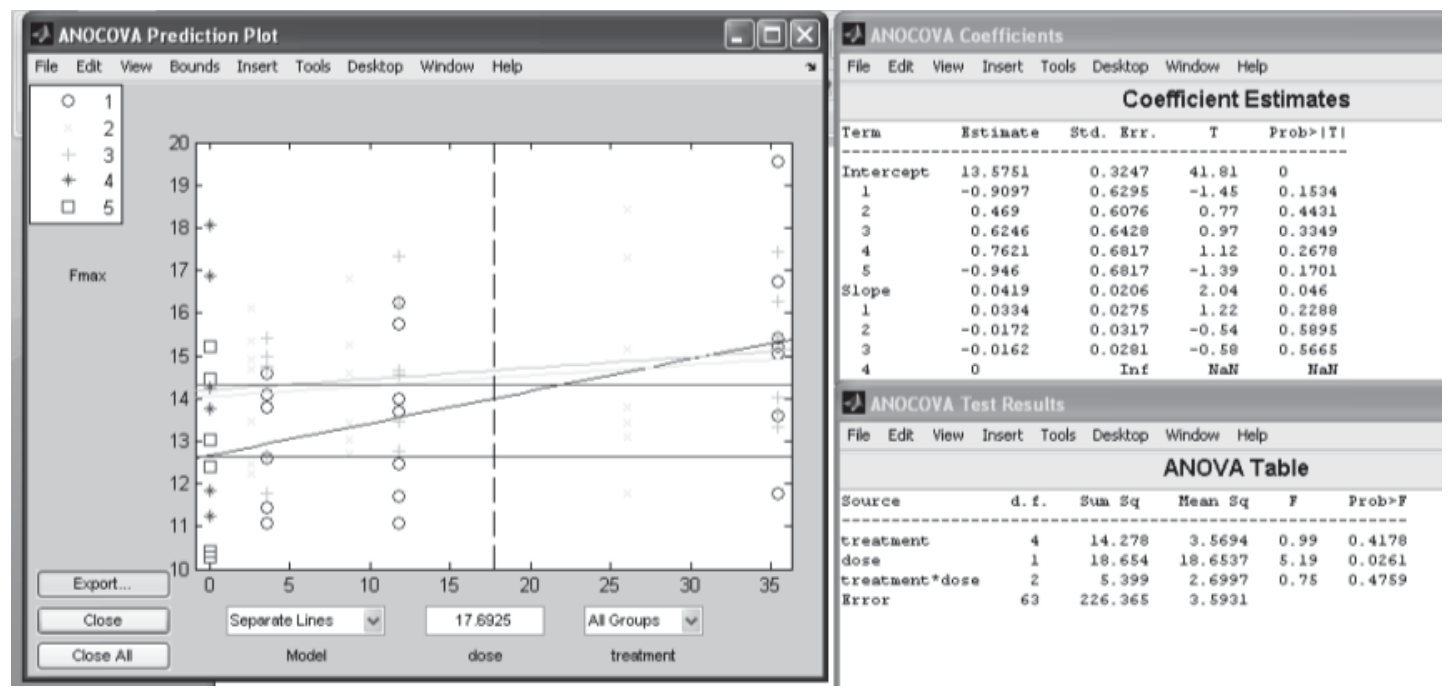

Figure 5.3: Dose response for Fmax 


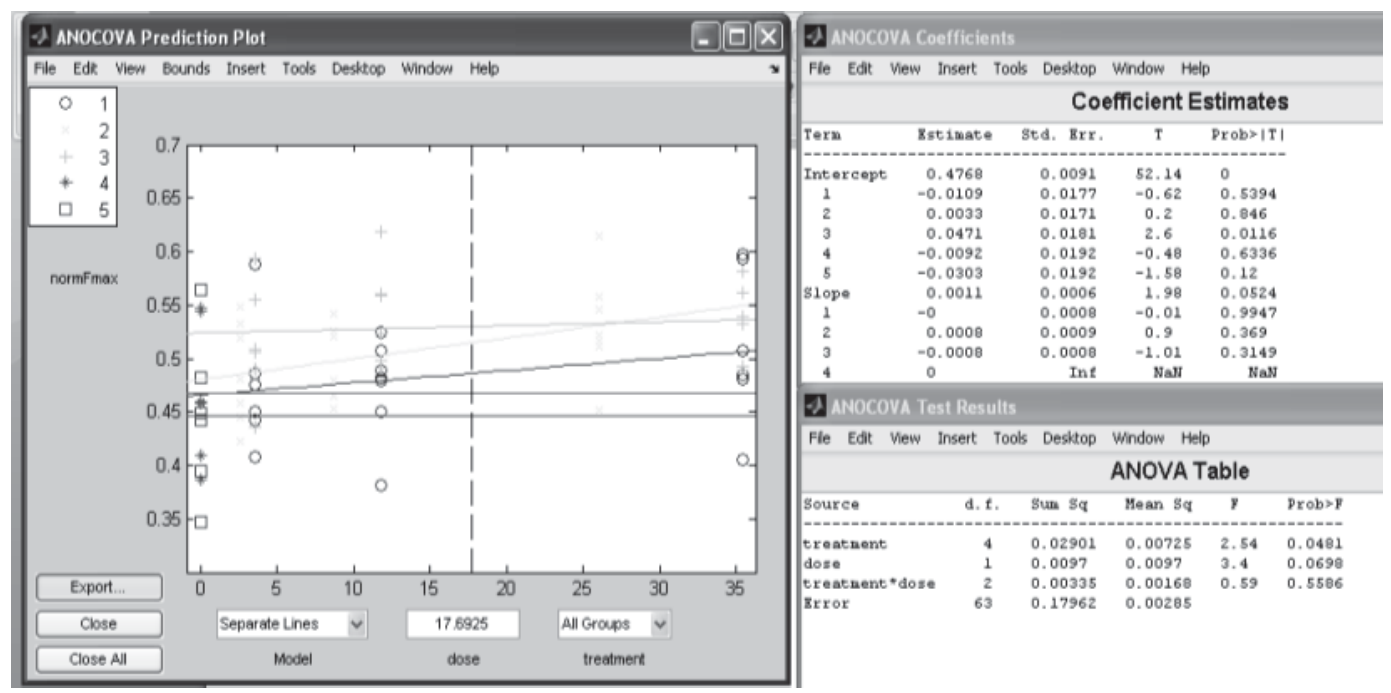

Figure 5.4: Dose response for normalizing Fmax

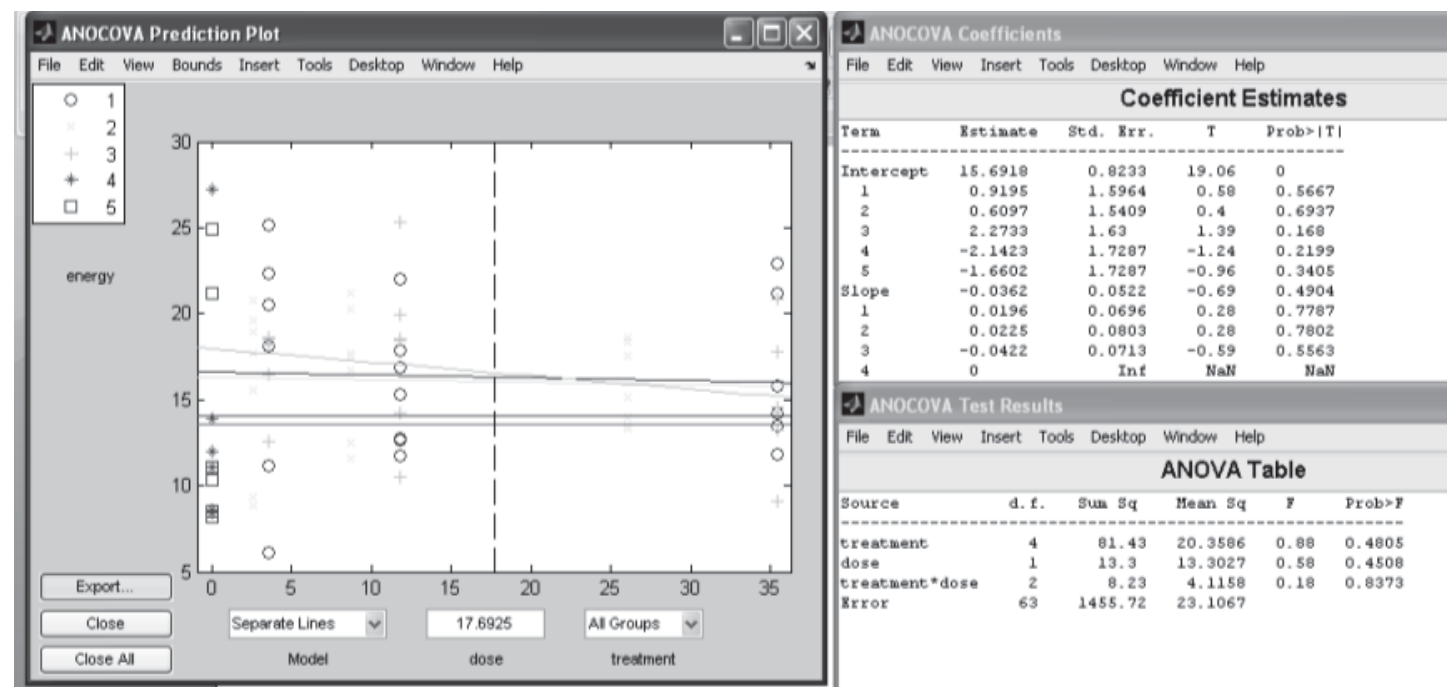

Figure 5.5: Dose response for energy to failure 


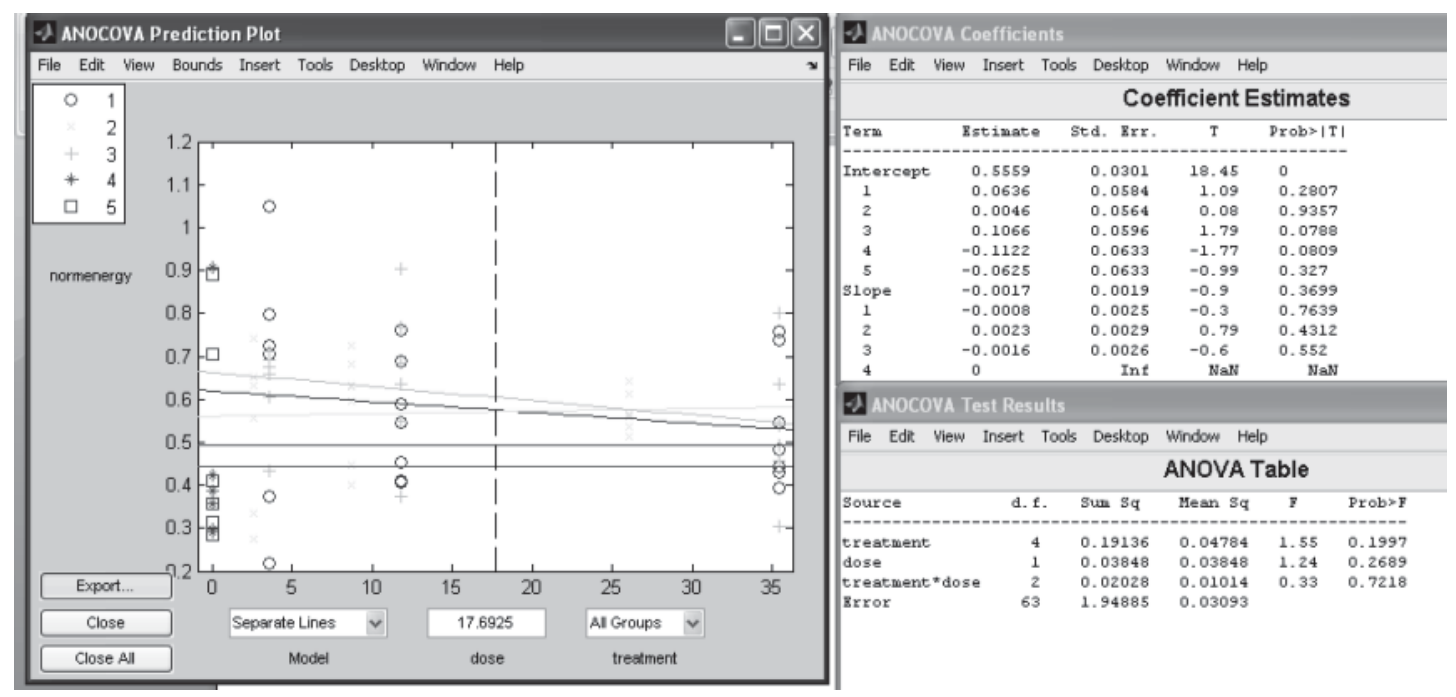

Figure 5.6: Dose response for normalized energy

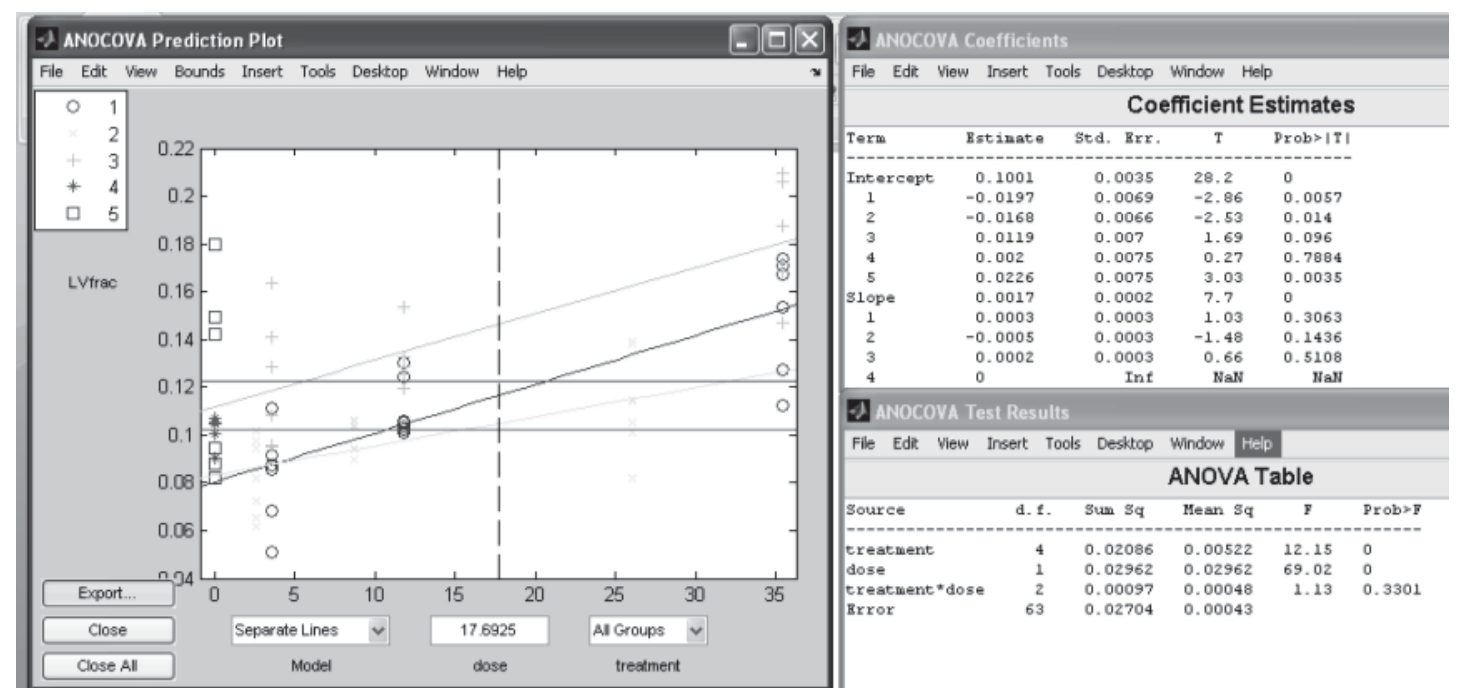

Figure 5.7: Dose response for $L V$ bone volume fraction 


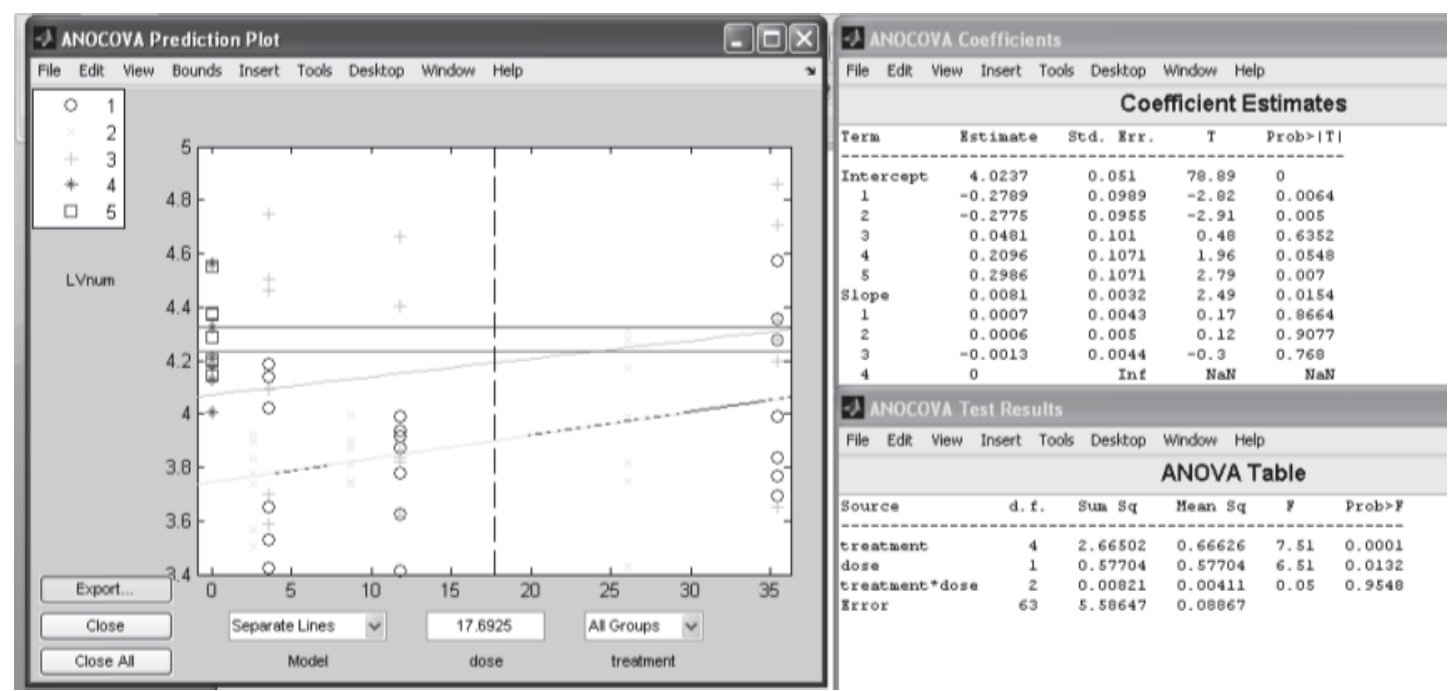

Figure 5.8: $\quad$ Dose $\quad$ response for $\quad$ LV trabecular number

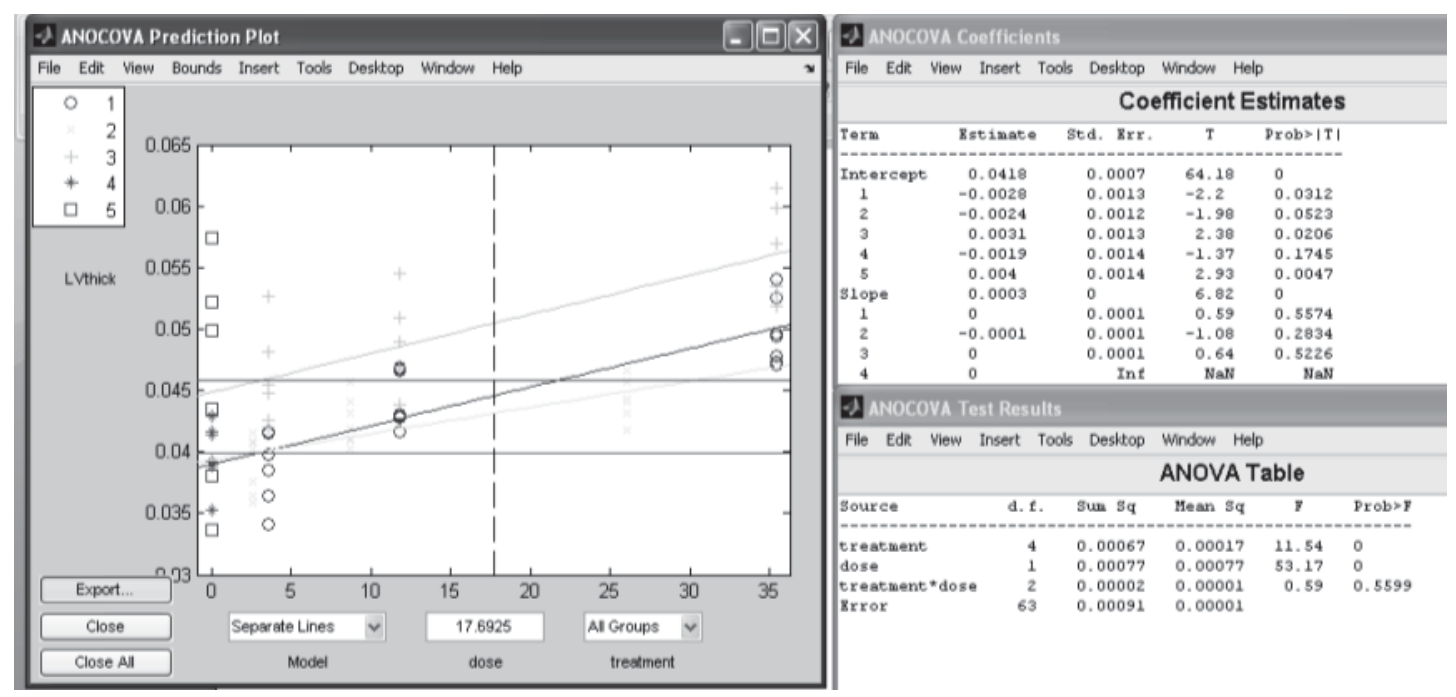

Figure 5.9: Dose response for $L V$ trabecular thickness 


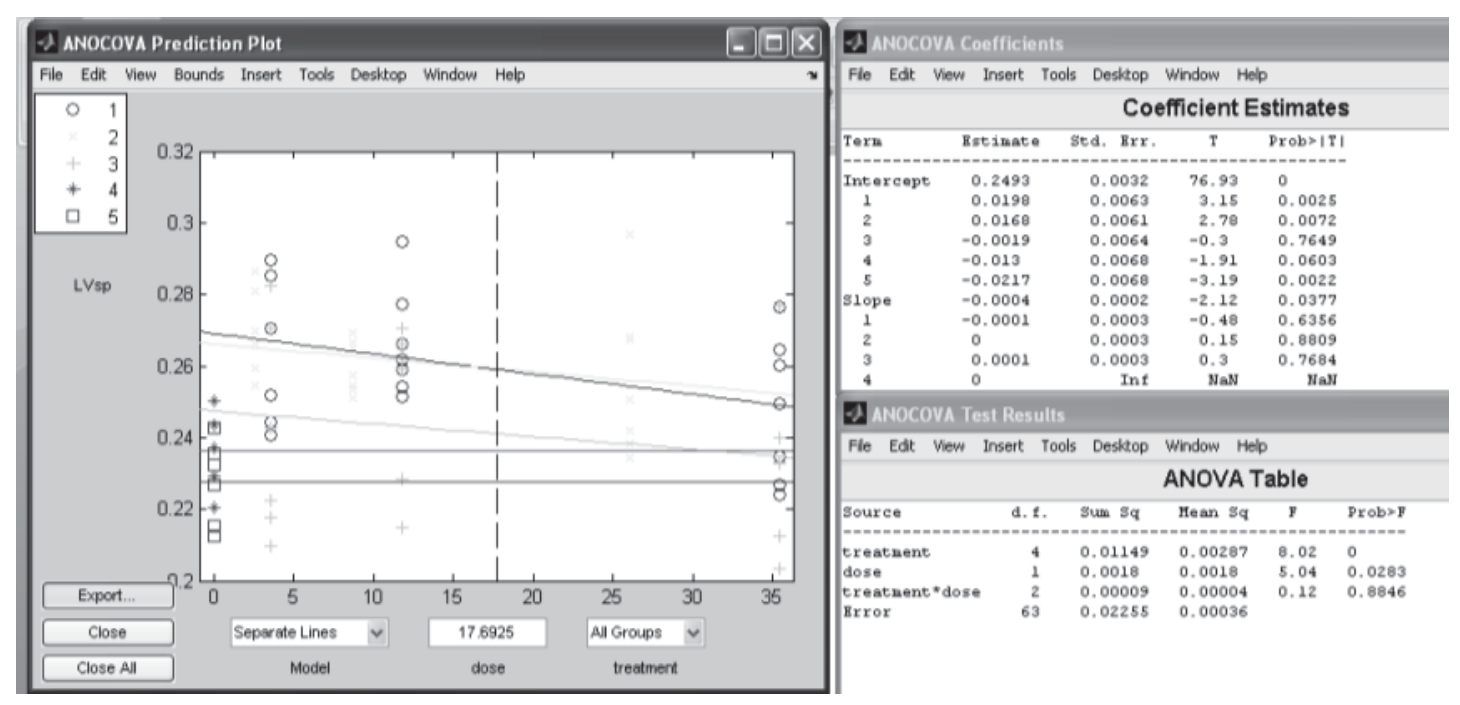

Figure 5.10: Dose response for $\quad$ LV trabecular spacing

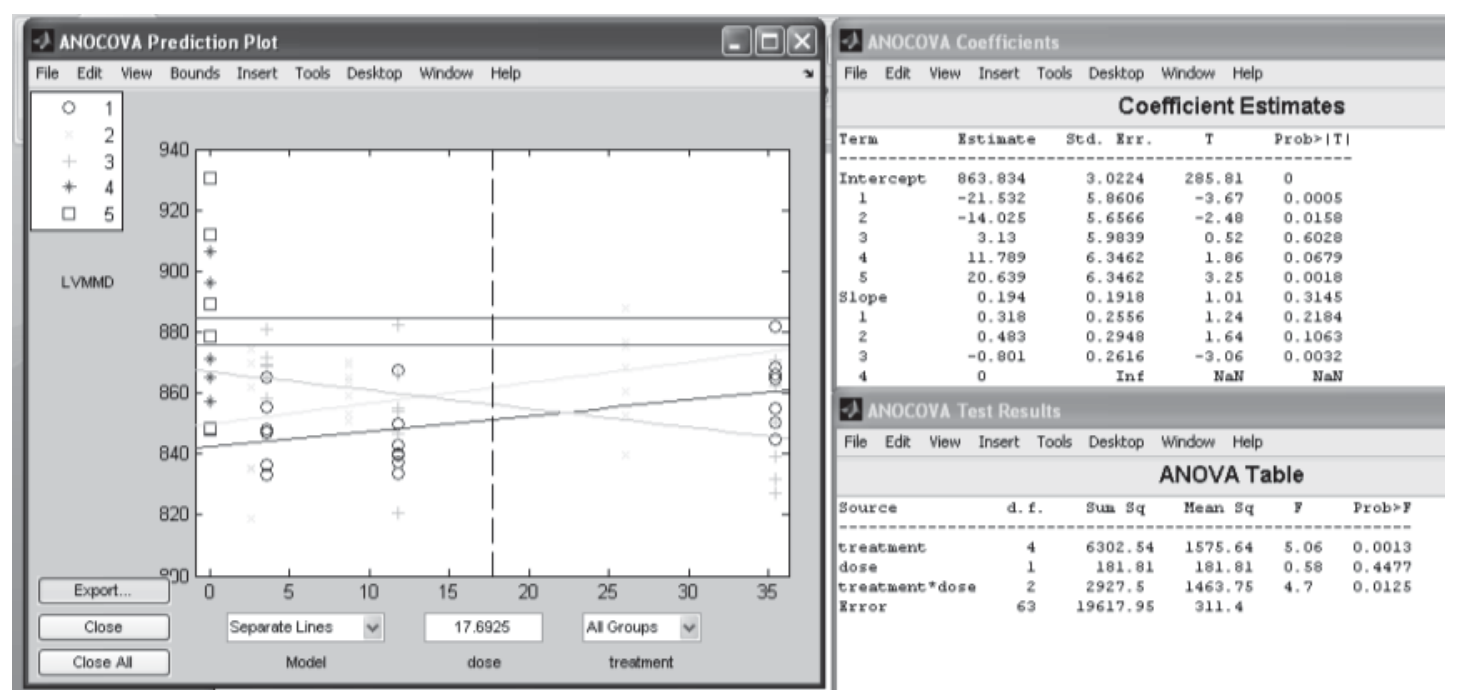

Figure 5.11: Dose response for LV MMD 


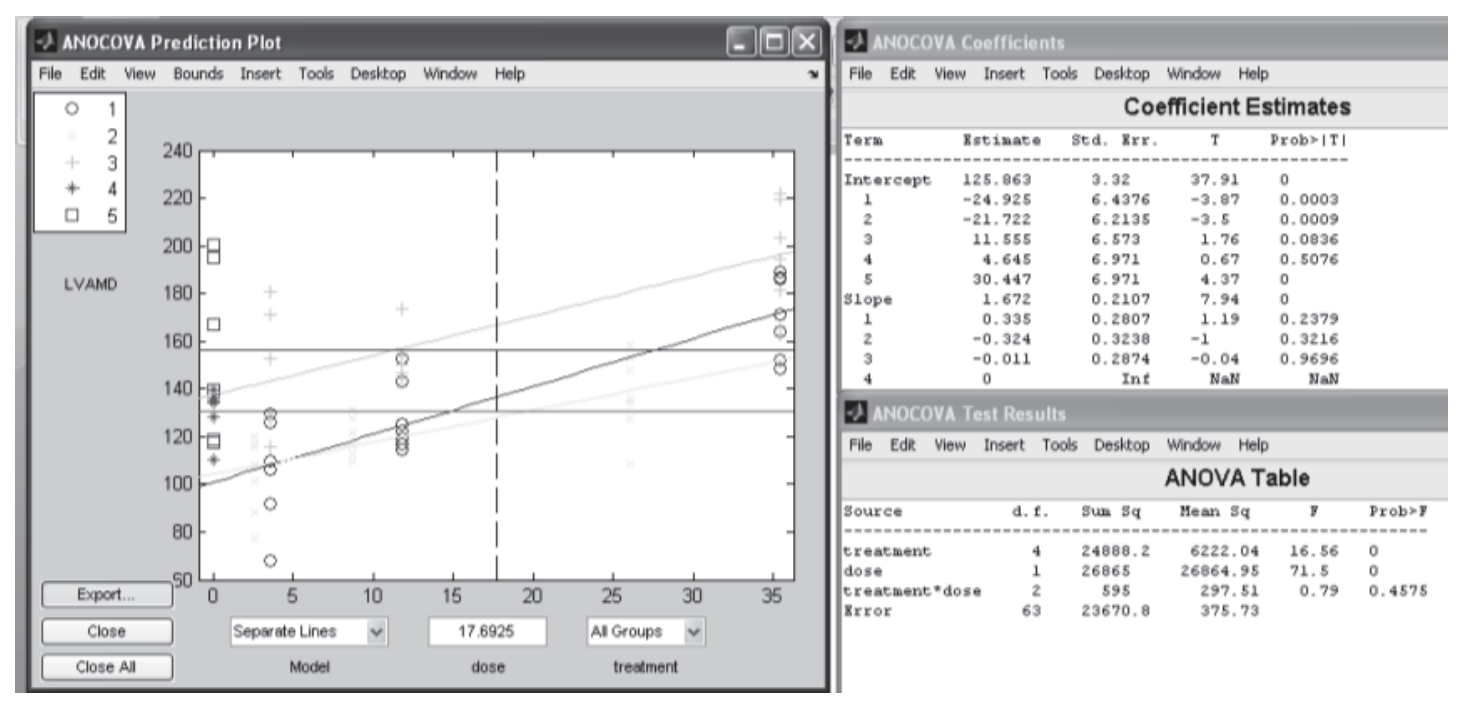

Figure 5.12: Dose response for $L V$ AMD

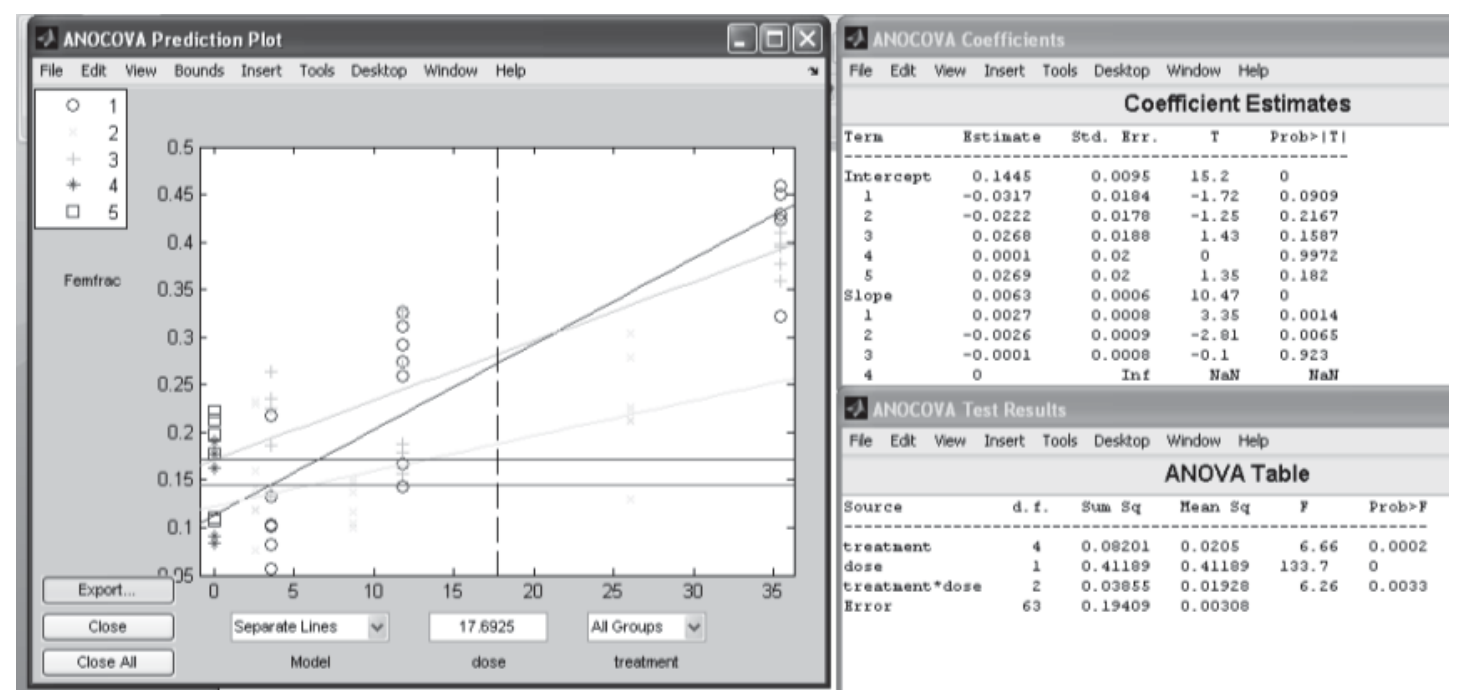

Figure 5.13: Dose response for femur bone volume fraction 


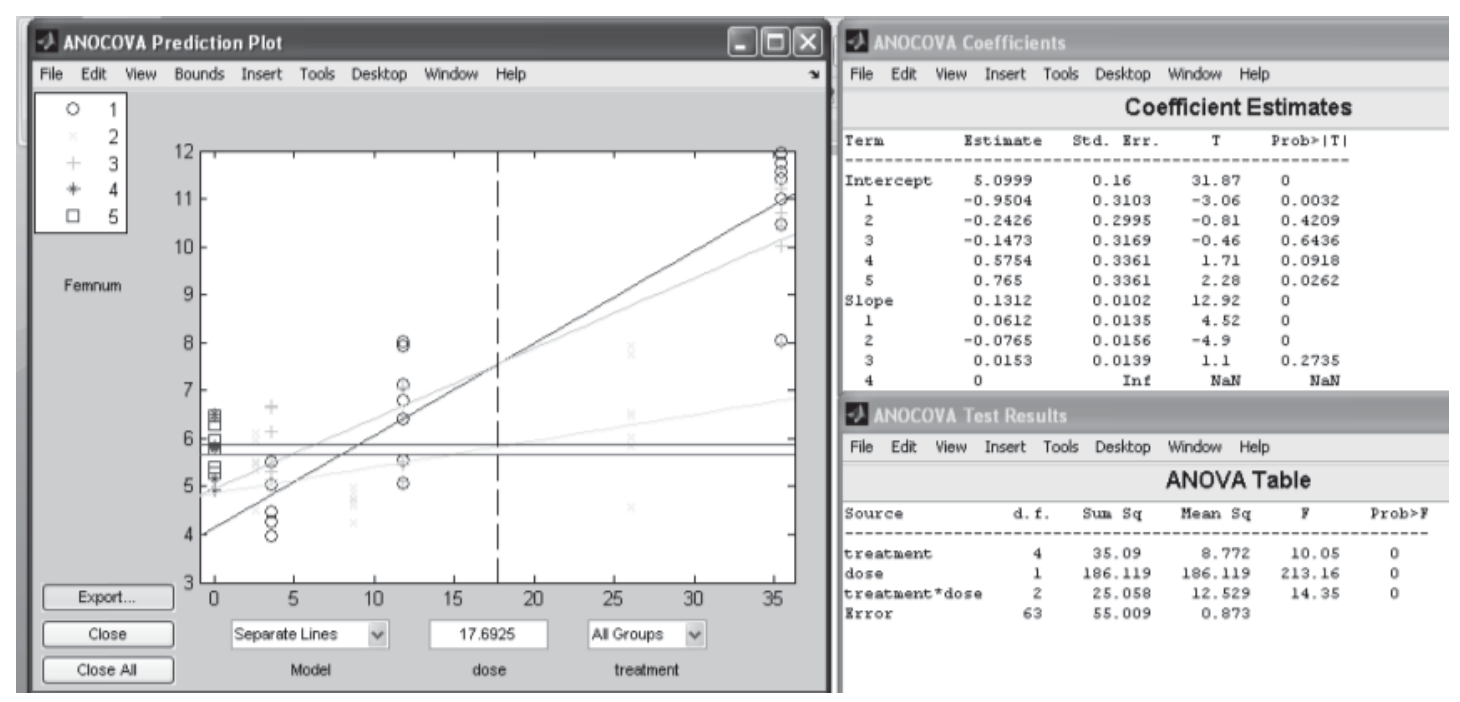

Figure 5.14: Dose response for femur trabecular number

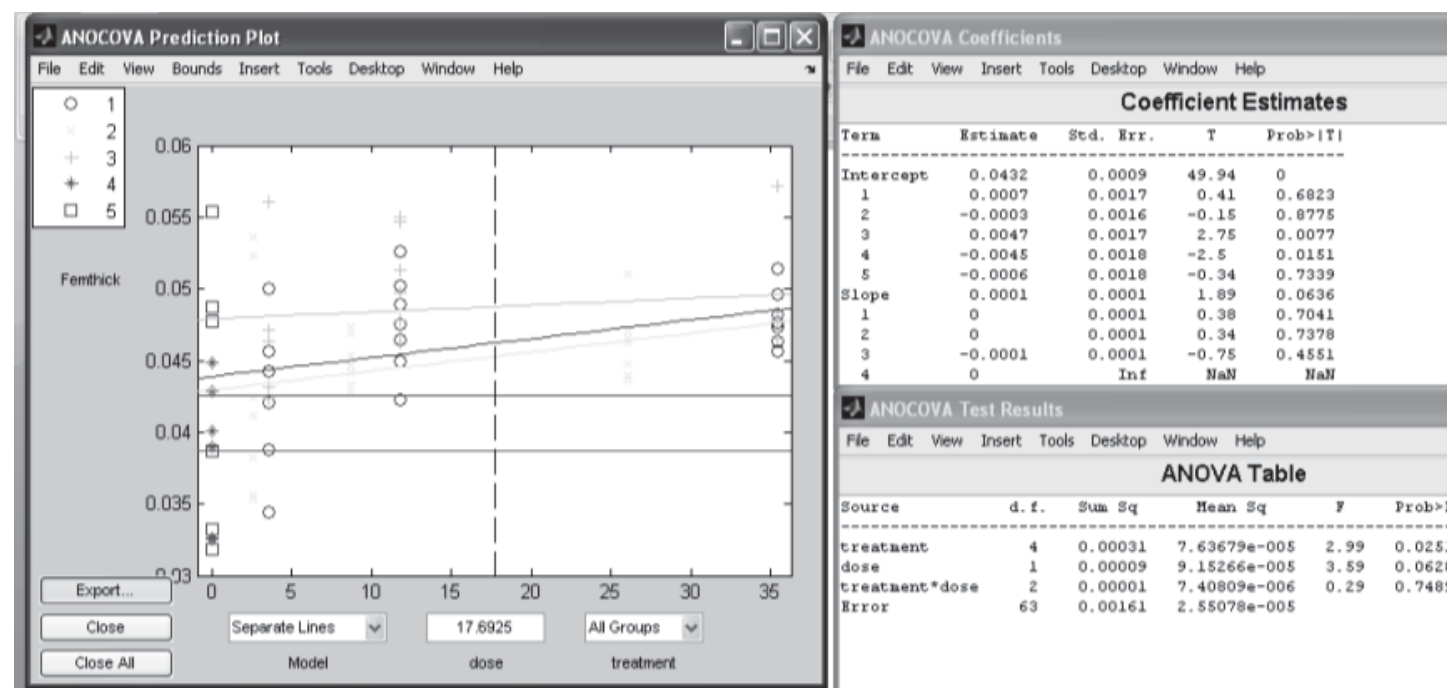

Figure 5.15: Dose response for femur trabecular thickness 


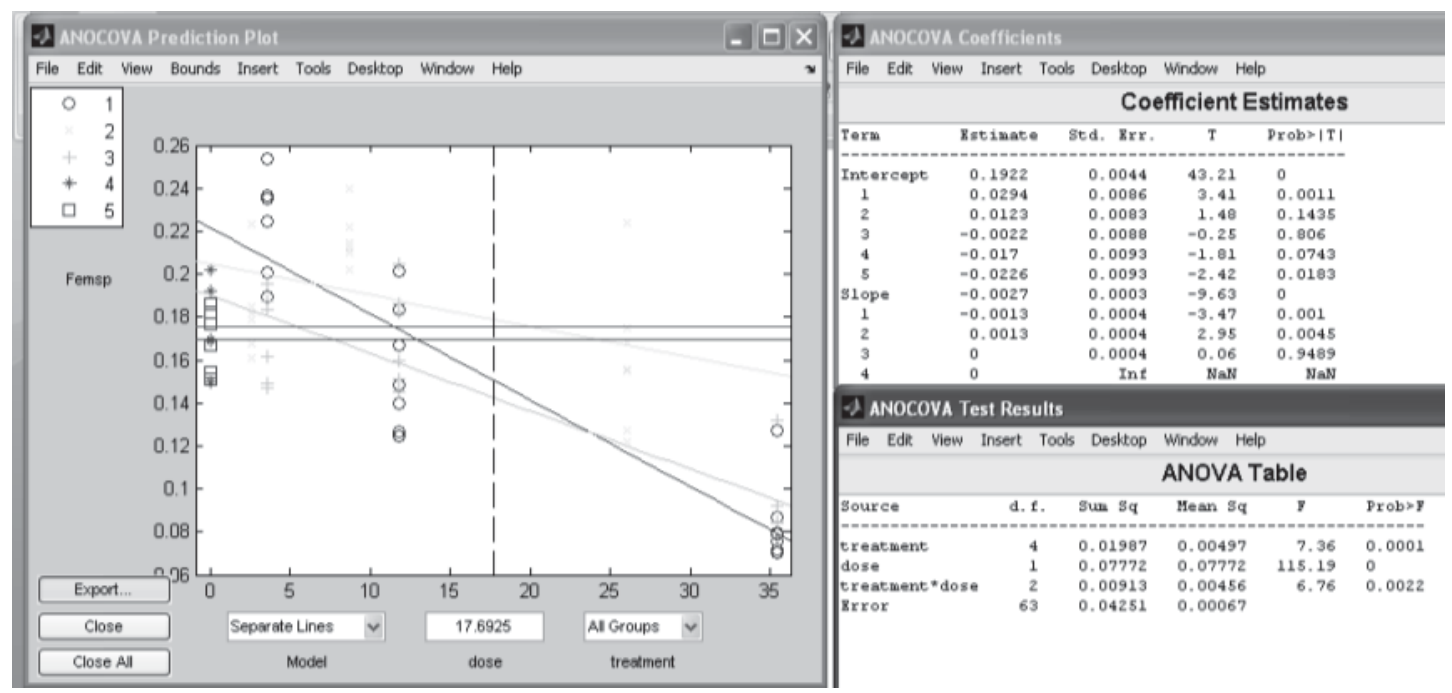

Figure 5.16: Dose response for femur trabecular spacing

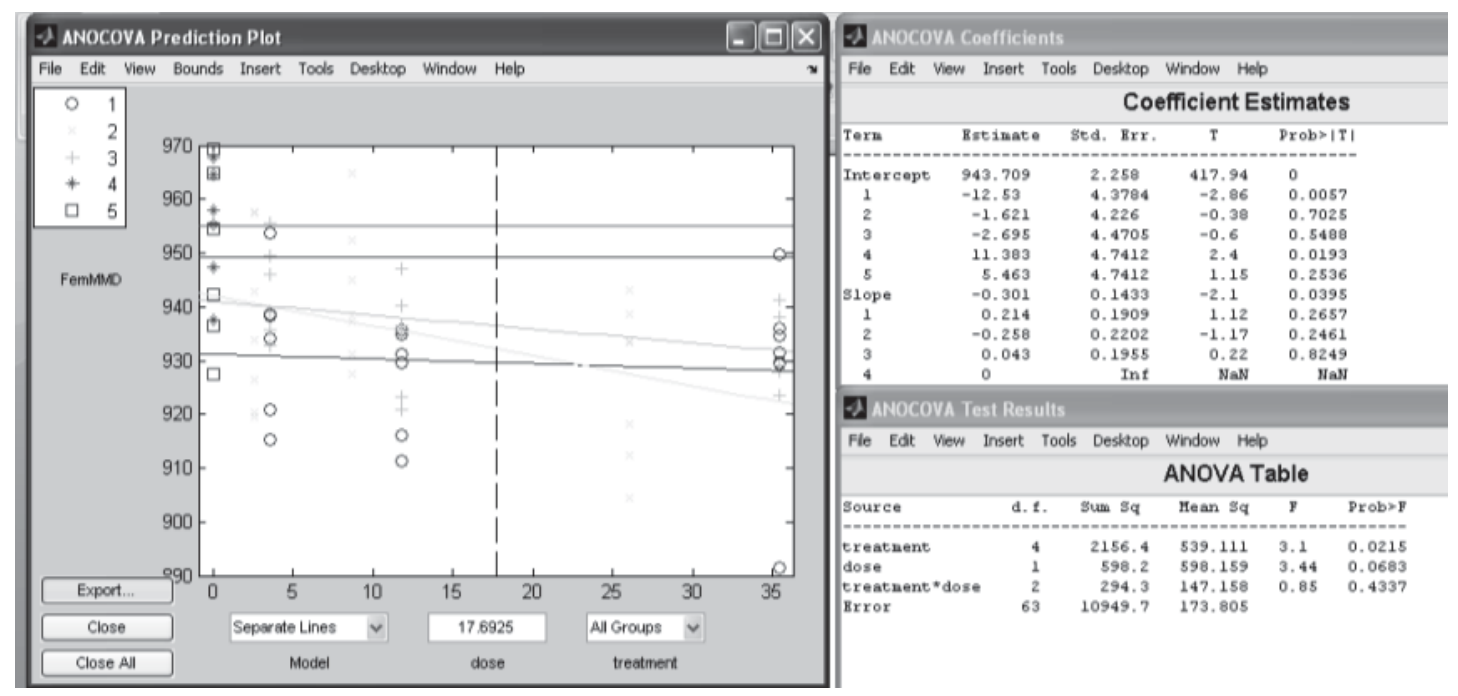

Figure 5.17: Dose response for femur MMD 


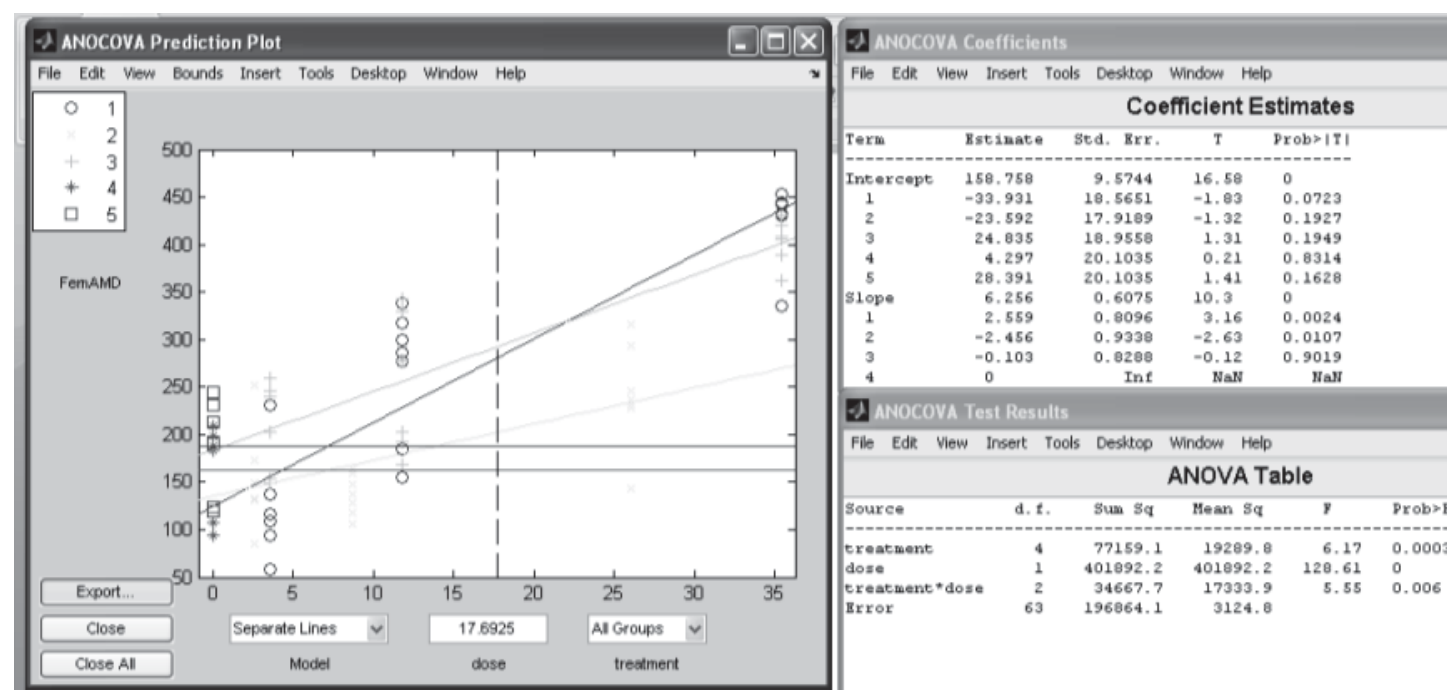

Figure 5.18: Dose response for femur AMD

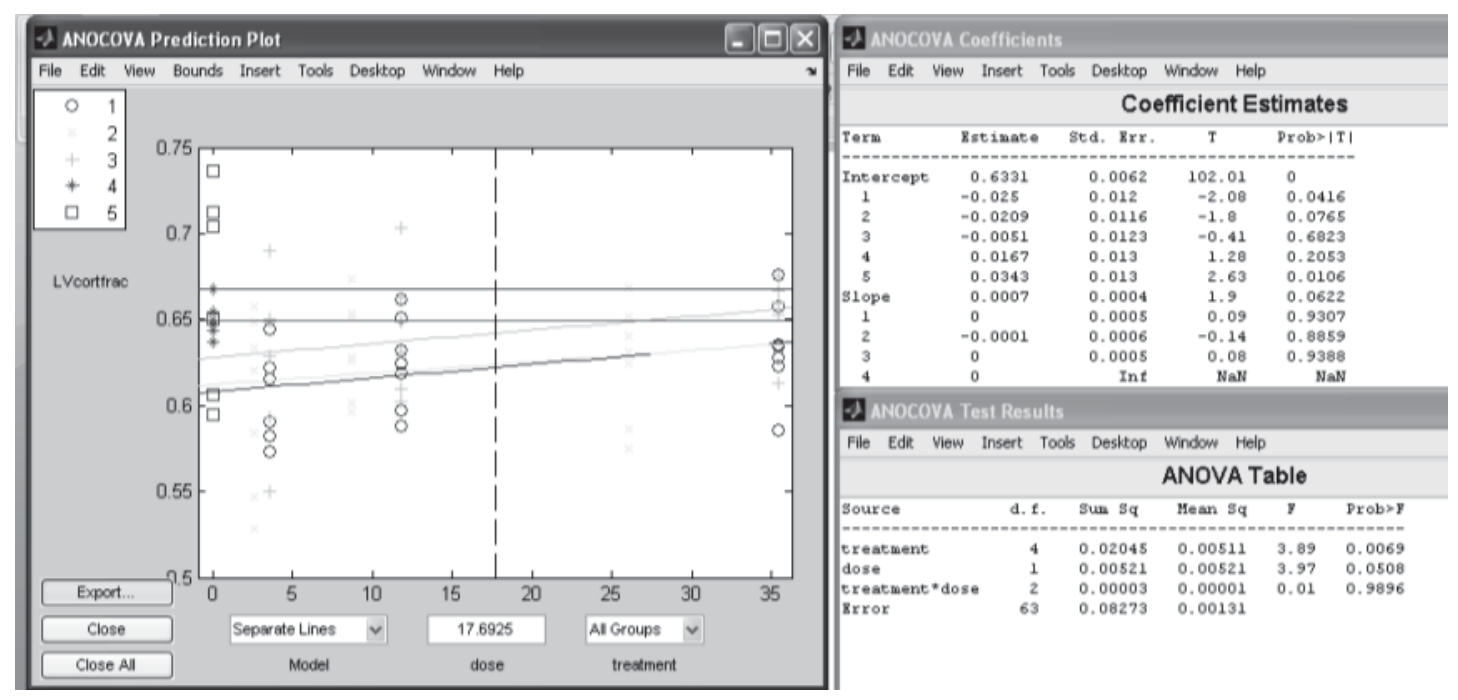

Figure 5.19: Dose response for $\mathrm{LV}$ cortical bone volume 


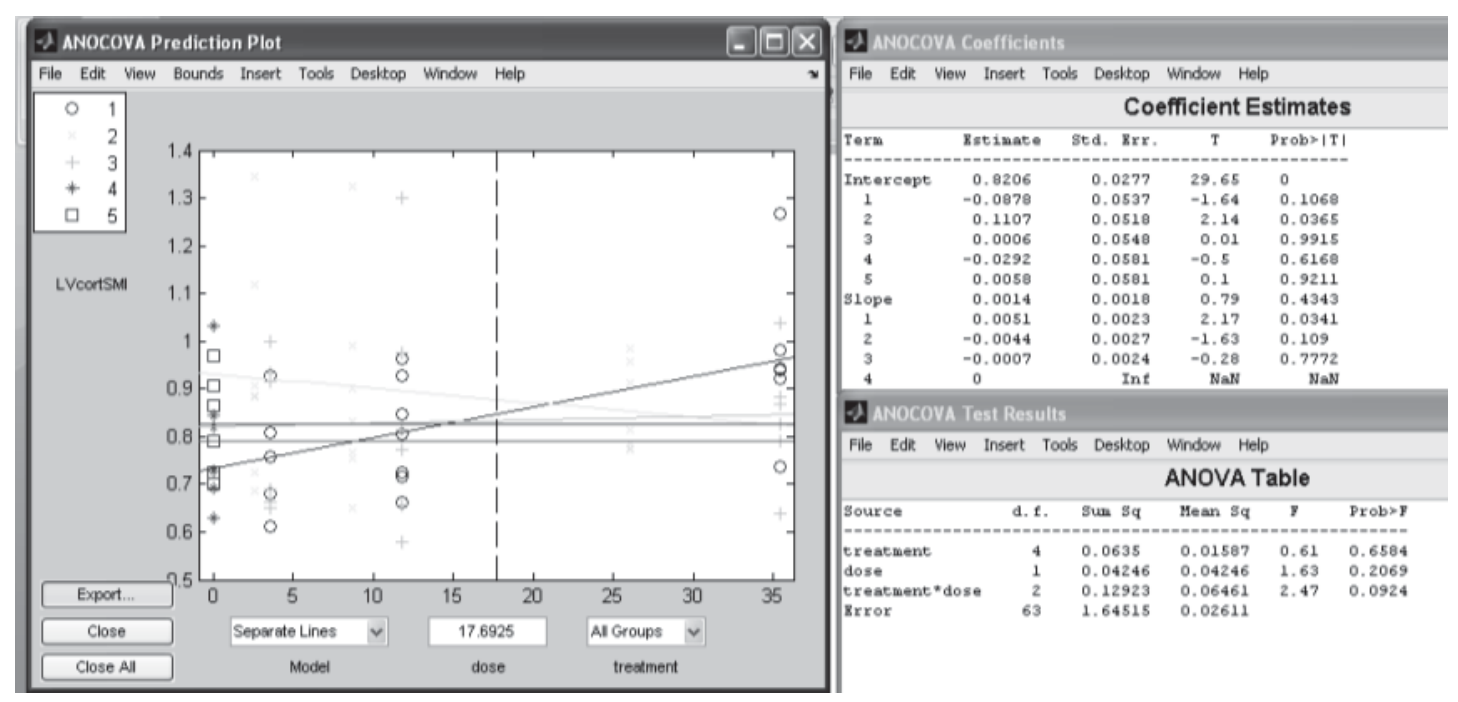

Figure 5.20: Dose response for $L V$ cortical structural modulus

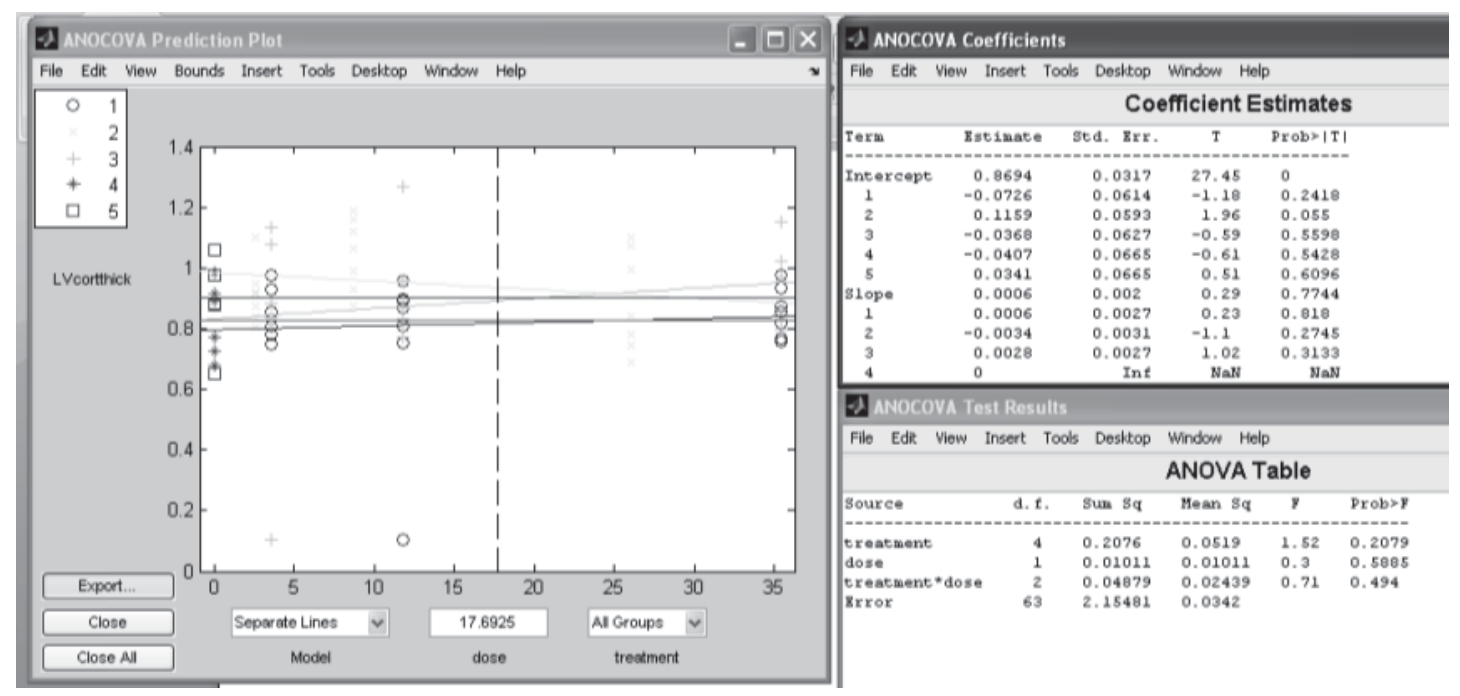

Figure 5.21: Dose response for $L V$ cortical thickness 


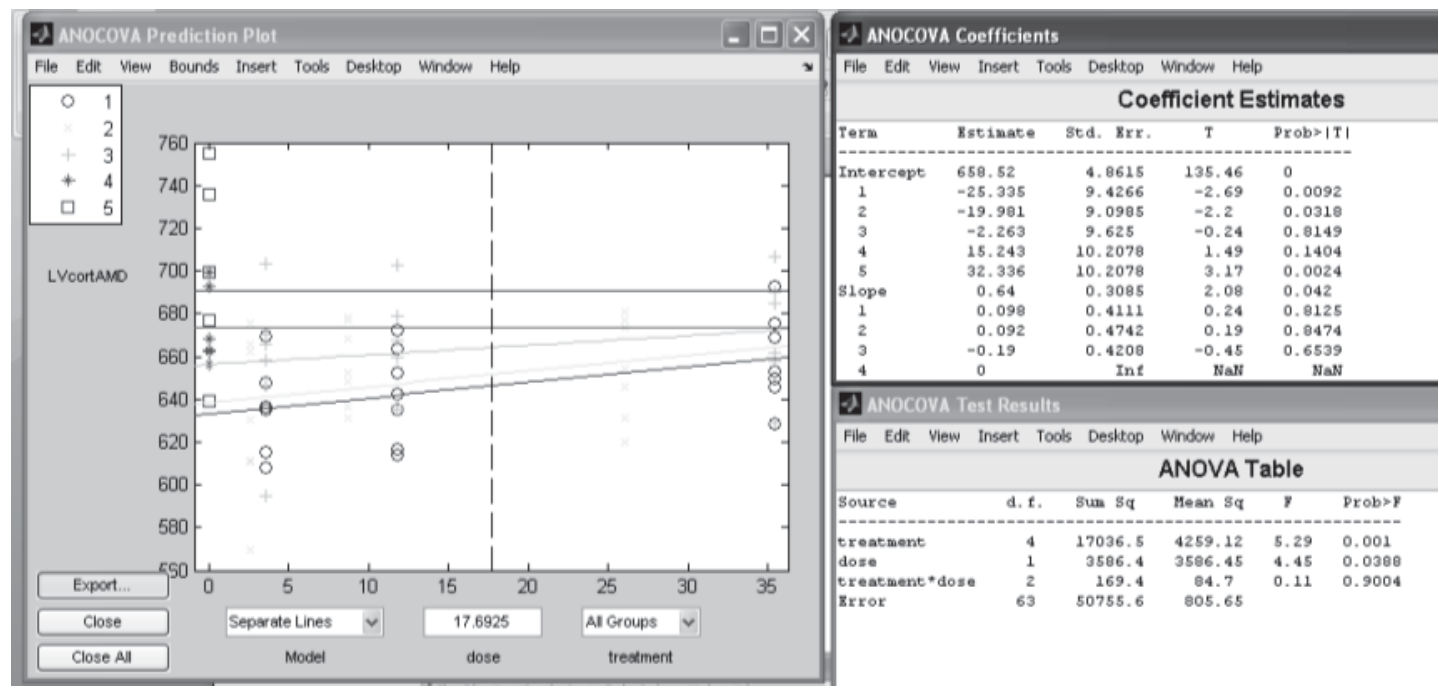

Figure 5.22: Dose response for $\mathrm{LV}$ cortical AMD

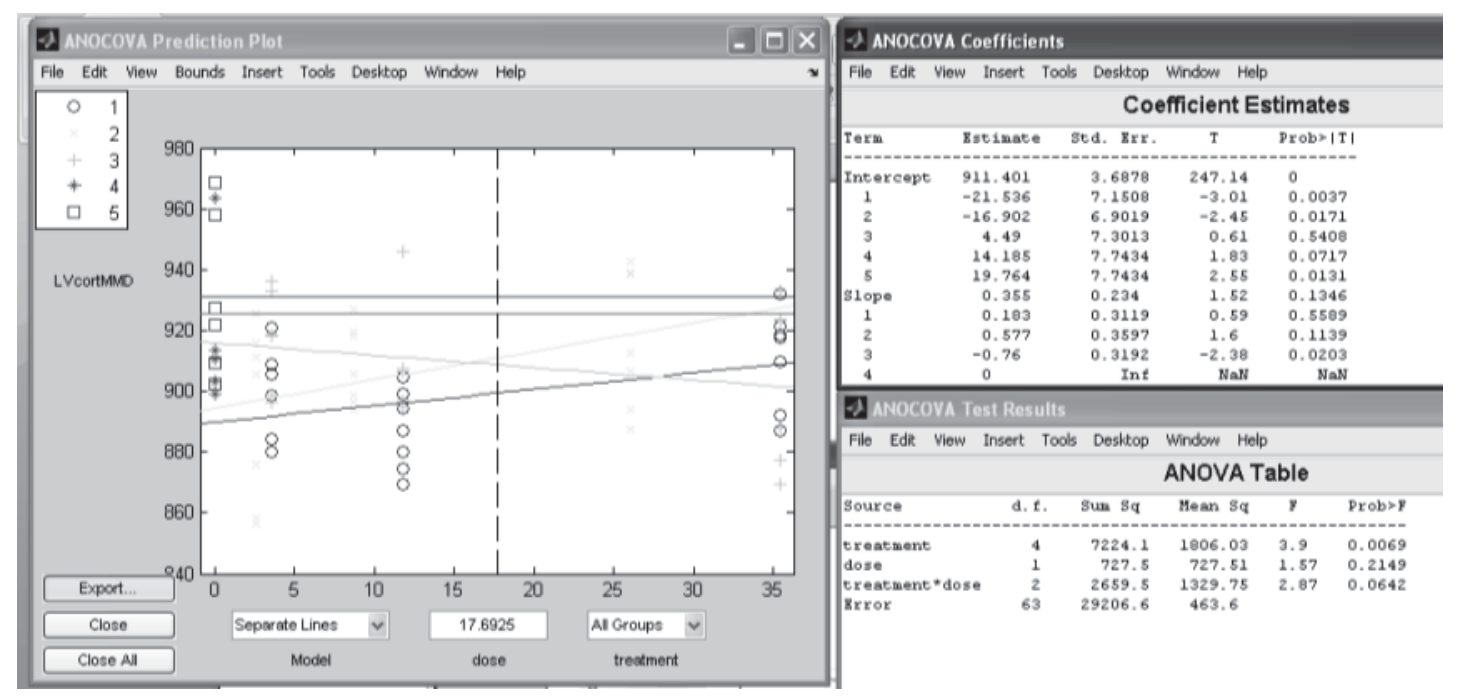

Figure 5.23: Dose response for $L V$ cortical MMD 


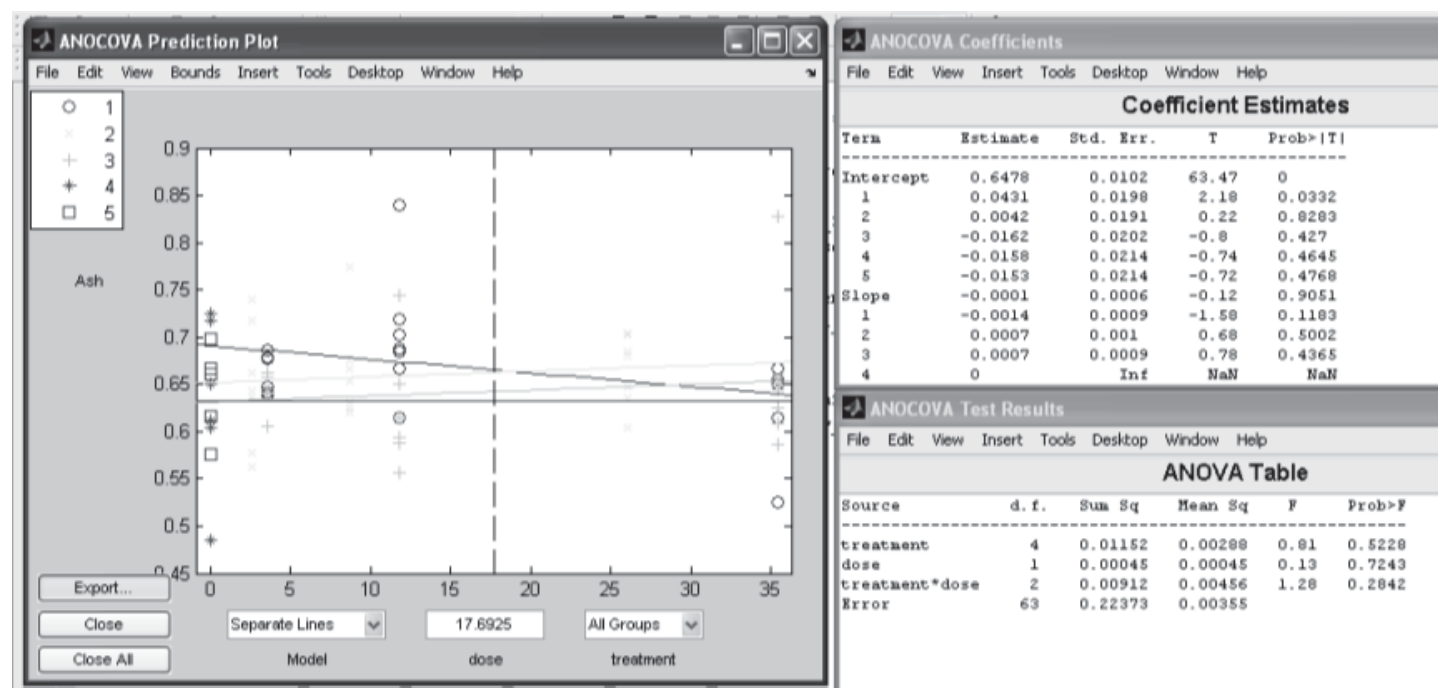

Figure 5.24: Dose response for ash fraction

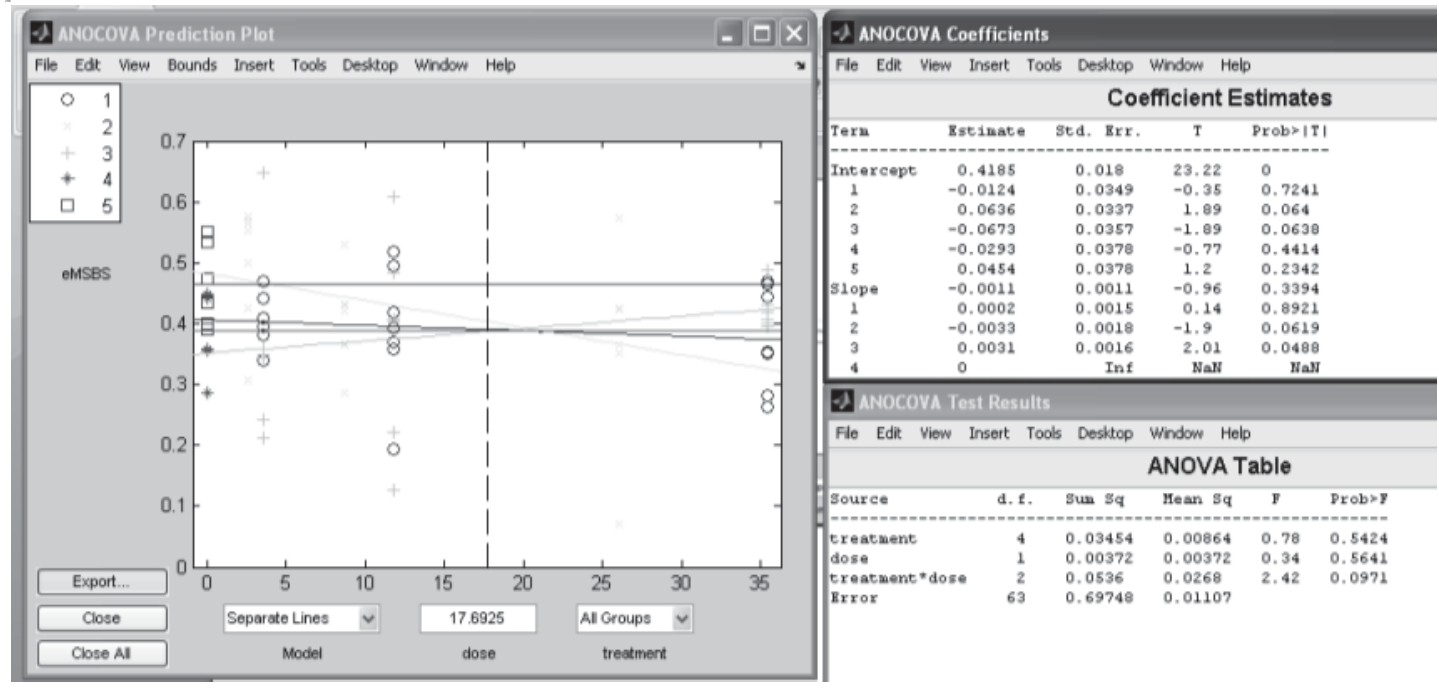

Figure 5.25: Dose response for endosteal mineralizing surface 


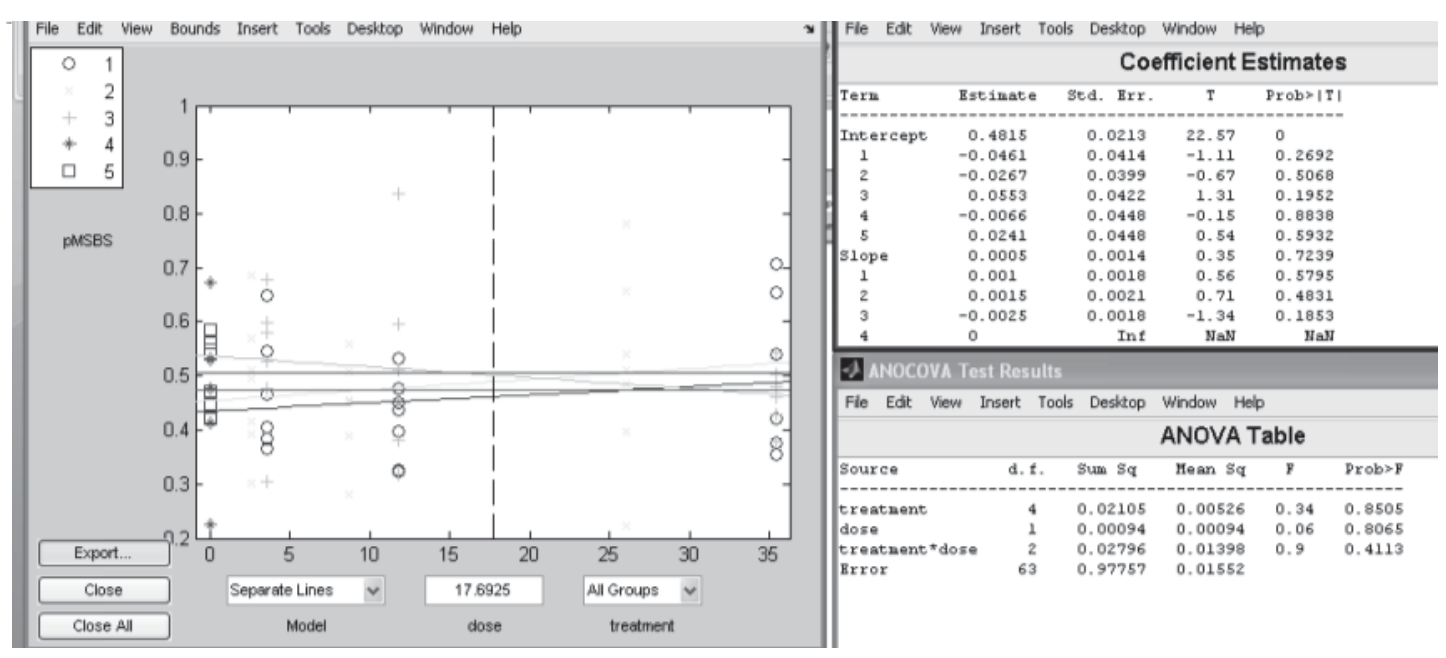

Figure 5.26: Dose response for periosteal mineralizing surface

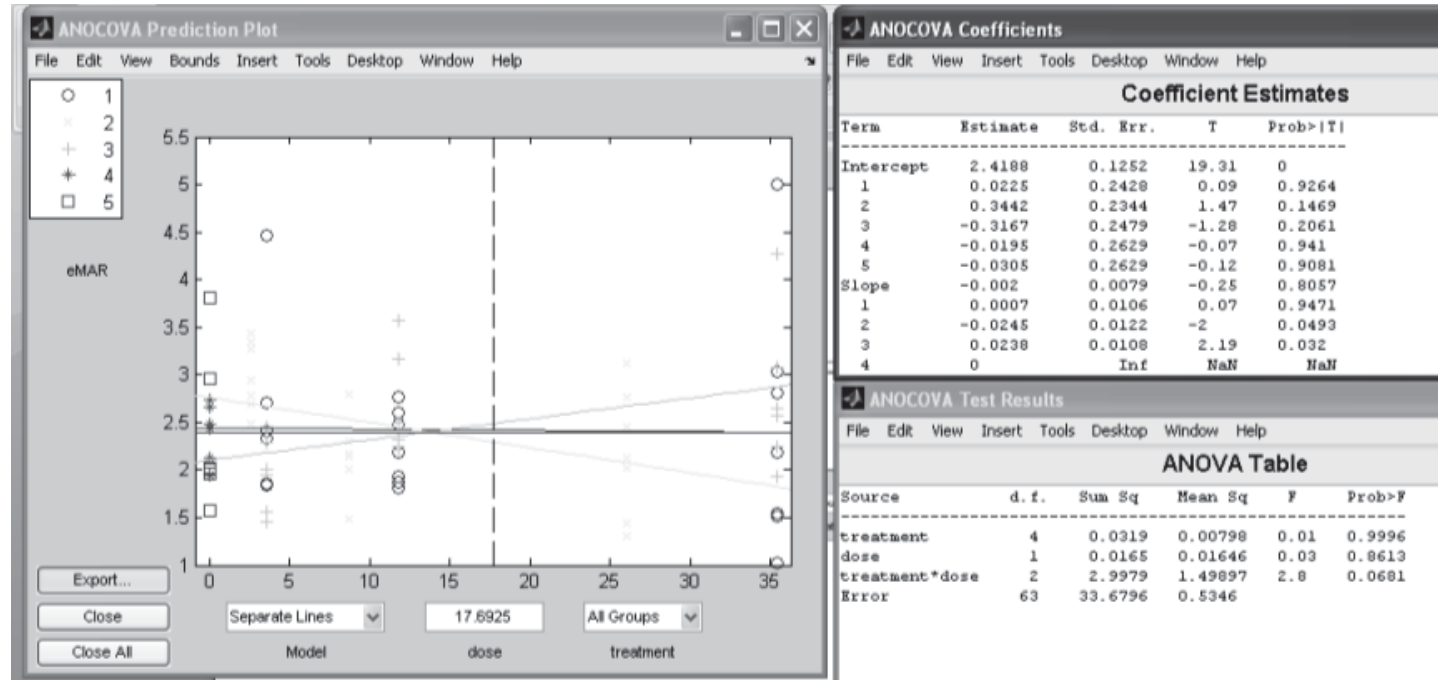

Figure 5.27: Dose response for endosteal mineral apposition rate 


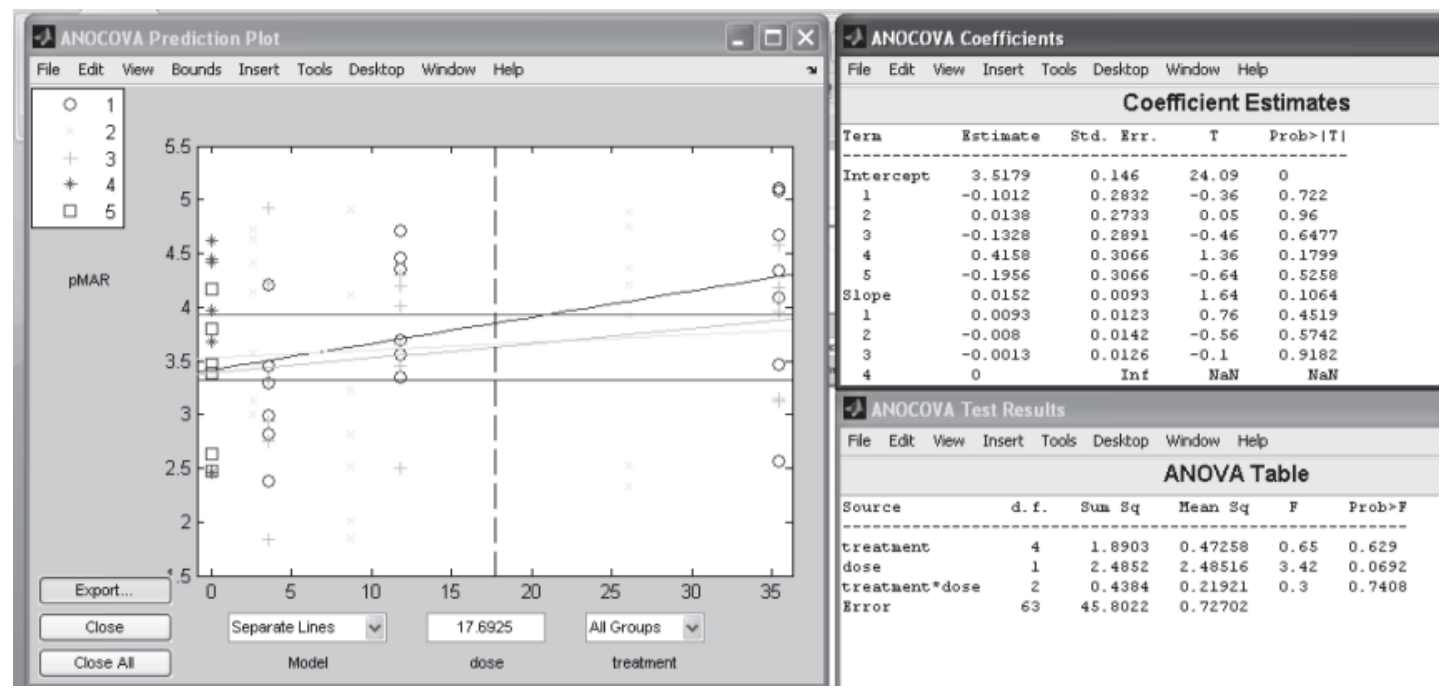

Figure 5.28: Dose response for periosteal mineral apposition rate 


\subsection{A.2 Dose Response Calculations Using the Delta Method}

95\% confidence interval determined using Delta Method

$\mu=$ wild type vehicle-treated mean

$\mathrm{a}=\mathrm{bbPTH}$ equation slope

$\mathrm{b}=\mathrm{bbPTH}$ equation intercept

$\mathrm{c}=\mathrm{hPTH}$ equation slope

$\mathrm{d}=\mathrm{hPTH}$ equation intercept

$\operatorname{var}(\mathrm{x})=$ variance of $\mathrm{x}$

$\operatorname{var}(g)=\operatorname{var}\left(\frac{\mu-a}{b} * \frac{d}{\mu-c}\right)$

$\operatorname{var}(g)=\operatorname{var}(\mu)\left(\frac{d g}{d \mu}\right)^{2}+\operatorname{var}(b)\left(\frac{d g}{d b}\right)^{2}+\operatorname{var}(d)\left(\frac{d g}{d d}\right)^{2}+\operatorname{var}(a)\left(\frac{d g}{d a}\right)^{2}$

$+\operatorname{var}(c)\left(\frac{d g}{d c}\right)^{2}+2 \operatorname{covar}(a, b)\left(\frac{d g}{d a}\right)\left(\frac{d g}{d b}\right)+2 \operatorname{covar}(c, d)\left(\frac{d g}{d c}\right)\left(\frac{d g}{d d}\right)$ 
Relative potency calculated as ratio of dose of hPTH to achieve wild type vehicle levels to bbPTH dose to achieve wild type levels

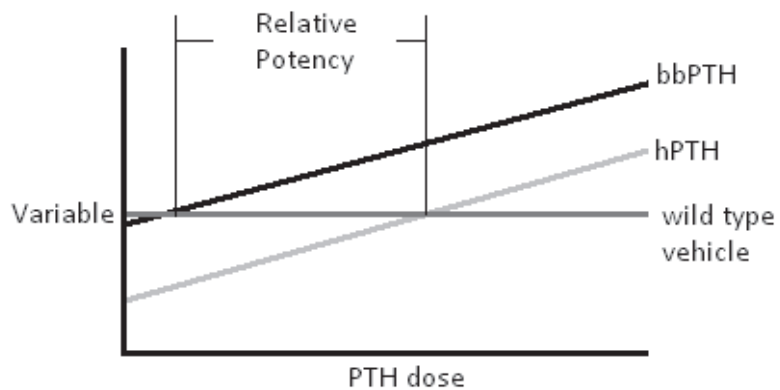

Figure 5.29: Sketch indicating determination of relative potency occurs at wild type vehicle levels 


\title{
5.3 A.3 Copyright Clearance
}

\author{
ELSEVIER LICENSE \\ TERMS AND CONDITIONS
}

Aug 31, 2012

This is a License Agreement between Sarah Gray ("You") and Elsevier ("Elsevier") provided by Copyright Clearance Center ("CCC"). The license consists of your order details, the terms and conditions provided by Elsevier, and the payment terms and conditions.

\begin{tabular}{|c|c|}
\hline \multicolumn{2}{|c|}{$\begin{array}{l}\text { All payments must be made in full to CCC. For payment instructions, please see } \\
\text { information listed at the bottom of this form. }\end{array}$} \\
\hline Supplier & $\begin{array}{l}\text { Elsevier Limited } \\
\text { The Boulevard,Langford Lane } \\
\text { Kidlington,Oxford,OX5 1GB,UK }\end{array}$ \\
\hline $\begin{array}{l}\text { Registered Company } \\
\text { Number }\end{array}$ & 1982084 \\
\hline Customer name & Sarah Gray \\
\hline \multirow[t]{2}{*}{ Customer address } & 813 S Lincoln Dr \\
\hline & Hancock, MI 49930 \\
\hline License number & 2977770573698 \\
\hline License date & Aug 28, 2012 \\
\hline Licensed content publisher & Elsevier \\
\hline $\begin{array}{l}\text { Licensed content } \\
\text { publication }\end{array}$ & Bone \\
\hline Licensed content title & $\begin{array}{l}\text { Black bear parathyroid hormone has greater anabolic effects on } \\
\text { trabecular bone in dystrophin-deficient mice than in wild type mice }\end{array}$ \\
\hline Licensed content author & $\begin{array}{l}\text { Sarah K. Gray,Meghan E. McGee-Lawrence,Jennifer L. } \\
\text { Sanders,Keith W. Condon,Chung-Jui Tsai,Seth W. Donahue }\end{array}$ \\
\hline Licensed content date & September 2012 \\
\hline
\end{tabular}




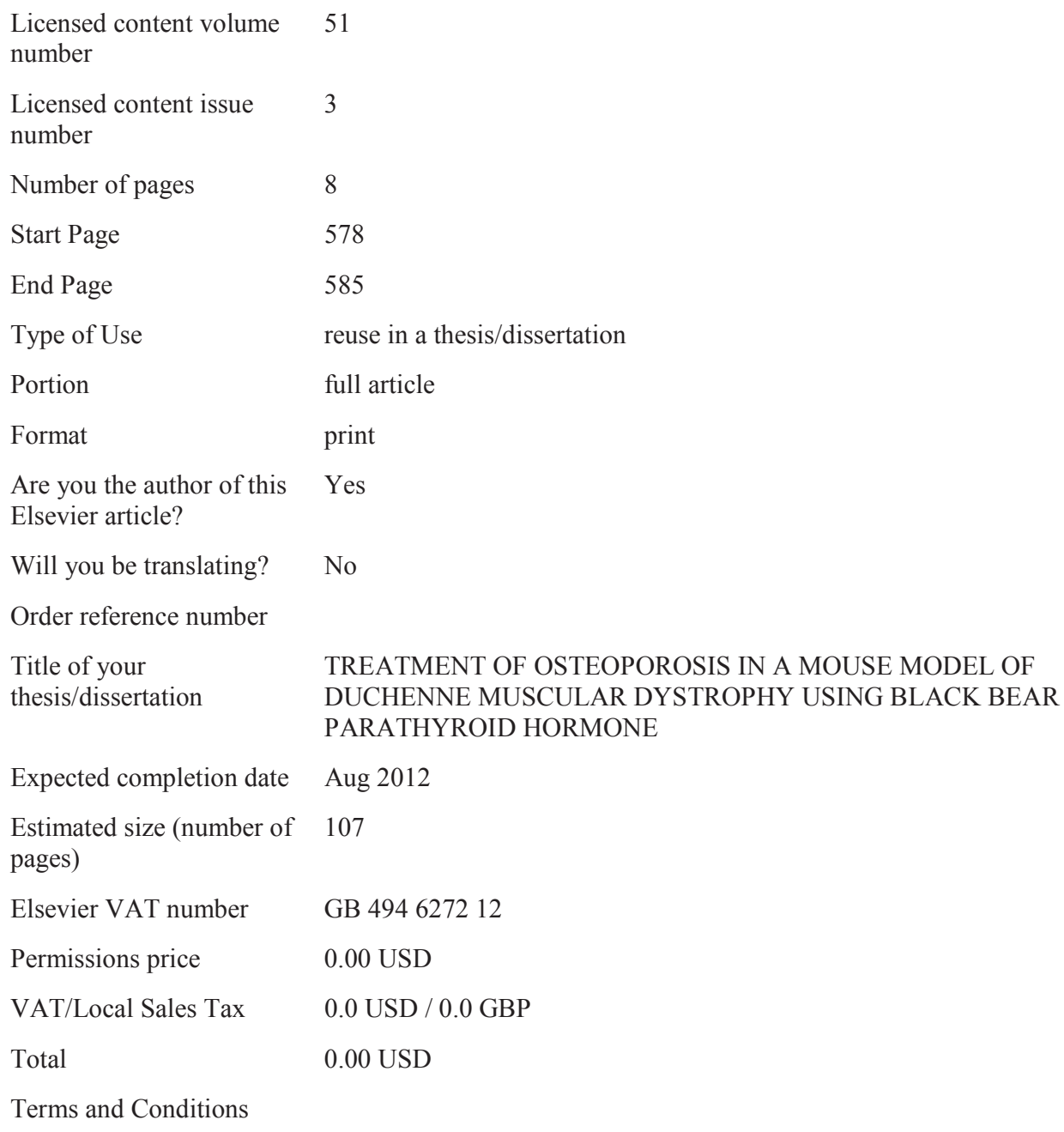

Terms and Conditions

\section{INTRODUCTION}

1. The publisher for this copyrighted material is Elsevier. By clicking "accept" in connection with completing this licensing transaction, you agree that the following terms and conditions apply to this transaction (along with the Billing and Payment terms and conditions established by Copyright Clearance Center, Inc. ("CCC"), at the time that you opened your Rightslink account and that are available at any time at http://myaccount.copyright.com).

\section{GENERAL TERMS}


2. Elsevier hereby grants you permission to reproduce the aforementioned material subject to the terms and conditions indicated.

3. Acknowledgement: If any part of the material to be used (for example, figures) has appeared in our publication with credit or acknowledgement to another source, permission must also be sought from that source. If such permission is not obtained then that material may not be included in your publication/copies. Suitable acknowledgement to the source must be made, either as a footnote or in a reference list at the end of your publication, as follows:

"Reprinted from Publication title, Vol /edition number, Author(s), Title of article / title of chapter, Pages No., Copyright (Year), with permission from Elsevier [OR APPLICABLE SOCIETY COPYRIGHT OWNER].” Also Lancet special credit - "Reprinted from The Lancet, Vol. number, Author(s), Title of article, Pages No., Copyright (Year), with permission from Elsevier."

4. Reproduction of this material is confined to the purpose and/or media for which permission is hereby given.

\section{Altering/Modifying Material: Not Permitted. However figures and} illustrations may be altered/adapted minimally to serve your work. Any other abbreviations, additions, deletions and/or any other alterations shall be made only with prior written authorization of Elsevier Ltd. (Please contact Elsevier at permissions@elsevier.com)

6. If the permission fee for the requested use of our material is waived in 
this instance, please be advised that your future requests for Elsevier materials may attract a fee.

7. Reservation of Rights: Publisher reserves all rights not specifically granted in the combination of (i) the license details provided by you and accepted in the course of this licensing transaction, (ii) these terms and conditions and (iii) CCC's Billing and Payment terms and conditions.

8. License Contingent Upon Payment: While you may exercise the rights licensed immediately upon issuance of the license at the end of the licensing process for the transaction, provided that you have disclosed complete and accurate details of your proposed use, no license is finally effective unless and until full payment is received from you (either by publisher or by CCC) as provided in CCC's Billing and Payment terms and conditions. If full payment is not received on a timely basis, then any license preliminarily granted shall be deemed automatically revoked and shall be void as if never granted. Further, in the event that you breach any of these terms and conditions or any of CCC's Billing and Payment terms and conditions, the license is automatically revoked and shall be void as if never granted. Use of materials as described in a revoked license, as well as any use of the materials beyond the scope of an unrevoked license, may constitute copyright infringement and publisher reserves the right to take any and all action to protect its copyright in the materials.

9. Warranties: Publisher makes no representations or warranties with 
respect to the licensed material.

10. Indemnity: You hereby indemnify and agree to hold harmless publisher and CCC, and their respective officers, directors, employees and agents, from and against any and all claims arising out of your use of the licensed material other than as specifically authorized pursuant to this license.

11. No Transfer of License: This license is personal to you and may not be sublicensed, assigned, or transferred by you to any other person without publisher's written permission.

12. No Amendment Except in Writing: This license may not be amended except in a writing signed by both parties (or, in the case of publisher, by CCC on publisher's behalf).

13. Objection to Contrary Terms: Publisher hereby objects to any terms contained in any purchase order, acknowledgment, check endorsement or other writing prepared by you, which terms are inconsistent with these terms and conditions or CCC's Billing and Payment terms and conditions. These terms and conditions, together with CCC's Billing and Payment terms and conditions (which are incorporated herein), comprise the entire agreement between you and publisher (and CCC) concerning this licensing transaction. In the event of any conflict between your obligations established by these terms and conditions and those established by CCC's Billing and Payment terms and conditions, these terms and conditions shall control.

14. Revocation: Elsevier or Copyright Clearance Center may deny the 
permissions described in this License at their sole discretion, for any reason or no reason, with a full refund payable to you. Notice of such denial will be made using the contact information provided by you. Failure to receive such notice will not alter or invalidate the denial. In no event will Elsevier or Copyright Clearance Center be responsible or liable for any costs, expenses or damage incurred by you as a result of a denial of your permission request, other than a refund of the amount(s) paid by you to Elsevier and/or Copyright Clearance Center for denied permissions.

\section{LIMITED LICENSE}

The following terms and conditions apply only to specific license types:

15. Translation: This permission is granted for non-exclusive world

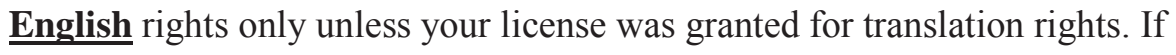
you licensed translation rights you may only translate this content into the languages you requested. A professional translator must perform all translations and reproduce the content word for word preserving the integrity of the article. If this license is to re-use 1 or 2 figures then permission is granted for nonexclusive world rights in all languages.

16. Website: The following terms and conditions apply to electronic reserve and author websites:

Electronic reserve: If licensed material is to be posted to website, the web site is to be password-protected and made available only to bona fide students registered on a relevant course if: 
This license was made in connection with a course,

This permission is granted for 1 year only. You may obtain a license for future website posting,

All content posted to the web site must maintain the copyright information line on the bottom of each image,

A hyper-text must be included to the Homepage of the journal from which you are licensing at http://www.sciencedirect.com/science/journal/xxxxx or the Elsevier homepage for books at http://www.elsevier.com , and

Central Storage: This license does not include permission for a scanned version of the material to be stored in a central repository such as that provided by Heron/XanEdu.

17. Author website for journals with the following additional clauses:

All content posted to the web site must maintain the copyright information line on the bottom of each image, and the permission granted is limited to the personal version of your paper. You are not allowed to download and post the published electronic version of your article (whether PDF or HTML, proof or final version), nor may you scan the printed edition to create an electronic version. A hyper-text must be included to the Homepage of the journal from which you are licensing at http://www.sciencedirect.com/science/journal/xxxxx . As part of our normal production process, you will receive an e-mail notice when your article appears on Elsevier's online service ScienceDirect (www.sciencedirect.com). That e-mail will include the article's Digital Object Identifier (DOI). This number provides the electronic link to the published 
article and should be included in the posting of your personal version. We ask that you wait until you receive this e-mail and have the DOI to do any posting.

Central Storage: This license does not include permission for a scanned version of the material to be stored in a central repository such as that provided by Heron/XanEdu.

18. Author website for books with the following additional clauses: Authors are permitted to place a brief summary of their work online only. A hyper-text must be included to the Elsevier homepage at http://www.elsevier.com . All content posted to the web site must maintain the copyright information line on the bottom of each image. You are not allowed to download and post the published electronic version of your chapter, nor may you scan the printed edition to create an electronic version.

Central Storage: This license does not include permission for a scanned version of the material to be stored in a central repository such as that provided by Heron/XanEdu.

19. Website (regular and for author): A hyper-text must be included to the Homepage of the journal from which you are licensing at http://www.sciencedirect.com/science/journal/xxxxx. or for books to the Elsevier homepage at http://www.elsevier.com

20. Thesis/Dissertation: If your license is for use in a thesis/dissertation your thesis may be submitted to your institution in either print or electronic form. Should your thesis be published commercially, please reapply for 
permission. These requirements include permission for the Library and Archives of Canada to supply single copies, on demand, of the complete thesis and include permission for UMI to supply single copies, on demand, of the complete thesis. Should your thesis be published commercially, please reapply for permission.

21. Other Conditions: 